\title{
SOCIEDAD, CULTURA Y ACTUALIDAD ARTÍSTICA EN LA ESPAÑA DE FINES DEL SIGLO XIX A TRAVÉS DE LAS PUBLICACIONES PERIÓDICAS MUSICALES: ZARAGOZA Y LA REVISTA EL CORREO MUSICAL, $1888 .{ }^{1}$ (I)
}

Begoña Gimeno ARLANZÓN

\begin{abstract}
This paper deals with the cultural movement, especially the musical one, in Saragosse at the end of the $19^{\text {th }}$ century, by analysing and studying a local periodical called El Correo Musical, and the eighteen scores there included. This first part offers an analysis of the changing styles and fashions, the usual musical activities and the then common theatre and concert programmes in the period surrounding the review. I will reflect on the context of the period, related musical periodicals, societies, musical circles and associations, academies and schools of music, local centres with musical activity -coffee-houses and theatres-, and I will reach some.
\end{abstract}

\section{Resumen}

Este estudio, en su totalidad, pretende reflejar el movimiento cultural y, en concreto, el musical en Zaragoza a finales del siglo XIX, a través del análisis y estudio de una publicación periódica, la revista El Correo Musical, que incluye dieciocho partituras de música de salón. En esta primera parte se refleja un análisis de los "gustos" y modas, actividades musicales frecuentes y programaciones lírico-teatrales y de concierto en los años que rodean al de la publicación de la revista. En este sentido, se tratarán temas como las publicaciones periódicas musicales, sociedades, círculos y asociacionismo, centros de enseñanza musical y centros locales de actividad musical -cafés y teatros-, repasando, a continuación, las representaciones de zarzuela y ópera que en el año natural de 1888 se dieron en el Teatro Principal de Zaragoza, para concluir con unas valoraciones finales.

\section{CONTEXTO SOCIAL Y CULTURAL EN ZARAGOZA A FINALES DEL SIGLO XIX}

\section{Publicaciones periódicas}

Para aproximarnos al contexto en que se desarrolló la música española a finales del siglo XIX, es preciso hacer referencia al interés que por la música tuvieron nuestros antepasados en dicha época,

1. Este artículo se basa en el material utilizado para el homónimo trabajo de investigación predoctoral, defendido el 25.05.2005 en la Universidad de Valencia, dirigido por el Dr. Antonio Ezquerro Esteban, a quien agradezco sus lecturas y revisiones. La segunda parte estará dedicada a la revista El Correo Musical.

Anuario Musical, 60 (2005) 
demostrado a través de numerosos escritos, estudios, publicaciones periódicas locales, prensa diaria y actividades en salas de concierto, cafés, teatros y círculos sociales o agrupaciones artísticas.

Solamente respecto a revistas decimonónicas dedicadas en nuestro país a la música y, a veces, otras artes, se puede decir que hubo una verdadera eclosión: por citar algunos ejemplos, en la capital madrileña nacieron La Iberia Musical (más tarde se le añadió el calificativo y literaria, fundada en 1842 por Joaquín Espín y Guillén y por Mariano Soriano Fuertes, la cual incluía en cada una de sus entregas, como suplemento, una página musical para canto y piano o piano solo), El Anfión Matritense (1843), El Pasatiempo musical (1849), Correo de los Teatros (1850), La España musical (1852), Gaceta musical (1855, fundada y dirigida por Hilarión Eslava), o La zarzuela (1856). En Barcelona -como en otras ciudades, aunque en estas últimas en menor medida-, también apareció un gran número de publicaciones por estas fechas. ${ }^{2}$

Pero precisamente, varios años más tarde, y ya dentro del período histórico objeto de estudio, fueron también muchas las publicaciones especializadas. Entre las aparecidas en Madrid, figuran $L a$ Ilustración Artística y Teatral (1884), Almanaque Musical (1885), La España Musical (1886), o La España Artística (1888), y en Barcelona, Notas musicales y literarias (Felipe Pedrell, 1882), La ilustración musical (1883), Ilustración Musical Hispanoamericana (1888) o La Aurora (1890).

Entretanto, en Zaragoza, se habían comenzado a publicar la Revista de Aragón. Ciencias, letras, artes é intereses generales (directores fundadores, Mariano de Cavia y Baldomero Mediano, Imprenta del Hospicio, 1878) ${ }^{3}$, la Gaceta Musical. Periódico literario, artístico, teatral y recreativo ${ }^{4}$

2. De estos mismos años, podemos citar en Barcelona, por ejemplo: El Filarmónico (1845), El Barcino Musical (1846), Violeta de Oro (1851), Calendario Musical (1859), Eco de Euterpe (1859), o El Metrónomo (1863). Entretanto, conocemos otras publicaciones aisladas, de este mismo tipo, en otras ciudades españolas, como por ejemplo en A Coruña (El Propagador Musical, 1855), Alicante (La Lira, 1855), Sevilla (Revista Musical Española, 1857), o Valencia (Las Bellas Artes, 1858).

3. La primera etapa de la Revista de Aragón corresponde a los años 1878-1880; en ella escribían literatos y periodistas como el mismo Mariano de Cavia, Cosme Blasco, Faustino Sancho y Gil, Gerónimo Borao o Agustín Peiró, todos ellos ateneístas, y éste último, además, colaborador de la revista objeto de este estudio. Juan Pedro Barcelona y Luis Montestruc son otros de los que coinciden en las dos revistas. La segunda etapa de la Revista de Aragón se publicaría entre 1900 y 1905 . Existe una edición microfotográfica con un estudio de José Carlos Mainer e índices de $\mathbf{M}^{a}$ Angeles Naval, editada por el Instituto de Estudios Turolenses de la Excma. Diputación Provinicial de Teruel; vid. también: -José Carlos Mainer: Regionalismo, burguesía y cultura. Revista de Aragón (1900-1905). Zaragoza, Guara, 1982. Fue el literato aragonés Mariano de Cavia quien promovió, junto a Eusebio Blasco, la Fiesta de la Jota, celebrada en Madrid el año 1895 con gran entusiasmo y afán regionalista, en la que participaron el guitarrista zaragozano Santiago Lapuente y el bandurrista aragonés Ángel Sola. Vid.: -Antonio Ezquerro, ed.: Antonio Lozano González: La Música Popular, Religiosa y Dramática en Zaragoza: desde el siglo XVI hasta nuestros días. [Zaragoza, 1895], $3^{\mathrm{a}}$ edición, Zaragoza, DGA-Diputación-Ayuntamiento de Zaragoza, 1994, pp. 13[133], [250]130.

4. Revista trimensual, propiedad del, asimismo, editor musical zaragozano Félix Villagrasa. En ella colaboraban "los mejores músicos nacionales y selectos escritores". -José Blasco Ijazo: Historia de la prensa zaragozana (1683-1947). Zaragoza, El Noticiero, 1947, p.205. Sobre publicaciones periódicas en Aragón, vid. también: -Eloy Fernández Clemente y Carlos Forcadell: Historia de la prensa aragonesa. Zaragoza, Guara, 1975, pp. 114-115. Algunos de los 25 colaboradores que figuran en la portada de la revista, son comunes a El Correo Musical, como Joaquín Liso y Torres, Santiago Lorda, Eladio Núñez -quien, después de colaborador, sería el director literario de El Correo Musical-, Elías Villarreal y Agustín Yanguas. También ofrecía un suplemento musical con cada número: según los sumarios del material conservado, se publicaron Morena pero graciosa, mazurka para piano por Melchor Bordoy -de quien se conoce únicamente un vals para piano, Recuerdos íntimos, según afirma $\mathrm{M}^{\mathrm{a}}$ Encina Cortizo en su artículo "Bordoy, Melssión" (en Diccionario de la música española e hispamoamericana, Madrid, SGAE, 1999, vol. 2, p.632)-; una polka militar titulada Numancia, sin nombre de autor en la partitura pero perteneciente a J. Liso y Torres; un pasodoble para piano, Los hijos de Aragón, de S. Enciso; una mazurka de Agustín Pérez Soriano y, por último, la polka Saudades, de José Sigler, com- 
(1883-1885, fundada y dirigida por Rafael Fuster y $\mathrm{Sas}^{5}$, Imprenta y litografía de Félix Villagrasa), $L a$ Ilustración Zaragozana. Ciencias, Letras, Artes (Imprenta de la Ilustración Zaragozana, 1886) ${ }^{6}$, una Gaceta literaria aragonesa (1886), La Ilustración aragonesa (director, Luis Montestruc, 1888) ${ }^{7}$ y, también en el mismo año de 1888, fecha de aparición de nuestra revista El Correo Musical, -de la que trataré más adelante-, aparecía como competidora suya otra publicación periódica, titulada Aragón Artístico (1888). Unos años después se iba a publicar en Zaragoza, con carácter gratuito, una revista musical que tendría un particular éxito: El Bretoniano. Órgano de la Asociación Bretoniana de Zaragoza (1912-1916). ${ }^{8} \mathrm{Un}$, para la época, rico listado de publicaciones en una ciudad media española, que nos da idea de los intereses intelectuales de la burguesía y clases acomodadas en poblaciones urbanas durante el último cuarto del siglo XIX y primeros años del XX. ${ }^{9}$

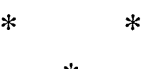

positor de género chico y zarzuela grande que debutó como barítono de zarzuela en 1884 (-Emilio Casares: "José Sigler" en Diccionario..., op. cit., vol. 9, p.1008), además de "excelente actor" según E. Cotarelo y Mori (en su Historia de la zarzuela, o sea, el Drama lírico en España, desde su origen a fines del siglo XIX. [Madrid, Tipografía de la Revista de Archivos, Bibliotecas y Museos, 1934]. Ed. facsímil, Madrid, ICCMU, 2000, p. 864), cuando aparecía en las compañías que actuaban a finales del siglo -siempre al lado de Lucrecia Arana-; entre su producción escénica figura la humorada Miss Hisipí (estrenada en 1892), en colaboración con José $\mathrm{M}^{\mathrm{a}}$ Alvira, colaborador de El Correo Musical. No se han conservado los contenidos de la revista, a excepción de la Sección infantil y dos de las partituras -la polka militar de J. Liso y Torres y el pasodoble de S. Enciso-.

5. En El Correo Musical ([1888] Año I, n ${ }^{\circ} 1$, p.8) encontramos una nota necrológica de este personaje aragonés, redactada tres años después de su fallecimiento $(\dagger 1885)$, en la que se le cita, por error, como Rafael Fuster y Las, repetidamente. En ella se reconoce su labor impulsora de la cultura y la música. Por esta nota, que reproduzco brevemente a continuación, sabemos de las actividades musicales y editoriales de Fuster y Sas: "Al profesor distinguido, crítico entendido, al infatigable propagador del arte de Orfeo [...] Fundador y director de la Gaceta Musical, á la que consagró los últimos días de su vida". Tras la puesta en marcha de la revista que dirigió, Rafael Fuster y Sas pasó a figurar como fundador, y Rafael Fuster y Camprovín, profesor de primaria y colaborador desde el principio, aparece como nuevo director - de ahí, tal vez, la nueva Sección infantil-.

6. Aquí volvemos a encontrar a Agustín Peiró entre sus colaboradores. De esta revista, de periodicidad quincenal, se conserva su primer número, con fecha 15 de abril de 1886. No sabemos, por tanto, si la Dirección cumplió con las fotografías de hombres notables y de monumentos de la provincia que prometía como regalo a los suscriptores, así como la próxima impresión a color de su portada. En ella escribían, entre otros, Mariano de Cavia, Ramón Ram de Viu y Faustino Sancho y Gil, a quienes volveremos a encontrar más adelante.

7. Su director, Luis Montestruc Rubio (*Tardienta -Huesca-, 1868; †Biescas -Huesca-, 1897), consta también como colaborador de El Correo Musical. Aragonés republicano, a los quince años se inició como periodista en el Diario de Avisos de Zaragoza. En 1888, cuando contaba veinte, dirigió La ilustración aragonesa, periódico del que se anuncia su "próxima e inminente aparición" en El Correo Musical ([1888], Año I, n¹0, p.80). En 1894 fundó y dirigió La República y, más tarde, el Heraldo de Aragón. Como político fundó el Partido Republicano centrista y fue diputado provincial en la corporación de Zaragoza. Fue, también, poeta, dramaturgo y un gran orador: entre otras, dio una conferencia sobre El regionalismo en Aragón, celebrada en el Ateneo zaragozano el 27 de enero de 1888, del que fue vocal de la Junta en el siguiente curso, 1888-1889. Falleció de tuberculosis el 29 de julio de 1897, engrosando la lista de poetas ateneístas que murieron jóvenes. Vid. -Francisca Soria Andreu: El Ateneo de Zaragoza (18641908). Zaragoza, Institución Fernando el Católico, 1993, p. 294; -Gran Enciclopedia aragonesa. Zaragoza, Unión Aragonesa del Libro, 1980, vol. 13, p. 3218.

8. Revista musical dirigida por Tomás Urbano Lanaspa, "Minúsculo", periodista aragonés fallecido el 1 de febrero de 1927, y, más tarde, por Teodoro Iriarte. Su nº 4 -el más antiguo de los que se han podido localizar- data de octubre de 1913 . Tras el subtítulo Arte aragonés, Arte español, ofrece un contenido enteramente musical. Esta asociación solía ofrecer sus conciertos en el Teatro Circo (véase nota 75) y, en alguna ocasión extraordinaria, en el Teatro Principal (véase nota 73).

9. Para hacernos una idea más aproximada del contexto ciudadano de la Zaragoza de finales del siglo XIX, el cual condicionaría el público potencial de teatros, salas de concierto, actividades artísticas, etc., y en lo que nos afecta, adquisición de revistas especializadas en música, téngase en cuenta que en el año 1887 la provincia de Zaragoza contaba con 415.195 habitantes, de los que 92.407 correspondían a la población de hecho de la capital. Entretanto, no ha de pasarse por alto que, para ese mismo año, la población española que sabía leer supone, únicamente, un 28 ' $49 \%$ del total (un porcentaje que había ido no obstante en ascenso, si se compara con el 5'96\% [!] que correspondía a 1803). [Datos extraídos de: -Jacinto Torres: "Fuentes para la historiografía musi- 


\section{Sociedades, círculos culturales y asociacionismo:}

\section{a) Sociedad de Conciertos a Grande Orquesta \\ b) Sociedad de Cuartetos \\ c) Sociedad Filarmónica y \\ d) Sociedad coral 'La Coronilla'}

En esta segunda mitad del siglo XIX, se produjo un evidente despertar y auge musicográfico, llevado a cabo por músicos, críticos, compositores, intérpretes en algunos casos, o historiadores, todo en un intento de abrir horizontes culturales y camino de un "Regeneracionismo" 10 que iba a definir al que sería el tercer Ateneo de Zaragoza. ${ }^{11}$ Recordemos que en los años que nos ocupan la capital zaragozana cuenta con el Ateneo Científico, Literario y Artístico de Zaragoza (1880-1896) -misma denominación que la del madrileño, creado en 1835-, lugar de confluencia de la burguesía intelectual; el Casino Principal ${ }^{12}$, punto de encuentro y actividades de la aristocracia y la alta burguesía; o el Centro Mercantil, Industrial y Agrícola, casino de la burguesía liberal e industrial. ${ }^{13}$

$\mathrm{Al}$ destacar como acontecimiento relevante la incorporación del arte musical en el Ateneo citado (ya que no llegó a haber una Sección de Música hasta 1898), reproduzco las palabras de Ruperto Ruiz de Velasco ${ }^{14}$ en la conferencia teórico-práctica celebrada la noche del 15 de abril de 1890 -obsér-

cal española del s. XIX: más de un centenar y medio de revistas musicales españolas", en Revista de Musicología, XIV/1, (1991), p.[6]38, quien a su vez extrae los datos de la Historia del Constitucionalismo español, de Sánchez Agesta (Madrid, IEP, 1974)].

10. Como es sabido, el movimiento regeneracionista entronca con la ideología de los fundadores de la Institución Libre de Enseñanza, Francisco Giner de los Ríos, el aragonés Joaquín Costa, y Nicolás Salmerón. Ya en 1878, Giner había criticado al Conservatorio de Madrid y su director, Emilio Arrieta, en un artículo publicado en El pueblo español; se quejaba ahí y ponía de manifiesto la ignorancia de los alumnos del Conservatorio, recalcando la necesidad de conocer la historia universal, de estudiar la acústica, estética e historia de la música, e historia general de las bellas artes, tal como se hacía en la Academia de Santa Cecilia de Cádiz, como bases necesarias para una ejecución musical de calidad. (Vid.: -Carlos Gómez Amat: Historia de la Música española. Siglo XIX. Vol.5. Madrid, Alianza Música, 1984, pp.259-260). Por su parte, E. Casares define o enmarca este inicio del regeneracionismo musical como fenómeno decimonónico, aunque protagonizado ya a comienzos del siglo XX por hombres, a su vez, formados en el XIX. (Vid.: -Emilio Casares Rodicio: "La música española hasta 1939, o la restauración musical", en Actas del I Congreso Nacional de Musicología [1979]. Zaragoza, Institución Fernando el Católico, 1981 (véase epígrafe "Identidad histórica del período y definición social", p. 365).

11. El primer Ateneo se fundó en 1864, llegando a su fin en 1872. La segunda etapa de esta sociedad, fundada por socios mayoritariamente republicanos, abarca los años comprendidos entre 1880 y 1896 . La institución renació por tercera vez en 1898 y se mantuvo hasta 1908. Para un conocimiento amplio de los protagonistas del Ateneo zaragozano en sus diferentes etapas, perfil ideológico y actividades, vid.: -Francisca Soria Andreu: El Ateneo de Zaragoza..., op. cit..

12. Sobre agrupaciones socio-culturales, véase: -J. Claude Vanhille-Lité: Casinos y círculos en Zaragoza (1830-1908). Zaragoza, Institución Fernando el Católico, 2001.

13. Según L. G. Zubero, nos encontramos en un contexto socio-económico, próximo a las últimas décadas del siglo, en el que Aragón se había estancado respecto a su nivel en el sector industrial, con una economía atrasada que condiciona sus posibilidades productivas y comerciales. (Vid.: -Luis Germán Zubero: "La configuración de la estructura económica en Aragón”, en Enciclopedia Temática de Aragón. Zaragoza, Moncayo, 1989, vol. 10, "Ciencias sociales”, pp. 21-22, 25-27.

14. Ruperto Ruiz de Velasco (*Calahorra-La Rioja-, 1858; †Zaragoza, 1897): desarrolló su actividad como musicógrafo y crítico musical (colaboró en el Diario de Avisos de Zaragoza), impulsando la vida musical desde la Universidad de Zaragoza -donde ejerció la docencia- así como desde la propia ciudad. Cofundador, junto con Antonio Lozano, de la Escuela de Música (germen del primer conservatorio que tuvo la ciudad) de la que fue su primer director, y profesor de Piano, Canto y Estética musical. Compuso varias obras líricas, así como una serie de piezas para piano dentro del género de música de salón, y escribió un pionero estudio sobre la jota. (Vid.: -Emilio Casares Rodicio: "Ruiz de Velasco, Ruperto", en Diccionario de la Música española..., op. cit., vol. 9, p.483). Otro ejemplo de su labor musicográfica es esta conferencia celebrada en el Ateneo zaragozano, en 1890, sobre "Historia de los músicos españoles, especialmente de los siglos XV al XVII" (Véase: -Francisca Soria Andreu: op. cit., p.294). En la 
vese que, para entonces, habían transcurrido diez años desde su fundación-, con la que se inauguran estas sesiones musicales y donde el orador agradece a la sección de Literatura, con el calor y estilo alambicado propios del momento, su contribución a la tan necesaria protección de la música:

Ha decidido abrir sus puertas á la música, hermana cariñosa de la literatura; ha decidido que, en algunas de sus sesiones [...] el lenguaje de los sonidos llegue á nuestros oídos ilustrado por la voz de un orador que os ayude á conocer las bellezas encerradas en las obras clásicas. [...] La música es el arte que más protección necesita. El Ateneo de Zaragoza, uniéndose expontáneamente al movimiento que informa los progresos de este arte en todas las naciones modernas, al inaugurar estas sesiones, arroja la semilla que, indudablemente, ha de producir en el porvenir óptimos frutos para la cultura aragonesa. ${ }^{15}$

Varias fueron las conferencias teórico-prácticas que, a partir de entonces, se celebraron en las distintas asociaciones y círculos culturales: sobre la Jota Aragonesa ${ }^{16}$-Agustín Pérez Soria-

portada de la publicación de esta conferencia -Zaragoza, Establecimiento tipo-litográfico de F. Villagrasa, 1890- el tema aparece titulado "La música en España" -coincidiendo con el testimonio de A. Lozano-, y se presenta a su autor como "Doctor en Filosofía y Letras, profesor auxiliar numerario en la Universidad de Zaragoza, ex-director de orquesta del Teatro Principal, etc." (En una nota para justificar al empresario de este teatro por la falta de asistencia de tres músicos, firmada por Ruiz de Velasco en marzo de 1886, éste se presenta como "maestro director y compositor y encargado por la empresa del Teatro Principal para formar la orquesta del mismo [de 40 profesores], así como para tocar la parte de arpa ó piano en las partituras que la tengan escrita" [a disposición del compositor y director Mariano Taberner]). Siendo de interés los músicos a quienes recurrió para ilustrar musicalmente sus palabras en la conferencia, enumero los ejemplos utilizados: algunos fragmentos de composiciones para voces, como el Andante-Plegaria del maestro de capilla de El Pilar Valentín Metón, de la que dice "belleza no vulgar, sello especial de melancolía no rebuscada, facilidad que retrata la inocencia"; fragmentos de un juego de versos para órgano de Domingo Olleta, con los que demuestra la tendencia de éste "á conservar íntegras las notas del canto llano"; por último, para tratar los cantos populares interpretó algunas canciones de Sebastián Iradier: Lola (canción española) o El banderillero (canción andaluza con texto de Agustín Azcona). Un hijo de Ruiz de Velasco, llamado Eduardo, aparece como autor de algunos poemas y cuentos publicados en la Revista de Aragón (19001905) anteriormente citada. (Vid.: Revista de Aragón, Año III, varios números, 1902).

15. Tal vez, Ruiz de Velasco se refiera a la música como "hermana cariñosa de la literatura" aludiendo a la tradición de hacerlo así por encontrarse reunidas aquélla y la poesía en el canto.

16. A propósito de la jota aragonesa, reproduzco las palabras de Balbino Orensanz -presidente del Orfeón Zaragozano en 1924 y amigo de Tomás Bretón- en su artículo "Bretón y la jota" (en El Bretoniano, IX/13, (1924), p.13): "Ha sido llevada [la jota aragonesa] por todo el mundo en obras de Barbieri, Oudrid, Fernández Caballero [su zarzuela en un acto La jota aragonesa se estrenó el 30 de junio de 1879 en el Teatro Pignatelli de Zaragoza], Bretón, [Tomás] Barrera [Saavedra] y otros ilustres músicos; y más modestamente, pero no con menos entusiasmo, Pérez Soriano, Ruiz de Velasco, Retana y otros; pues bien, ninguno de ellos era aragonés. Es triste condición la nuestra de despreciar todo cuanto puede enaltecernos, sobre todo la Jota, que es tal vez lo único que nos caracteriza. Los más ilustres compositores catalanes, valencianos, andaluces, vascos, gallegos, los de todas las regiones españolas, se afanan en producir obras basadas en sus cantos populares. Es en Aragón, salvo muy raras excepciones, donde no se hace nada en este sentido; y no es que carezcamos de elementos para ello, que es lo más sensible". Palabras que emergen de un clima regionalista y patriótico como el de la propia revista El Bretoniano en este número dedicado a Bretón, tras su reciente fallecimiento; sin embargo Julián Ribera, entre otros y por las mismas fechas, nos habla de la jota como rasgo, en un principio, no peculiar de Aragón sino como género popular en toda la península. Aunque, del mismo modo, es obligado demostrar el esplendor de la jota durante el siglo XIX como cante característico propiamente aragonés, así como que en esas fechas ya había impactado en grandes compositores no sólo españoles: Glinka, con su Capricho brillante para gran orquesta sobre la Jota Aragonesa (estrenado en Zaragoza en 1903, en un concierto con motivo de la visita de Alfonso XIII a la ciudad, donde Eduardo Viscasillas dirigió una orquesta de 70 profesores); Mahler, que utiliza el material temático correspondiente a la parte vocal de esta misma jota en su III Sinfonía, sacando gran partido de la célula motívica principal en lo que sería una cita reiterada a lo largo de la obra en diferentes momentos; Liszt, que también utiliza la misma jota en su Rapsodia española; Chabrier (en España, rapsodia para orquesta); Gottschalk (La jota aragonesa. Caprice espagnol para piano, El sitio de Zaragoza), Gevaert (entre otros aires nacionales españoles, trata de manera especial la jota), Saint-Saëns o Massenet; entre los españoles figuran Sebastián Iradier con su Jota Aragonesa del vestido azul o la Jota de las Avellanas, entre otras; Falla, Granados o Albéniz, todo ello reflejo de un momento en que en otros países se enamoraban de España y lo español. [Sobre Glinka y el concierto que se celebró en la Lonja de Zaragoza, véase: -Mariano A. Faci Ballabriga: "Glinka, un ruso fascinado por la jota", en Heraldo de Aragón, 22 de octubre de 2003, p.37]. Tampoco hay que olvidar, dentro de las mismas fechas, su impacto al otro lado del océano, del que nos da cuenta el musicólogo cubano Natalio Galán cuando 
no ${ }^{17}$, , sobre la Importancia de las sociedades corales, ya se las considere en el terreno del arte o ya en su íntimo enlace con los beneficios de civilización, cultura y moralidad que determinan -encargada por el Orfeón Zaragozano a Antonio Lozano-, la impartida por J. Joaquín Oña sobre Mozart y sus obras (1892), o la que dio también A. Lozano sobre la Historia del cuartetto, con ejemplos musicales de Haydn interpretados por la Sociedad de Cuartetos que dirigía Teodoro Ballo, de la que trataré más adelante.

Así pues, vemos cómo la década de 1880 y principios de 1890 son años de incipiente progreso social, económico y cultural en la ciudad, tras la etapa de crisis anterior.

En cuanto a asociaciones y agrupaciones musicales, a partir de los modelos que se crearon en ciudades europeas como Londres ("Academy of Ancient Music", 1710) 18, o París (que inauguró en 1725 la Sociedad de "Concerts Spirituels"), fueron apareciendo otras de similares características en diversas ciudades del continente europeo ${ }^{19}$; bien es cierto que en España no tiene lugar este tipo de agrupaciones orquestales con plena actividad musical hasta mediado el siglo XIX.

habla de Julián Fontana, condiscípulo de F. Chopin: "pero en sus días [mediado el siglo XIX] era un tema obligado jotear en la sala de concierto y no era difícil manejarla para convencer [de] que la jota era exóticamente universal y trascendía los Pirineos hasta hacer su impacto en Rusia, Polonia y las Antillas". Por otro lado, las colecciones de jotas que cita el ya mencionado académico arabista Julián Ribera $(* 1858 ; \uparrow 1934)$ en su ensayo sobre este canto y baile popular, dan idea de su florecimiento en Aragón en el siglo XIX (tres de los autores de estas colecciones son colaboradores de nuestra revista El Correo Musical): Transcripción para piano de la jota aragonesa que interpretan con guitarra y bandurria D. Santiago Lapuente y D. Angel Sola, por José Mª Alvira; Aragón. Treinta cantos de jota, arreglados, de muy fácil ejecución para piano, por M. Arenas; Jota aragonesa, imitando guitarras, guitarros y bandurrias, con veinte variaciones y cinco cantares de los más modernos del pueblo, arreglada para piano, por Justo Blasco; ;Viva Aragón! Jota aragonesa para piano, por Justo Blasco; Agustina de Aragón. Gran jota aragonesa, por Justo Blasco; Borja. Gran jota aragonesa para piano, con veinte variaciones de verdadera imitación a guitarras, etc., y cuatro cantos populares de los más modernos, por_Justo Blasco; otras de Isidoro Hernández, de J. Gonzalo, de A. Pérez Soriano (Jota aragonesa; verdadera imitación de la rondalla al estilo del país), o de A. S. Arista completan el listado. -Julián Ribera y Tarragó: La música de la Jota Aragonesa. Ensayo histórico. Madrid, Instituto de Valencia de Don Juan, 1928, pp.20-22 y 149-150; -Natalio Galán: Cuba y sus sones. Valencia, Pre-Textos, 1997, p.245.

17. A. Pérez Soriano: pianista, director en el Teatro Principal y autor de algunas zarzuelas; leyó su conferencia en el Ateneo Científico-literario el 31 de mayo de 1890. Vid.: -Antonio Ezquerro, ed.: Antonio Lozano: La Música Popular, Religiosa y Dramática en Zaragoza: desde el siglo XVI hasta nuestros días. [Zaragoza, Imprenta de Julián Sanz, 1895], pp.124, 129, 130, 142. -Francisca Soria Andreu: El Ateneo..., op. cit., p.294. También se habla de Pérez Soriano como pianista acompañante en el Teatro Pignatelli (El Correo Musical, sección "Buzón", n¹1, 20 de julio de 1888, p.88). En el catálogo del Archivo de la Unión Musical Española, (-Judith Ortega, ed.: Archivo histórico de la Unión Musical Española. Partituras, métodos, libretos y libros. Madrid, SGAE, 2000) se encuentran varias zarzuelas de este autor: Atila (Madrid, ed. B. Zozaya), El guitarrico (dedicada a B. Chavarri, letra de Luis Pascual Frutos y Manuel Fernández de la Puente, hijo de M. Fernández Caballero), El rosario de coral (texto de Arpe / Pinedo), Gorón (zarzuela cómica en un acto, texto de Montesinos / Torres), La molinera de Campiel (con letra de Eusebio Blasco, dedicada a la soprano Lucrecia Arana, gran cantante de jotas además de zarzuelas), y Pepito Melaza (letra de Federico Urrecha); además se recoge una Danza eslava, capricho para piano; Homenaje a Peral: gran jota aragonesa; La zagala, mazurka dedicada a los hermanos Álvarez Quintero y iMarincha!, vals brillante dedicado a la actriz María Guerrero. Asimismo, es coautor, junto con Luis Foglietti Alberola, de una Fantasía morisca en un acto, titulada El Ramadán y del juguete El mundo marcha, estrenado en el Teatro Pignatelli de Zaragoza en agosto de 1888 , con decorados realizados por el pintor-escenógrafo Alejo Pescador. Parece que este último (contratado por cuatro años por el empresario del Teatro Principal a propuesta del ayuntamiento), habría aprovechado el período veraniego -en el que no tendría trabajo ahí- para realizar labores similares en el Teatro Pignatelli. (El Correo Musical, n¹4, 30 de agosto de 1888, p.112).

18. Sociedad londinense formada por músicos aficionados y eminentes profesionales, probablemente fundada en $1710 . \mathrm{Su}$ génesis es algo incierta: John Hawkins, miembro desde 1750, da la fecha de 1710 para su fundación. Parece que sí es clara su fundación en 1726 como "Academy of Vocal Music". Vid. "Academy of Ancient Music" en The New Grove Dictionary of Music and Musicians. Nueva York, Oxford University Press, 2001, vol.1, p.45 y vol.15, pp.119-124 y 129-130 [Simon McVeigh] y -Henry Raynor: "London", Vid.: “London, SV, 2.", pp.192-195.

19. Además de diversas sociedades musicales de carácter civil, valgan también como referencia las orquestas siguientes: Orquesta del Gewandhaus de Leipzig (1781); Orquesta de la Royal Philarmonic Society de Londres (1813); Orquesta de La Scala de Milán (1814); Orquesta Filarmónica de Viena (1842); Nueva York, Idem (1842); Berlín, Idem (1882); París, Orquesta de los Conciertos Lamoureux (1882); Amsterdam, Orquesta del Concertgebouw (1888); Oslo, Orquesta de la Capilla Real (1890); o Praga, Orquesta Filarmónica (1894), entre un largo etcétera. 
Entre la década de 1840 y la Revolución de 1868, la actividad musical se centra en los teatros y, con máximo auge, en los salones de la aristocracia y la burguesía y en los cafés. A partir de aquí se reivindica el género sinfónico, como se verá seguidamente, además de continuar con las oberturas (o "sinfonías") y bailes, que es en lo que venía consistiendo, fundamentalmente, la música orquestal. ${ }^{20}$

Es el momento en que en Madrid -mucho tuvieron que ver en ello Barbieri, Monasterio, Gaztambide o Guelbenzu - se pasa de ofrecer óperas italianas y zarzuelas, a dar a conocer el repertorio clásico-romántico, que, al igual que el público, los mismos instrumentistas desconocían. ${ }^{21}$ En este contexto se comienza a contratar a los profesores músicos con cierta estabilidad y a formar sociedades, lo que proporcionaría la posibilidad de ensayar con asiduidad antes de ofrecer conciertos al público: son, pues, las Sociedades de Conciertos las que dieron a conocer primeramente las obras de los "clásicos". Estos hechos entroncan con las consecuencias, muy negativas en el ámbito musical hispano de las desamortizaciones de Mendizábal (1835-37) y Madoz (1851) -eclesiástica y civil ${ }^{22}$, respectivamente-, así como con el Concordato de la Santa Sede de 1851.

Por otro lado, y tras el retraso con respecto a Europa en la aparición de las primeras sociedades musicales de conciertos constituidas en Madrid o Barcelona ${ }^{23}$, es necesario esperar hasta el año $1867^{24}$ para encontrar sólo la primera manifestación de este tipo en Zaragoza, la cual tuvo lugar en el café $L a$ Iberia $^{25}$, según cuenta el musicógrafo Antonio Lozano:

20. Vid. -Andrés Ruiz Tarazona: “Orquestas”, en Diccionario de la música española e hispanoamericana. Madrid, SGAE, 1999, vol 8, pp.194-196.

21. El interés por esta novedad, tanto por parte del público como por los propios músicos, viene dado por la importación de modelos franceses, ingleses y alemanes que trajeron consigo los exiliados en su vuelta a España, tras la amnistía promulgada por María Cristina de Borbón. R. Sobrino y $\mathrm{M}^{\mathrm{a}}$ E. Cortizo estudian ampliamente este tema: -Ramón Sobrino: El sinfonismo español en el siglo XIX. La Sociedad de Conciertos de Madrid, Tesis doctoral, Universidad de Oviedo, 1992; -M ${ }^{\mathrm{a}}$ Encina Cortizo y Ramón Sobrino: "Asociacionismo musical en España", en Cuadernos de música iberoamericana, 8-9 (2001), pp.11-16; vid. también: -Emilio Casares: “La Sociedad Nacional de Música y el asociacionismo musical español”, ibid., pp.313-322, -Ramón Sobrino y $\mathrm{M}^{\mathrm{a}}$ Encina Cortizo: "Sociedades", en Diccionario de la Música..., op. cit., vol. 9, pp.1065-1071.

22. Este proceso culminará con la firma, en 1851, del Concordato entre el Estado español y la Santa Sede, por el que la Iglesia española acepta las desamortizaciones anteriores, y el Estado se compromete a pagar el "subsidio de culto y clero". Con todo ello, el clero se vio abocado a un proceso de economización de gastos. Ante la nueva y preocupante situación económica para la Iglesia española, naturalmente, una de las primeras medidas de ahorro consistió, muy a menudo, en economizar en la partida de gastos por el concepto relacionado con la música (empleando a menos músicos, reduciendo las plantillas orquestales -a menudo en beneficio de una pretendida "vuelta a los orígenes": canto gregoriano, coros a pocas voces...-, etc.). Y aún más: las nuevas directrices del Concordato obligaban a que todos los músicos de capillas eclesiásticas abrazaran el estado eclesiástico, con lo que numerosos músicos, anteriormente al amparo de capillas catedralicias y demás entidades eclesiásticas -me refiero a músicos seglares casados, con hijos, o incluso a muchos solteros que no se sentían llamados a cambiar de estado-, pasaron, "voluntaria" sobre el papel, aunque forzadamente en la realidad cotidiana, a tener que engrosar la lista de artistas músicos "desempleados".

23. Se crean en Barcelona la Sociedad Filarmónica (1845) y la Sociedad de Conciertos Clásicos (Juan Casamitjana, 1866), y en Madrid la Sociedad de Cuartetos (Jesús de Monasterio, 1863), la Sociedad de Conciertos (Barbieri, 1866) y la Unión Artístico Musical (1878), todas ellas en cuanto a asociaciones formadas por músicos cuyo estatus, poco a poco, comenzaba a profesionalizarse de manera más o menos generalizada.

24. Según legajos correspondientes a la sección "Diversiones y espectáculos", en la provincia de Zaragoza, Calatayud contaba una Sociedad de Música en 1866, con un teatro para 700 localidades en el que se celebraron ese año dos funciones de ópera; también Belchite tenía una sociedad musical en el año 1867, y las de Caspe y Aguarón eran de aficionados. En el año 1868, según la Estadística de Teatros y Sociedades de Recreo, en Zaragoza había 17 cafés (1933 asientos), 146 tabernas, 4 tertulias públicas (300 asientos) y 4 teatros, con 3.750 localidades, que en ese año celebraron 140 funciones dramáticas y 50 de zarzuela (Archivo de la Diputación Provincial de Zaragoza, subfondo del Gobierno Político de Aragón, secc. Estadística, Espectáculos y diversiones, cajas $1413,1408,1406)$.

25. Ubicado en el Paseo de la Independencia, 23, con un gran salón de invierno y un jardín cerrado, fue un café popularísimo, donde se daban conciertos, se hacían tertulias, actuaban las bandas militares, y servía de cantera para cronistas locales de la época. Se cerró en 1890. En el diario La Derecha (septiembre de 1890) se anuncia su alquiler y se lee su capacidad para 100 mesas, 
El organizador fue D. Rafael Navarro ${ }^{26}$, quien dispuso de las obras entonces más en boga, e hizo arreglos para septimino [...] Despertóse muy pronto la afición a tan culto espectáculo y se organizaron conciertos en la mayor parte de los cafés. [...] En distintas ocasiones vinieron a Zaragoza sociedades que dieron conciertos en el género instrumental ${ }^{27}$ : estaba en el ánimo de todos ver organizada una sociedad de esta índole en Zaragoza, donde tantos y tan valiosos elementos hay. ${ }^{28}$

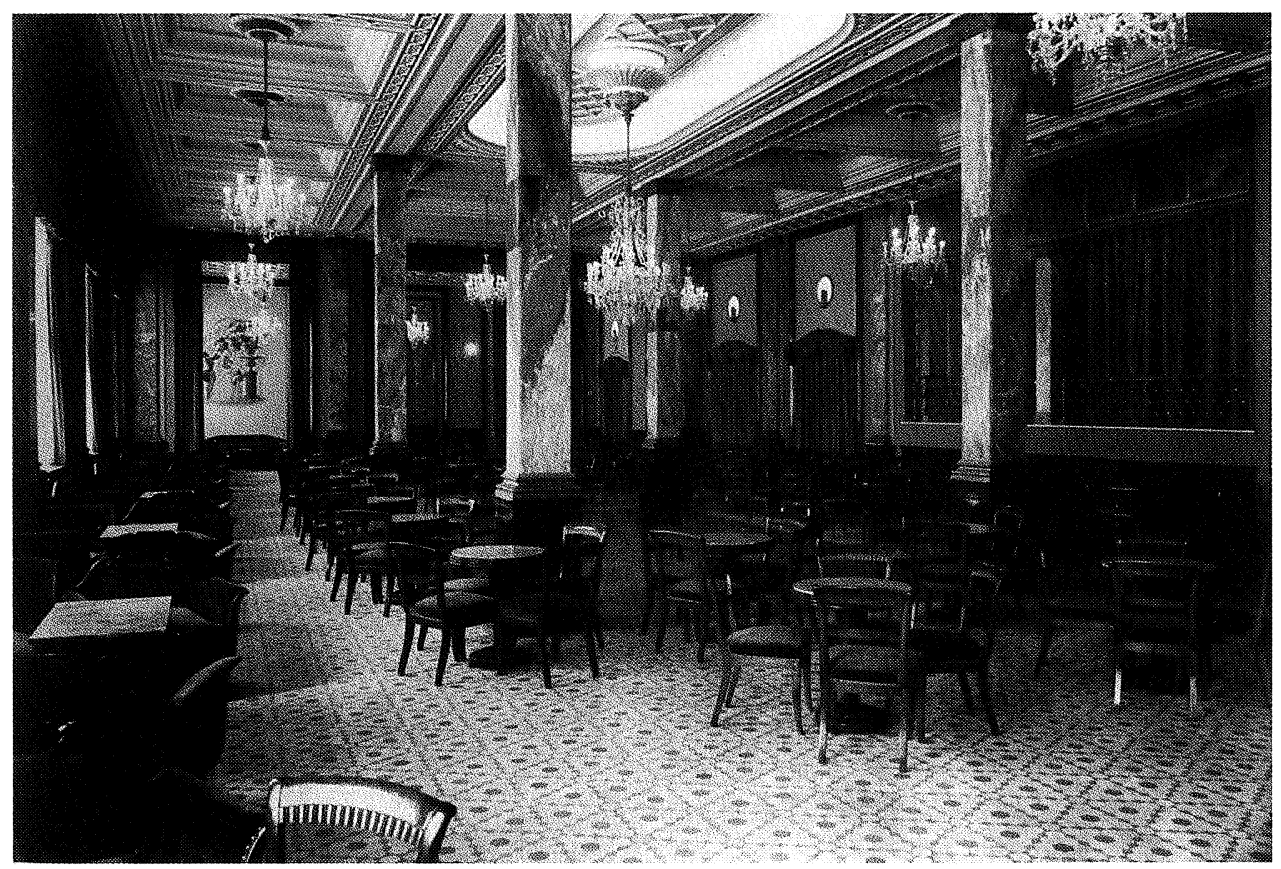

Fig.1. Café Ambos Mundos, en la década de 1930.

Considerado uno de los grandes de Europa, se inauguró el 1 de octubre de 1881.

(foto: Marín Chivite)

a las que se añaden de 180 a 200 en el jardín. Después de instalarse en sus locales la Sociedad 'Club Velocipédico de Zaragoza', que funcionó durante tres o cuatro años, se abrió el Café España, cuya estancia allí amenizaba un Sexteto dirigido por Teodoro Ballo y en el que figuraban los profesores Joaquín López de Zubiría, Juan Laclaustra, Mariano Latre, Miguel Gil y una violinista. Vid.: -José Blasco Ijazo: Zaragoza y sus locales de espectáculos. Los que fueron y los que son. Casi dos siglos de curiosa historia. 17641945. Zaragoza. Talleres Editoriales de "El Noticiero", 1945, p.25.

26. Rafael Navarro $(\dagger 1889)$ : Director de orquesta y pianista, que sirvió como Organista segundo en El Pilar, con los cargos anejos de flauta, fagot, clarinete, chirimía y oboe o corno inglés (!). Vid.: -Antonio Ezquerro, ed.: Antonio Lozano: La Música..., op. cit., pp.73-74. Rafael Navarro figura también entre los colaboradores de El Correo Musical.

27. Así nos presenta Antonio Lozano la novedad que suponía el hecho de tratarse de asociaciones no dedicadas a la ópera, como se ha expuesto anteriormente.

28. -Antonio Ezquerro, ed.: Antonio Lozano: La Música..., op. cit., pp.131-132. 
Fig. 2.

De grandes dimensiones, el Café Moderno (n ${ }^{\circ} 1$ de la zaragozana calle Alfonso),

fue punto de encuentro, con actuaciones musicales.

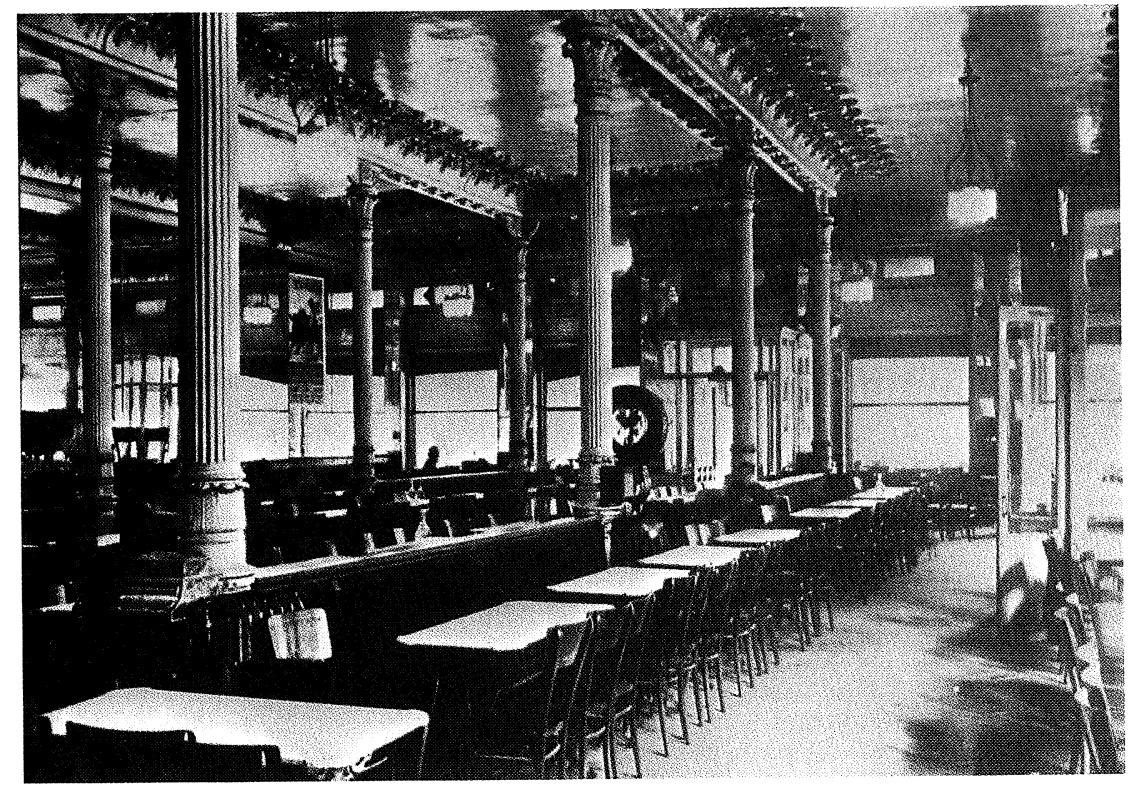

Fig. 3.

Otra imagen del Café Ambos Mundos.

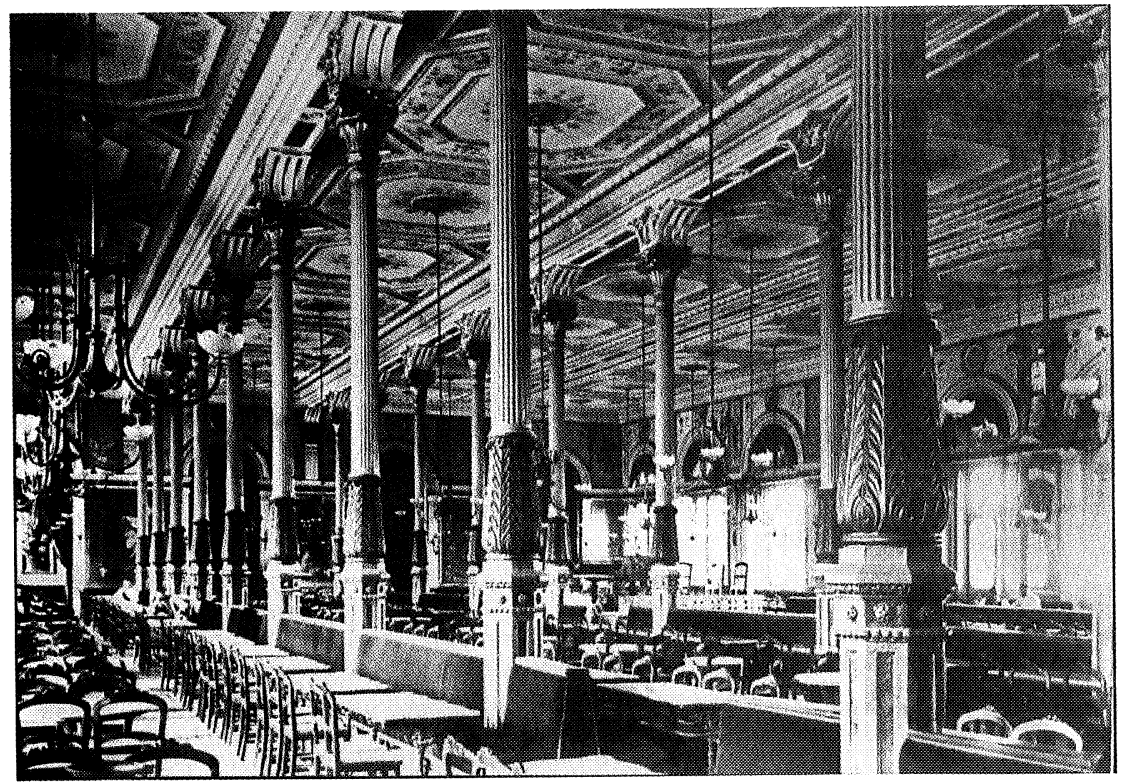

Ante la escasez de atractivos de la vida callejera por aquellos años, era común organizar tertulias domésticas a diario, de carácter íntimo, donde, además de conversación, juegos de cartas, de prendas -los más jóvenes-, se terminaba "haciendo música", bien tocando el piano, bien con otros instrumentos o cantando con acompañamiento instrumental. Si los salones de las casas no reunían 
condiciones o espacio suficiente, el entretenimiento estaba servido en los cafés ${ }^{29}$, y de ahí se pasó a la creación de sociedades instrumentales. Desde cualquier perspectiva se confirman las inquietudes culturales y de índole instructiva, además de recreativas, de la burguesía intelectual, liberal y mercantil, alta burguesía, aristocracia o de las clases obreras, éstas con sus sociedades corales y orfeones.

\section{a) Sociedad de Conciertos a Grande Orquesta de Zaragoza}

Tras varias tentativas se constituyó, pues, la primera Sociedad musical de conciertos, Sociedad de Conciertos a Grande Orquesta en marzo de 1885, presidida por el Marqués de Ayerbe ${ }^{30}$-recuérdese el apoyo de la aristocracia y alta burguesía a este tipo de sociedades-, y que tenía como miembros de la junta, entre otros, a Eduardo Viscasillas ${ }^{31}$ y Benigno Cariñena ${ }^{32}$, éste último director de la Sociedad.

29. Ejemplos del esplendor "cafeteril" en Zaragoza -término utilizado por el abogado y cronista de la ciudad José Blasco Ijazo-, comenzado en la década de 1860, y que se enumeran por lo significativo dentro del contexto, son el Español, el café de la Canalización, de las Delicias, de la Constancia, el Valenciano, el de González, el de Gimeno, de la Peña, el de la Amistad o el de las Cuatro Calles. Cafés cantantes fueron el Oriente y el de la Unión. Respecto a la transformación de los cafés, Blasco Ijazo anota lo siguiente: "Andando el tiempo, la decadencia del parlamentarismo trajo la decadencia del Café y nació el bar que es una manera de discurrir de pie y con prisa. No es de suponer que de la barra de un bar surja ni un sistema filosófico, ni una imagen poética, ni siquiera una conversación [...]. Los hombres que no estudian ni leen ¿qué pueden saber ahora sin la enseñanza del Café? Al Café se acudió [...] a conversar, a observar, a opinar, a discutir, a dar lecciones, y a propagar noticias". -José Blasco Ijazo: Zaragoza y sus locales..., op.cit., p.82.

30. D. Juan Jordán de Urriés y Ruiz de Arana, marqués de Ayerbe, de Lierta y de Rubí, conde de San Clemente, casado con Dña. Caralampia ("Carita") Méndez Vigo Arizcun Ossorio y Flores, condesa de Santa Cruz de los Manueles. En el Palacio de Ayerbe -ubicado en la desaparecida calle del Pilar, que existía antes de confluir en una misma plaza el templo de El Pilar y La Seose celebraban espléndidas fiestas, entre ellas el baile de honor de la Reina $\mathrm{M}^{\mathrm{a}}$ Cristina de Habsburgo en su visita a Zaragoza en 1888. -José M. Laguna Azorín: "La vida de sociedad de hace cincuenta años. Las chicas de aquellos tiempos", conferencia organizada por el Ateneo de Zaragoza y pronunciada en el salón de fiestas del Centro Mercantil, Industrial y Agrícola el 21 de abril de 1945 por José M. Laguna Azorín, decano del Ilustre Colegio Notarial.

31. Eduardo Viscasillas Blanque (Zaragoza, *1848; fl.1898): compositor y diplomático, fue destacado a Italia. Tomó contacto con artistas y compositores becados en la Academia Española de Bellas Artes en Roma, de la que fue secretario. Estudió piano, violín y composición (bajo la dirección de Benigno Cariñena y, más tarde, con Antonio Lozano). Entre sus obras figuran una serenata-barcarola titulada Notte in Venezia para orquesta, una Salve y un Gradual, ambas para voces y orquesta, varias obras instrumentales y una ópera. En 1887 se trasladó a Barcelona, donde formó parte en la Orquesta del Teatro del Liceo. Obtuvo un galardón en el certamen de la Exposición Internacional de Música de Bolonia, con sus obras Notte in Venezia, op. 14, Meditazione y el Graduale Santa Cecilia per quattro voci, cori ed orchestra, op. 16. -Luis Miguel Gracia Iberni: "Viscasillas Blanque, Eduardo", en Diccionario de la Música Española..., op. cit., vol.10, p.971. En 1888 escribió una ópera, Pelayo (o, según otras fuentes, Página Goda), cuyo protagonista es Don Pelayo: el fracaso de su estreno -el 17 de enero de 1899, siendo Viscasillas presidente de la sección de música del Ateneo-, se debió exclusivamente al libreto de Ram de Viu -quien para entonces se había alejado de las ideologías liberales ateneístas-, en el que este último no estuvo afortunado: reconoció lo desdichado de su argumento en público y se disculpó ante Viscasillas alabando el mérito de éste. Vid.: -M Ángeles Naval: Luis Ram de Viu. Vida y obra de un poeta de la Restauración. Zaragoza, Institución Fernando el Católico, 1995, pp.54-56. En el no 4 de la revista Aragón ilustrado, cuatro días después del estreno, el cronista escribe: "'Página Goda' [...] fue un triunfo para D. Eduardo Viscasillas, que dio una prueba más de inspiración y talento. Al poeta, autor del libro, ningún recuerdo grato ha podido dejarle el estreno de 'Página Goda' y se comprende" (21 de enero de 1899). Por otro lado, se tiene conocimiento de una solicitud por parte de Eduardo Viscasillas al Ayuntamiento de Zaragoza, escrita y firmada el 6 de marzo de 1888 de su puño y letra, para que se ejecutasen, bajo su dirección y con la orquesta del Teatro, tres composiciones instrumentales suyas en la función a beneficio (la segunda en ese año) de la Casa-Amparo, petición que se le concedió a condición de que los gastos de los ensayos corrieran de su cuenta. Según la respuesta del Ayuntamiento, las partituras que adjunta Viscasillas "titúlanse Notte in Venezia, Serenata Barcarola, Celebre Meditazione di Crescentini y Pelayo, Preludio Orquestal del drama lírico en un acto y en verso original de D. Luis Ram de Viu" (Archivo Municipal de Zaragoza, Gobernación, secc. "General e indiferente", caja 1482, expte. 401/1888). La orquestación de la ópera es la siguiente: cuerda, flautín, flauta, oboes, clarinetes, fagotes, trompas, cornetines, trombones, tuba y timbales. Sabemos, por un suelto de El Correo Musical ( $\mathrm{n}^{\circ} 4,10$ de mayo, p.31) que se interpretaron estas obras intermediando El salto del pasiego (F. Caballero), y que dirigía la orquesta del Teatro Principal Ruperto Ruiz de Velasco. 
Formaban la orquesta sesenta profesores (!) entre socios artistas y socios contratados. Estuvo dirigida por Benigno Cariñena, Rafael Navarro -quien utilizaba el seudónimo Varanor, anagrama de su primer apellido- y se contó con la participación, en los dos últimos conciertos, de Goula, hijo del compositor y director Juan Goula ${ }^{33}$, de quien se interpretó su Gran Polonesa de concierto. Esta orquesta solía actuar en el Teatro Pignatelli ${ }^{34}$ (ver Figs. 4, 5 y 6) y, pese a lo que se auguraba, sólo se mantuvo durante dos temporadas, con un total de ocho conciertos, cubriendo el espacio que dejaban las funciones de los teatros -la Sociedad inició los conciertos de su segunda temporada el 28 de mayo de 1886-: parece que a la falta de apoyo moral y material hacia los profesores, se sumó la falta de reconocimiento por parte de éstos a alguno de los directores de orquesta -muy posiblemente al joven Goula-, así como los conflictos que se crearon entre los propios directores a la hora de acordar la elección de uno de ellos. ${ }^{35} \mathrm{Si}$ bien es difícil deducir esta conclusión desde el respeto y el gran sentido de la ética de Antonio Lozano para con sus contemporáneos, éste determina como la principal causa del final de esta sociedad la última expuesta. Así, desaparecía la primera orquesta sinfónica de la ciudad, que dio su último concierto el 7 de junio de $1886 .^{36}$

32. Benigno Cariñena Salvador (*Calahorra -La Rioja-, 1829; †Zaragoza, 1886): Organista, violinista, compositor y maestro de capilla, estudió armonía y composición con el maestro de capilla de La Seo de Zaragoza, Domingo Olleta. Ganó, por oposición, el puesto de maestro de capilla de El Pilar, al que tuvo que renunciar por no desear ordenarse sacerdote. -José Vicente González Valle: "Cariñena Salvador, Benigno", Diccionario de la Música Española..., op. cit., vol. 3, pp.188-189.

33. Juan Goula (*San Feliu de Guíxols, 1843; †Buenos Aires, 1917) fue director, maestro de canto y compositor. Se inició en la música en Barcelona, con el maestro Manent, y en 1866 comenzó su carrera de director en Palma de Mallorca, donde dirigió la orquesta del Teatro Principal. En 1870 fue, contratado, al Teatro Imperial de Moscú; dirigió varias temporadas de ópera en San Petersburgo y más tarde en Baden y Hamburgo. Realizó una campaña con gran éxito por las principales ciudades alemanas como director. De vuelta a Barcelona dirigió una temporada extraordinaria en el Teatro de Novedades. En 1902 desapareció misteriosamente; residió en Argentina desde 1903, donde organizó una gran compañía de ópera española que fracasó por falta de respuesta del público argentino. Como compositor figuran entre sus obras un ballet, música escénica, una cantata, piezas corales, obras religiosas y lieder. Vid.: -Higinio Anglés y Joaquín Pena: Diccionario de la música Labor. Barcelona, Labor, 1954, tomo I, p.1113. Cfr. -Jaume Carbonell i Guberna: "Goula, Juan" en Diccionario de la Música..., op. cit., vol.5, pp.800-801. En el penúltimo concierto de la Sociedad se interpretó su Gran Polonesa de Concierto, que dirigió Goula (hijo), quien figura como maestro director y concertador en la lista de la compañía de ópera del Teatro Principal por esas mismas fechas, en la temporada $1885 / 86$

34. Ubicado en el Paseo de la Independencia, $n^{\circ} 33,35$ y 37 (actualmente, edificios de Correos y Telefónica), en los terrenos ocupados por la antigua Exposición Aragonesa, se inauguró el 8 de agosto de 1878 con Un drama nuevo de J. Tamayo y Baus, representado por la compañía de Rafael y Ricardo Calvo Revillo y Elisa Mendoza Tenorio; con ocasión de la llegada de Alfonso XII, en 1882, se puso en escena La Mascota, ya estrenada, cuyo "dúo de los pavos” cantaron la Montañés y Ripoll. Allí actuaron artistas como Tamberlik y la Nevada. En este teatro se estrenaron muchas obras de género chico y fue donde debutó el aragonés Pablo Luna. Además de conciertos de agrupaciones musicales zaragozanas, se dieron bailes en carnaval, parodias de mítines políticos, o discursos (Joaquín Costa fue uno de los protagonistas). Se clausuró en 1914, y fue derribado un año después. El Teatro Pignatelli tenía un aforo entre 1900 y 2000 espectadores. Obra del arquitecto Félix Navarro, éste lo había construido sin porches -no se hicieron hasta 1890-, para tener un teatro de verano: sólo hubo una temporada de invierno, en 1900, en la que actuó la compañía de María Guerrero, además de algunas otras, que incorporaban espectáculos de circo, magia y varietés. Hasta el año 1898 no dispuso de alumbrado eléctrico. Vid.: -Amparo Martínez Herranz: La arquitectura teatral en Zaragoza. De la Restauración borbónica a la Guerra Civil (1875-1939). Zaragoza, Institución Fernando el Católico, 2003, vol. II, p.633. -José Blasco Ijazo: Zaragoza y sus locales..., op. cit., pp.12-14.

35. -Vicente Garcés Ubide: "Memoria de la Orquesta Sinfónica. 1949-1959", s.l. [Zaragoza], s.e., s.f., coincide con Lozano en cuanto a la falta de apoyos, que añade a otros motivos, como las incompetencias de algunos directores o la falta de salidas laborales de los instrumentistas, que terminaban por irse a otras ciudades.

36. Hasta el siglo siguiente, en febrero de 1949, no volvió a haber en Zaragoza una orquesta sinfónica, según cuenta el propio V. Garcés Ubide -trompista de la misma-, quien formó parte de la reunión de donde saldría la creación de la nueva orquesta. 


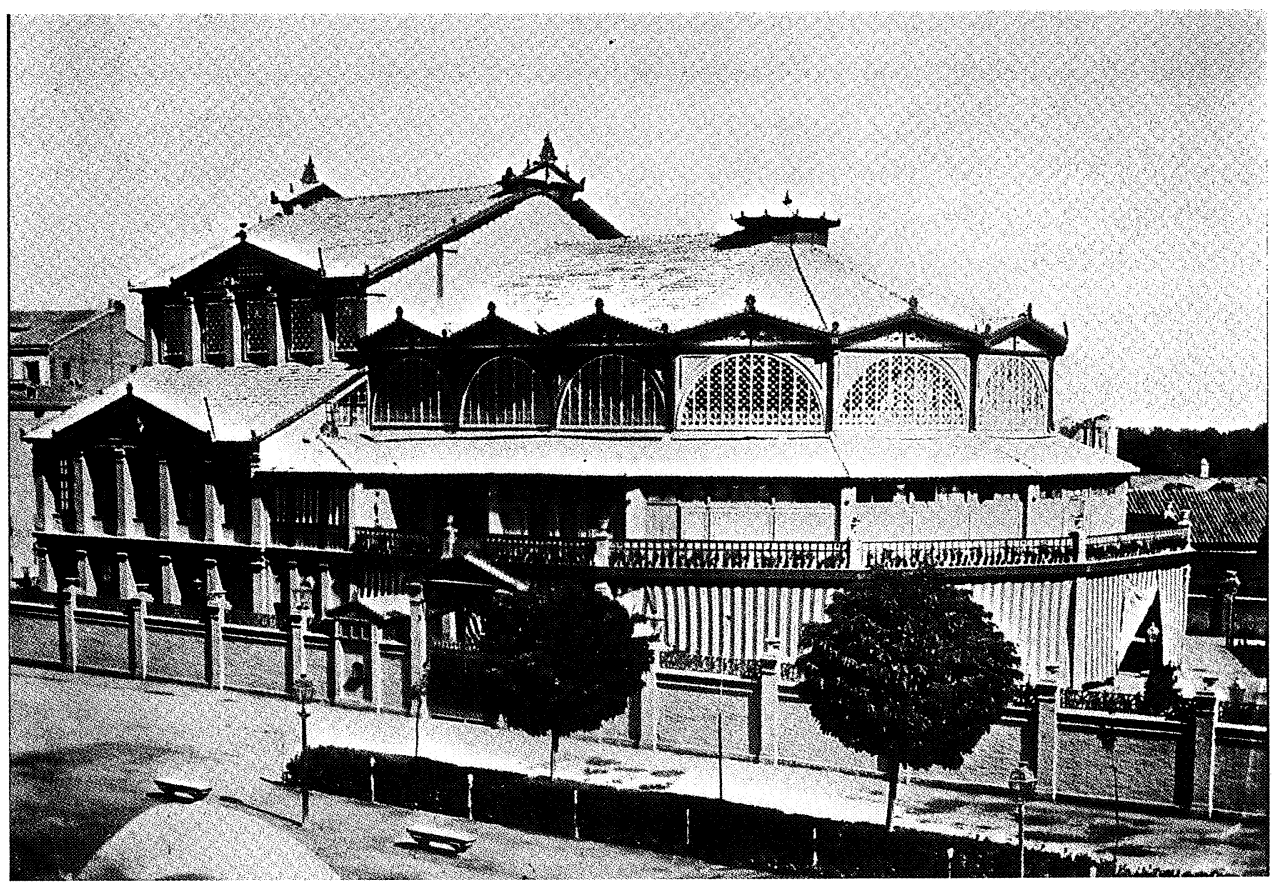

Fig. 4. Exterior del Gran Teatro Pignatelli (1878-1914) de Zaragoza, obra del arquitecto Félix Navarro. Situado en el Paseo de la Independencia, núm. 33-35-37 (actualmente manzana de los edificios de Correos y Telefónica), con un aforo entre 1.900 y 2.000 espectadores, abrió el 8 de agosto con la representación de Un drama nuevo (J. Tamayo y Baus), por la compañía de Rafael y Ricardo Calvo Revillo y Elisa Mendoza Tenorio.

A través de los compositores ${ }^{37}$, así como de las obras interpretadas a lo largo de los siete conciertos que se celebraron en las dos temporadas por aquella primera orquesta sinfónica, se puede seguir tanto el gusto del público zaragozano como, quizás, las pretensiones de la citada Sociedad. Así, figuran la obertura Xacarilla (Marliani), Presto de la Sinfonía en Si bemol, (Haydn), Polonesa de concierto (J. Iglesias), obertura de La Part du Diable (Auber), Marcha de las Antorchas, (Meyerbeer),

37. En las diferentes programaciones de conciertos figuraban obras de Adolphe Charles Adam (*1803; $† 1856)$, Daniel François Esprit Auber $(* 1782 ; \dagger 1871)$, Antonio Bazzini $(* 1818 ; \dagger 1897)$, Georges Bizet $(* 1838 ; \dagger 1875)$, Ruperto Chapí $(* 1851 ; \dagger 1909)$, Jules-Laurent Duprato $(* 1827 ; \dagger 1892)$, Gaspar Espinosa $(* 1836 ; \uparrow)$, Jules Godefroid $(* 1811 ; \dagger 1840)$, Juan Goula $(* 1843 ; \dagger 1917)$, Charles Gounod $(* 1818 ; \dagger 1893)$, Joseph Haydn $(* 1732 ; \dagger 1809)$, Juan Iglesias (compositor zaragozano y director en el Teatro Principal, compositor de buenos bailables y otras obras orquestales, en opinión de Antonio Lozano), Marco Aurelio Marliani (*1805;†1849), Félix Mendelssohn $(* 1809 ; \dagger 1847)$, Giacomo Meyerbeer $(* 1791 ; \dagger 1864)$, Domingo Olleta $(* 1819 ; \dagger 1895)$, Napoleón Henri Reber $(* 1807 ; \dagger 1880)$, Gioacchino Rossini $(* 1792 ; \dagger 1868)$, Franz von Suppé $(* 1819 ; \dagger 1895)$, Ambroise Thomas $(* 1811 ; \dagger 1896)$, Henry Vieuxtemps $(* 1820 ; \uparrow 1881)$, Eduardo Viscasillas Blanque $(* 1848 ; f l .1898)$ y Richard Wagner $(* 1813 ; \dagger 1883)$. Vid. -Antonio Ezquerro, ed.: Antonio Lozano..., op. cit., pp.133-136. Obsérvese una clara presencia española (seis compositores), francesa e italiana de autores de la centuria -particularmente, operistas y músicos que cultivaron géneros "ligeros"-, y que incluso aparecen autores entonces "novedosos" como Wagner -que provocaría toda una serie de enfrentamientos entre seguidores y detractores-. 
Stephanie-Gavotte (Czibulka), Moraima -capricho- $\left(\right.$ Espinosa) ${ }^{38}$, obertura de La Diadesté (Godefroid), Andante con moto, op. 42 (Bazzini), Canzonetta del Cuarteto op. 12 (Mendelssohn), Filemon et Baucis, entreacto (Gounod), La Giralda, obertura (Adam) ${ }^{39}$, La Déesse et le Berger, obertura (Duprato), Gran Sinfonía en Sol (Olleta) ${ }^{40}$, Serenata de la Fantasía morisca (Chapí), Paragraph III (Suppé) ${ }^{41}$, La danse Bohèmienne (Bizet), Le Roman d'Elvire (Thomas), Balada y Polonesa (Vieuxtemps), La nuit de Nöel (Reber), Kaiser-Marsch (Wagner), Gran polonesa de concierto (Goula), Notte in Venezia, serenata-barcarola (Viscasillas) ${ }^{42}$ o Capricho chinesco (Rossini). Cada concierto, invariablemente, constaba de tres números en cada una de sus tres partes. ${ }^{43}$

38. Gaspar Espinosa (*Murcia, 1836; †?): director y compositor, comenzó sus estudios de música en Murcia, aprendiendo a tocar varios instrumentos; más tarde se perfeccionó en composición con H. Eslava en Madrid. En Cartagena fundó la Sociedad de Conciertos El Orfeón, ciudad en la que fue director de orquesta y maestro de capilla; también dirigió, en Madrid, la Escuela Provincial de Música y la Banda del Hospicio. Con la obra que aparece en la programación de la sociedad de Conciertos zaragozana, Moraima, obtuvo el segundo premio del certamen organizado por la sociedad El buen pensamiento en 1887, interpretada por la Banda del Hospicio anteriormente mencionada. Se trata de un capricho orquestal escrito, en un principio, para banda y, más tarde, orquestada. Compuso música escénica -varias zarzuelas y comedias líricas entre otras obras-, sinfónica, un himno para coro, música para piano, para voz y piano, bailables, una habanera para banda -entre otras obras para esta formación- y música religiosa -motetes, misas, letanías, salves, un miserere y siete palabras-. Vid. -Ramón Sobrino: "Espinosa de los Monteros Jiménez, Gaspar", en Diccionario de música española..., op. cit., vol. 4, pp.783-784.

39. La Giralda es el título de una ópera cómica francesa con música de D. F. E. Auber, de la que Luis de Olona y Cristóbal Oudrid hicieron un arreglo: la zarzuela titulada Amor y misterio, que se estrenó en 1855, tiempos de gloria para el género francés en España. En el Catálogo de la Unión Musical Española se encuentra el arreglo de la obertura de La Giralda para piano y piano a 4 manos, de Adolfo [sic. Adolphe] Adam. Cfr.Cotarelo y Mori: op. cit., p.631.

40. Domingo Olleta (*Zaragoza, 1819; †id.,1895): se educó como niño de coro en La Seo zaragozana, recibiendo su formación del maestro de capilla Pedro León Gil, hasta que el cambio de voz no le permitió continuar; violinista segundo suplente allí, actuaba también de concertino en el Teatro Principal y fue, más tarde, primer violinista titular en la Seo, además de contrabajista. Organista por oposición de la iglesia de san Felipe y Santiago y catedrático de Canto llano del Seminario Conciliar, se ordenó sacerdote y ganó la plaza de maestro de capilla en la catedral donde se había formado y en la que daba clases de piano, solfeo, violín, armonía y contrapunto a los infantes. Entre su extensa producción -más de cuarenta obras- destaca la Gran Sinfonía en Sol, su Oficio y misa de difuntos, la Misa Valeriana, el Invitatorio o Bendita sea tu pureza. Entre sus discípulos se encuentran Benigno Cariñena, Alejo Cuartero (maestro de capilla de la catedral de Huesca), o Pascual Fañanás (profesor del Conservatorio Nacional de Música). J. Ricart i Matas, F. Pedrell, F. Viada, H. Eslava, V. Metón, J. M. Esperanza y Sola, M. de Cavia, R. Ruiz de Velasco, R. Chapí o B. Saldoni elogian y reconocen las aportaciones de Olleta a la música religiosa y al sinfonismo decimonónico. Vid. -Antonio Ezquerro Esteban: “Olleta Mombiela, Domingo" en Diccionario de la Música española ..., op. cit., vol.8, pp.63-67.

41. Franz von Suppé [Francesco Suppe Demelli] (*Dalmacia, 1819; †Viena, 1895). Este compositor austriaco de origen belga recibió lecciones de G. Donizetti, a quien conoció mientras realizaba sus estudios en el Conservatorio de Viena. Fue director de orquesta del Teatro Joseph Stadt, más tarde también en Presburgo (Bratislava) y en el teatro An der Wien. Célebre por sus numerosas obras ligeras (operetas, vaudevilles y ballets), de las que compuso más de doscientas. Una de las que más éxito obtuvo fue Paragraph 3, entre otras como La bella Galatea, Poeta y aldeano, La muchacha del campo, Boccaccio, Donna Juanita o Caballería ligera. Compuso, además, oberturas, una sinfonía, varios cuartetos, música religiosa, danzas, etc. Vid. -J. Ricart i Matas: Diccionario biográfico de la música. Barcelona, Iberia, [1956] p.1008.

42. Se conserva una de sus obras, la transcripción orquestal anteriormente citada Celebre Meditazione di Crescentini, trascrizione per grande orchestra y que escribió Viscasillas al año siguiente: se trata de una pieza originalmente para piano, propiedad de la casa editorial de F. Lucca de Milán, cuya partitura se conserva autentificada con el autógrafo del compositor en fecha de 22 de diciembre de 1887. Dedicada alla Signora Augusta Yarak, Nata Hiller, muestra la orquestación siguiente: flautín, flauta, oboe, clarinetes, fagotes, 4 trompas, 2 trompetas en La, 3 trombones, tuba, timbales en Si-Fa\#, y orquesta de cuerda. De su interpretación se escribió una crónica en el "Buzón" del nº de El Correo Musical (10 de mayo): "La Meditazione es una partitura digna [...] de oirse y también de estudiarse [...]. Italiana por su melodía predominante, y revistiendo la severa elegancia propia del canto elegiaco, las ideas se suceden con interés creciente merced á la novedad de timbres, variados artificios armónicos, oportunas imitaciones, detalles de colorido y en general por los innumerables é inesperados procedimientos á que rinde culto la moderna escuela. Deseamos muy de veras tener ocasión de oír nuevamente esta obra que al salirse algún tanto de la extructura [sic.] hoy más en boga, entra á formar con las modernas producciones en que resaltan por igual la inspiración y la filosofía del arte." Se trata pues de la primera vez que, en Zaragoza, se interpretó esta obra: la ocasión fue el segundo concierto a beneficio de la Casa-Amparo (Mayo de 1888), a cargo de la orquesta del Teatro Principal, dirigidos, como ya se ha dicho, por R. Ruiz de Velasco.

43. Si repasamos la legislación sobre la propiedad intelectual, que no artística como en otros países europeos, a través de la Ley de 10 de enero de 1879 y del Reglamento de 3 de septiembre de 1880, vemos que, según el artículo 96 de éste, al optar por 


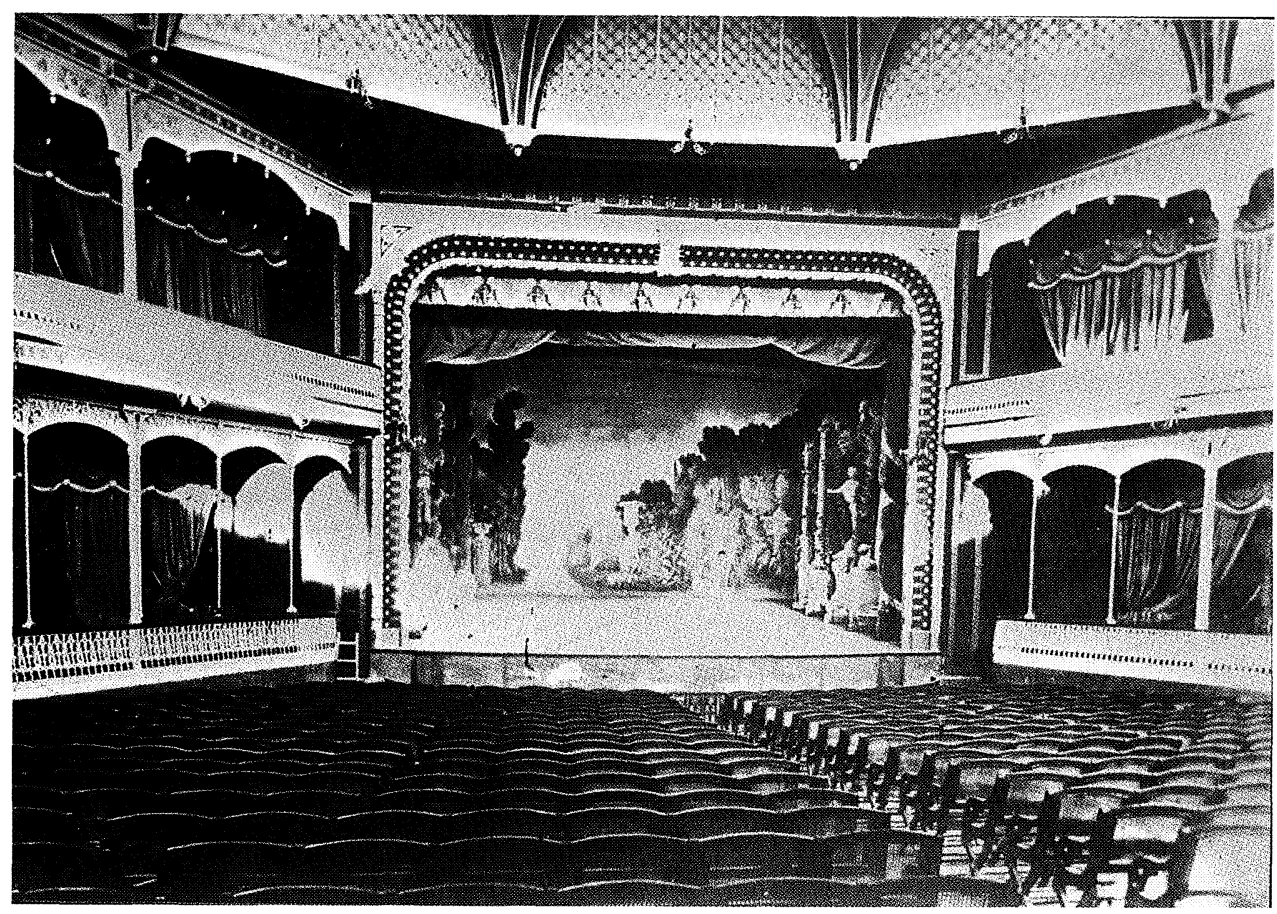

Fig. 5. Interior del Teatro Pignatelli. Con motivo de la visita de Alfonso XII en 1882, en la función de gala se representó La mascota, traducción de la opereta francesa, con música de Edmond Audran, en 3 actos.

el cobro del porcentaje del producto de las entradas, incluido el abono -opción más frecuente-, los arreglos devengaban la mitad del importe estipulado; las obras instrumentales tales como una gran sinfonía o fantasías en tres o más movimientos devengaban el $3 \%$ de la recaudación para el autor, pero una obertura original o fragmentos de las anteriores suponían el $1 \%$, lo mismo que un divertimento de baile en un acto; mientras que para el género lírico-dramático, a las obras en un acto correspondía el 3\% frente a un 7\% y un $10 \%$ si eran en 2 actos o en 3 (o más) respectivamente. Programas como el descrito eran representativos en el ámbito territorial español; además de los gustos del momento, partidarios de programas ligeros y variados, este asunto podría llevarnos también a sospechar posibles presiones por parte de los empresarios teatrales y demás intermediarios. Vid.: La Gazeta de Madrid, (6 de septiembre, 1880); -Antonio Gallego: "Aspectos sociológicos de la música en la España del siglo XIX", en Revista de Musicología, XIV/1-2 (1991), pp.[11]23-[13]25. Sobre legislación y Propiedad Intelectual, vid. también: -M. Carmen García Mallo: "La edición musical en Barcelona (1847-1915)", en AEDOM, Boletín de la Asociación Española de Documentación Musical, IX/1, (2002), pp. 69-77. No obstante, da la impresión de que, frente a unos empresarios corporativistas (recuérdese el Real Decreto Orgánico de los Teatros del Reino y Reglamento del Teatro Español de 1849, que ya favorecía a los empresarios de compañías lírico-dramáticas) y_ "manipuladores" de los contenidos musicales -me refiero a selecciones incompletas, modificaciones o acortamientos de las piezas- que, en virtud de dicha manipulación podían pasar a convertirse en mera música de circunstancias o de puro entretenimiento, los músicos y compositores tenían sus propias quejas. Una muestra de estas quejas a empresarios, es la que se lee en la diligencia siguiente, con fecha de 17 de mayo de 1855: "El Sr. Larraz dijo: que supuesto hoy debía subastarse el arriendo del Teatro cómico [Teatro Principal] de esta ciudad [Zaragoza], deseaba se tratase de corregir el abuso que hacen los Empresarios de alterar á su arbitrio los precios de la diversión aumentándolos á los que les acomoda sin ninguna autorización" (Archivo Municipal de Zaragoza, caja 07789, 40-7, arm.21, $\operatorname{leg}^{\circ} 7, n^{\circ} 13$ ). 


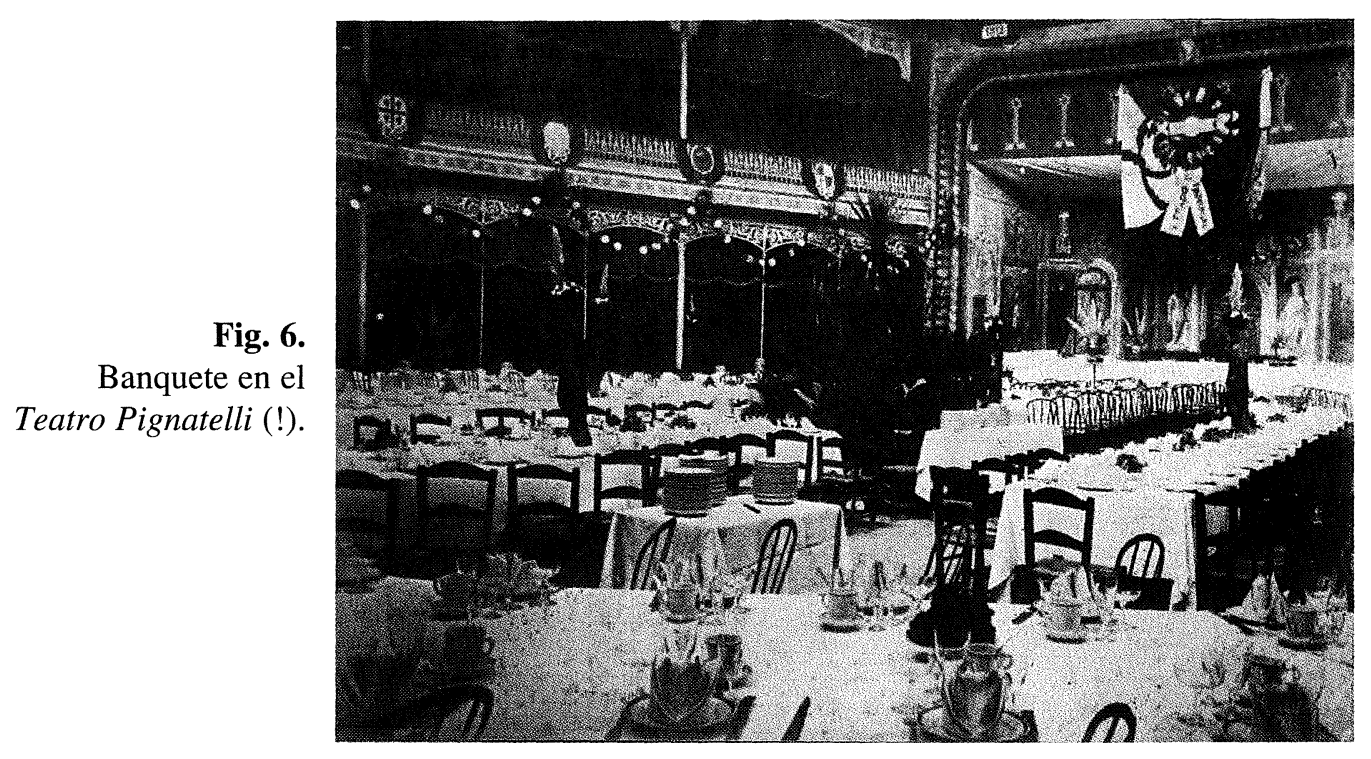

$\mathrm{Al}$ rastrear ese gusto musical de la época hay que atender al predominio de Meyerbeer y Gounod en los programas - sin duda, reflejo de la influencia de la moda francesa-, a quienes sigue Mendelssohn (en cuanto a número de veces interpretado con obras diferentes); también a las obras que constituyeron "repertorio" de la Sociedad: composiciones de Auber, Iglesias, Chapí, Rossini, Meyerbeer, Godefroid, Mendelssohn, Marliani, Bazzini, Goula o Espinosa; por último, y atendiendo a un criterio formal, se trata, fundamentalmente, de oberturas o partes instrumentales de óperas, operetas y zarzuelas por un lado y, por otro, movimientos de sinfonías o cuartetos y arreglos para orquesta, fantasías, serenatas, incluidas piezas de carácter y demás "pinturas sonoras": música, en su mayor parte, de gran lucimiento y efecto, dirigida a un público todavía muy acostumbrado a la música escénica. Un espectro formal apto para los salones de que disponía la ciudad (teatros que debían alternar todo tipo de espectáculos: musicales, teatrales, de varietés...), con una intencionalidad de "entretenimiento", y apto, también, para los gustos -no particularmente exigentes- del "gran público", pero al mismo tiempo ofrecían los componentes de esta Sociedad una literatura de cierta actualidad europea -como difusores de las modas- y extendían patrones constructivos musicales, aunque ya arraigados en buena parte de Europa, a los que el público español todavía no estaba acostumbrado (como, v.g., la música de cámara), de suerte que este tipo de programaciones servía como vía pedagógica para ir, poco a poco, adoctrinando en "el buen gusto" -invariablemente venido del exterior-a las clases emergentes burguesas, ávidas de prosperar y equipararse con la mejor sociedad de Madrid, Barcelona o París.

Hay que añadir, entre la actividad de esta Sociedad de Conciertos, uno de beneficencia ${ }^{44}$ en el que se interpretaron obras ya escuchadas en conciertos anteriores. No hubo una "Sociedad de Soco-

44. Ejemplos de funciones a beneficio de la Casa-Amparo, en 1888, son las celebradas en el Teatro Principal, con la zarzuela en tres actos de Manuel Fernández Caballero El salto del pasiego -escrita en 1878, con libreto de Luis Eguilaz-(27 de abril), 
rros Mutuos" constituida como tal, como en otras ciudades, pero se celebraron acontecimientos musicales con similares objetivos, señalando este hecho ciertos matices filantrópicos propios de este tipo de espectáculos -no olvidemos los conciertos donde se "verificaba el beneficio" del director, compositor, instrumentista o cantante correspondiente-.

\section{b) Sociedad de Cuartetos}

Le siguió la Sociedad de Cuartetos de Zaragoza, nacida cuatro años más tarde, cuyo reglamento se redacta en marzo de 1890, con Jesús de Monasterio como presidente honorario, fundador de la homónima sociedad madrileña, y constituida por los profesores Teodoro Ballo ${ }^{45}$ (primer violín y director), Manuel Cuartero (violín segundo), José Tremps (viola), Juan Laclaustra (violonchelo) y Santiago Carvajal (piano). ${ }^{46}$ Se estrenó en público con una serie de conciertos celebrados durante la Cuaresma -período idóneo para procurarse los músicos unos ingresos con la programación de conciertos, mientras permanecían cerrados los teatros-. En sus primeros programas se incluyen cuartetos de Haydn y Beethoven, la Canzonetta del Cuarteto op.12 de Mendelssohn o el Gran trío para piano, violín y violoncello sobre motivos de la Norma de Bellini, de V. di Meglio. ${ }^{47}$

De fecha 12 de enero de 1890 es la crónica de uno de los conciertos de esta Sociedad, y que se lee en el Diario de Zaragoza:

Teatro Principal. Concierto instrumental a beneficio de los pobres de esta capital: la Empresa de este coliseo en unión con la Sociedad de Cuartetos que dirige D. Agustín Pérez [Soriano], con objeto de allegar recursos con destino al socorro de los pobres de la localidad ha dispuesto para este día un gran

\footnotetext{
la comedia en tres actos de Eusebio Blasco El baile de la Condesa y el juguete cómico en un acto de Vital Aza Los tocayos (20 de noviembre) por lo que se recaudó, libre de gastos, 1570'50 reales de vellón; hay que decir que el empresario de este teatro, Miguel Sisamón, venía obligado a lo que dispusiera el Ayuntamiento en cuanto a este tipo de funciones; de otra manera, el empresario que dirigía la compañía de zarzuela del Teatro Goya (privado), Luis Boggiero, ofreció el $50 \%$ de los ingresos, deducido el presupuesto del día (13 de julio); también el empresario del Teatro Circo, Eduardo García Berges, director de la Compañía Nacional de zarzuela según el expediente localizado con fecha de 1888, colaboró en la misma causa con la representación de la zarzuela en tres actos $L a$ tempestad (Chapí) y la pieza en un acto El Gorro frigio -estrenada dos meses antes, en octubre de 1888, con música de Miguel Nieto- (28 de diciembre). Este empresario-cantante lo fue, también, del madrileño Teatro de la Zarzuela en la temporada de 189091. (Archivo Municipal de Zaragoza, Gobernación, secc. "Beneficencia", caja 1475, exptes. 621, 896 y 1495). Vid. -Luis Miguel Gracia Iberni: "Fernández Caballero, Manuel", en Diccionario de la Zarzuela. España e Hispanoamérica. Madrid, ICCMU, 2002, vol I, p.747. -Emilio Casares Rodicio: "Gorro frigio, El”, y "Compañías de zarzuela", ibid., pp.916-917 y p.528, respectivamente.

45. Teodoro Ballo (*Zaragoza, 1866; †id., 1962): después de comenzar sus estudios de violín y guitarra en Zaragoza, continuó los de violín con Jesús de Monasterio en Madrid, donde fue primer violín de la Sociedad de Conciertos en 1882 (con tan sólo 16 años) y del Teatro Real. De vuelta a Zaragoza amplió estudios de composición con Antonio Lozano. En el Gran Casino de San Sebastián actuó muchos años como concertino y segundo director. Profesor de su instrumento en la Escuela de Música de Zaragoza, dirigió la Sociedad de Cuartetos y varias orquestas zaragozanas. Gran impulsor de la música de cámara en esta ciudad, fue premiado con un alfiler de corbata de oro por el Ayuntamiento - que llevaba grabadas las ocho o diez primeras notas de la pieza que tocó en piedras o chispas de diamantes-, con ocasión de la función regia que se celebró en el Teatro Principal el 15 de mayo de 1888, para celebrar la llegada a Zaragoza de la entonces reina regente, $\mathrm{M}^{\mathrm{a}}$ Cristina de Habsburgo. Como compositor, destacan entre sus obras, de carácter patriótico y religioso, dos himnos y una Salve a 3 voces y órgano. -Antonio Ezquerro, ed.: Antonio Lozano: La Música..., op. cit., pp. 81, 138, 141, [89]. -José Vicente González Valle: "Ballo Tena, Teodoro", en Diccionario de la Música, op. cit., vol.2, p.120. Cfr.: -Fernando Castán Palomar: Aragoneses contemporáneos: 1900-1934. Zaragoza, Herrein, Tipografía La Académica, 1934, pp.71-72.

46. Según Antonio Lozano, fue fagotista en la capilla de La Seo de Zaragoza, renunciando más tarde a la plaza. Además de pianista, fue, también, profesor de solfeo en la Escuela de Música de Zaragoza.

47. Se trata del Trío sull'opera Norma di Bellini per violino, violoncello e pianoforte, op. 82, de Vincenzo di Meglio, Milano, Tito Ricordi, [1865]. [Página consultada <http://opac.sbn.it/> en octubre de 2003].
} 
concierto, en el que tomará parte, además de dicha sociedad, la orquesta de este teatro y la acreditada banda del regimiento de Infantería del Infante [...] cedida por su coronel D. Angel Aznar. [...] Nota: 'En esta noche dará a conocer al público la Sociedad de Cuartetos el magnífico piano de Cola, de la fábrica del Sr. Bernareche [Bernareggi] que ganó el primer premio en la Exposición de París' ${ }^{48}$

En el programa figuran obras de F. von Suppé -Paragraphe III-, G. Rossini -Sinfonía de Guillermo Tell- ${ }^{49}$, el propio A. Pérez Soriano -Fantasía sobre motivos de Un ballo in maschera de Verdi-, Beethoven, Ch. Gounod, J. Iglesias, A. Brull ${ }^{50}$ y P. Miguel Marqués. ${ }^{51}$

48. Faustino Bernareggi: miembro de una familia de fabricantes de instrumentos y editores de música, activos en Barcelona, Madrid y Zaragoza durante el siglo XIX, de quienes se sigue teniendo noticia a principios del XX. Su familia se había asociado en diferentes ocasiones con diversas firmas de fabricantes de instrumentos; en varias ocasiones fue reconocida su factura con distinciones y medallas en las numerosas exposiciones internacionales a las que llevaron sus instrumentos. Su antepasado Francisco había sido nombrado "Constructor de instrumentos de música de la Real Cámara de S.M., en 1829, por sus instrumentos de viento. Se dedicaron, además, a la calcografía y la edición, actividad, ésta última, en la que destacó Faustino Bernareggi. Asociado con Andrés Vidal y Llimona, formó la editorial madrileña "A. Vidal hijo y Bernareggi”; además dirigió en Barcelona el "Centro de Publicaciones Musicales" (1875-77). En 1877 tuvo un depósito de publicaciones e instrumentos en París; también tuvo, en 1880, una fábrica de pianos en Barcelona. En 1888, la entonces empresa "Bernareggi, Gassó y Cía." estaba fabricando nueve modelos diferentes de pianos. Fue uno de los principales editores de música de Zaragoza, cuya actividad se desarrolló entre los años 1878 y 1895 , donde también tuvo fábrica de pianos. Secretario y profesor de piano y de lenguas en esta Escuela de Música, que sería Conservatorio Profesional a partir de 1933. Las obras editadas por Faustino Bernareggi son, principalmente, piezas de salón para piano. Vid.: -Carlos José Gosálvez Lara y Beryl Kenyon de Pascual: "Bernareggi", en Diccionario de la Música..., cit., vol. 2, pp.406407. -Carlos J. Gosálvez: La edición musical española hasta 1936. Madrid, AEDOM, 1995, Colección de monografías, n¹, pp.181, 184. -Antonio Ezquerro, ed.: Antonio Lozano: La Música..., op. cit., pp.141, 145, [47], [49], [50]. -Mª Carmen García Mallo: "La edición musical en Barcelona (1847-1915)”, op. cit., pp. 21-22. Para una más amplia información sobre los Bernareggi como constructores de instrumentos - desde sus comienzos en el gremio de torneros a principios del s. XIX-, vid.: -Josep Borrás y Antonio Ezquerro: "Chirimías en Calatayud. Principio y final de un proceso constructivo", en Revista de Musicología, XXII/2, (1999), pp.71[19]-74[22]. -Josep Borràs Roca: "Constructors d'instruments de vent-fusta a Barcelona entre 1742 i 1826", en Revista Catalana de Musicologia, I (2001), pp.93-156. -Luis Serrano Pardo: Litografía Portabella. Biografía de una empresa familiar. Zaragoza, 1877-1945. Zaragoza, Diputación de Zaragoza, colección "Benjamín Jarnés" n6, 2003.

49. Esta obertura debió de estar entre las preferencias del público zaragozano, ya que aparece repetidamente entre el repertorio de las orquestas y sociedades musicales en diferentes fechas (en transcripción pianística el año 1859, en la temporada de ópera de 1884 , en $1888,1890 \ldots)$.

50. Apolinar Brull Ayerra (*San Martín de Unx -Navarra-, 1845; †Madrid, 1905): en el Conservatorio de Madrid estudió piano con Edmundo Compta y composición con Emilio Arrieta. Se le conoció principalmente por sus obras dramáticas, siendo uno de los compositores con más producción en el género chico. También compuso música de salón, sinfónica, para coro y una Lamentación para voz con acompañamiento. Véase: -Emilio Casares: "Brull Ayerra. 1. Apolinar" en Diccionario de la música..., op. cit., vol. 2, pp.735-737. El año en que se celebró el concierto mencionado (1890) nos sitúa al final de una etapa de formación del género teatral; cabe pensar, por el tipo de concierto reseñado, sin embargo, que el cronista se refiera a su producción sinfónica (entre la que fue muy popular su obra Polaca de concierto, estrenada en 1881 por la orquesta de la Sociedad Artístico Musical madrileña), o quizás a algún número instrumental de su ya extensa producción escénica. Felipe Severo Aragonés, periodista colaborador de $E l$ Correo Musical, que escribía bajo seudónimo, en su "Crónica artística" reseña el estreno en el Teatro Eslava de un boceto titulado Las virtuosas, con letra de [Ricardo] Monasterio y música de A. Brull, del que dice ser "un cuadro de moral hecho con gracia y con retoques de buen género. La partitura es bastante original. La obra representóse con lujo" (El Correo Musical, [1888], n²0, 20 de octubre, pp.155-156).

51. Pedro Miguel Marqués (*Palma de Mallorca, 1843; †id., 1918): estudió violín y composición, entre otros, con Jules Armingaud [*1820; †1900?], Delphin Alard, Joseph Lambert Massart y Emmanuel Joseph François Bazin en París, y fue discípulo de Berlioz en instrumentación y estética musical; de regreso a Madrid continuó con Monasterio sus estudios de violín y con Arrieta los de composición. Su producción sinfónica -gran parte de ella interpretada por la Sociedad de Conciertos de Madrid en innumerables ocasiones- tuvo gran acogida: escribió, entre otras obras, 5 sinfonías en 4 movimientos, una Sinfonía sobre motivos de zarzuelas modernas y una Séptima Gran Sinfonía (La vida), las melodías orquestales La canción del marinero y La primera lágrima, 6 Polonesas de concierto -la $2^{\mathrm{a}}$ fue interpretada en Zaragoza por la Sociedad de Cuartetos en este concierto cuya crónica aparece fechada en enero de 1890-, varias Marchas de concierto, preludios, oberturas, scherzi, etc. De casi todas sus obras se publicaron reducciones pianísticas o para canto y piano o, incluso para 4 manos. Se dedicó, también, a la zarzuela y el drama lírico y, a partir de 1889, al género chico, con juguetes cómico-líricos, zarzuelas en un acto, sainetes y otras obras cómicas; en su última etapa, de vuelta a Palma de Mallorca, se dedicó a escribir poemas sinfónicos, obras de cámara, música religiosa, más melodías orquestales y preludios. Máximo representante de la sinfonía española en la segunda mitad del siglo XIX, base del sinfonismo español de 

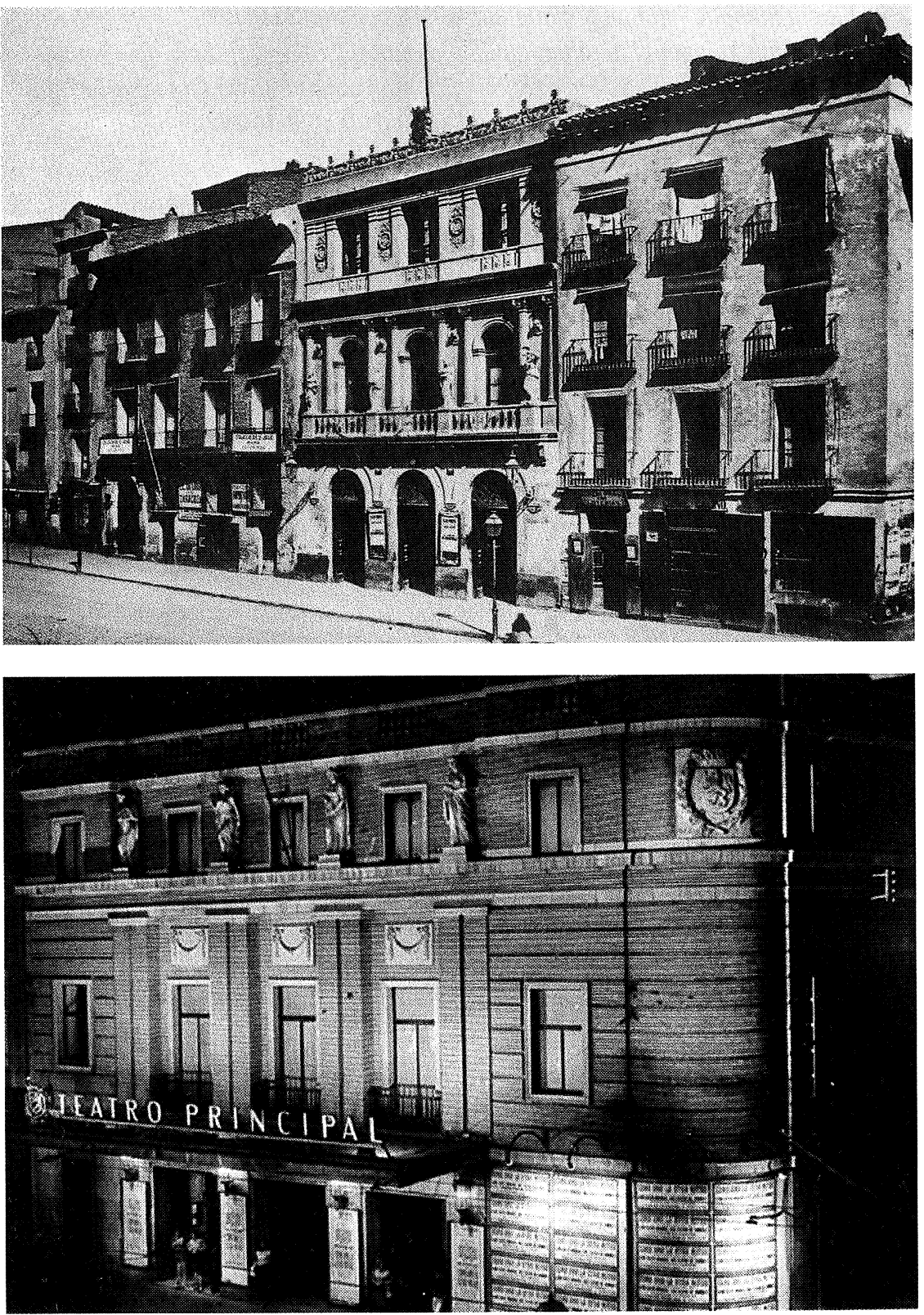

Fig. 7.

(Arriba) Fachada del Teatro Principal. Las estatuas alegóricas, en esta imagen situadas en el pórtico, datan de la reforma de 1848 , una de las innumerables que vivió el coliseo.

(Abajo) Imagen del teatro en la actualidad: en 1940 se abrió la calle de Eusebio Blasco, una vez derribado el edificio que se observa en la imagen anterior.

principios del XX, sus obras se interpretaron, comenzando por San Petersburgo, en París, Viena, Munich, Amsterdam, Teherán y varios países de América. Véase el amplio estudio que sobre él hace -Ramón Sobrino: "Marqués García, Pedro Miguel", en Diccionario de la música española e hispanoamericana..., op. cit., vol.7, pp.202-212. El Instituto Complutense de Ciencias Musicales (ICCMU) ha editado recientemente las cuatro primeras Sinfonías de P. M. Marqués, en edición crítica de Ramón Sobrino: Sinfonía $n^{o} 1$ en Sib $M, n^{\circ} 2$ en Mib $M, n^{\circ} 3$ en si $m$. Madrid, SGAE/ICCMU, 1993, 1995 y 1995, respectivamente, y Sinfonía $n^{\circ} 4$ en Mi M. Madrid, Ediciones Iberautor/ICCMU, 2002. 


\section{c) Sociedad Filarmónica}

Pocos años más tarde, en 1906, se creó la Sociedad Filarmónica de Zaragoza. De este comienzo tenemos noticia en la prensa local: en el Diario de Zaragoza, Periódico político de noticias generales y de avisos $^{52}$, con fecha de 19 de enero de 1906, se lee:

La Filarmónica: naciente sociedad. Se reúnen el próximo domingo en el Ateneo Científico y Literario, Coso 110, pral., para someter a aprobación los estatutos por que han de regirse la Sociedad y elegir la junta directiva.

El siguiente lunes, 22 de enero, aparece en el mismo diario:

Nota sobre los iniciadores de la Sociedad Filarmónica. Junta: Presidente, Paulino Savirón. Comité técnico: Mariano Baselga, Mariano Lafiguera y José M. Royo [Villanova]. Comité administrativo: Luis Ibarra, Roberto Soteras, Ángel López-Tudela y Eugenio López-Tudela. Los primeros conciertos irán a cargo de los señores [Teodoro] Ballo, [José] Orós, [José] Tremps, [Santiago] Carvajal y [Juan] Laclaustra.

Esta Sociedad ${ }^{53}$, de carácter profesional y cuyas primeras sesiones ${ }^{54}$ tuvieron lugar en el Salón de Conciertos de la Escuela de Música, ha celebrado sus conciertos sin interrupción hasta la fecha, con la salvedad de cuarenta y cinco meses dentro del período que abarca la guerra civil -desde julio de 1936 a abril de 1940, fecha en que reanudó su actividad-. ${ }^{55}$

52. Este diario comenzó su andadura en 1797. Se autodefinía en su cabecera como "proteccionista de la producción nacional", "periódico político liberal-conservador de noticias y avisos" y "defensor de las clases conservadoras del país".

53. La actividad de la Sociedad Filarmónica de Zaragoza será objeto de estudio en un próximo trabajo.

54. El primer concierto se celebró el 2 de marzo de 1906 en un local para doscientas personas que el marqués de Bobadilla, don Mauricio de Bobadilla y Escribá de Romaní, tenía arrendado a la Escuela de Música, en la calle Espoz y Mina, n 23 , pral. Los primeros programas que se escucharon incluían los siguientes compositores, en orden descendente en cuanto a número de ocasiones en que se interpretaron: Beethoven, Schumann, Chopin, Grieg, Mendelssohn, Haydn, Mozart, Tchaikowsky, Schubert, Weber, Liszt, Fauré, Franck, Chapí (Cuarteto en sol) y Lamote de Grignon (Reverie, por el Trío Marshall). A lo largo de la programación de los dos primeros años (1906-1908), Beethoven (Cuarteto en Mib para piano e instrumentos de arco, transcripción del Gran quinteto op.16, Romanza en fa para violín y piano, Sonata op. $53 n^{\circ} 21$ para piano -por Enrique Granados-, Trio en Sib op.97 para piano, violín y violoncello, varias sonatas para piano, Cuartetos op. $18 n^{\circ} 2$ y $n^{\circ} 4$ para cuerda, Obertura Egmont -por un sexteto de cuerda más piano-, $\sigma^{a}$ Sinfonía -orquesta de 60 profesores dirigidos por Teodoro Ballo-, Obertura Leonora, Serenade para flauta, violín y viola -por el doble quinteto de cuerda y viento de París-) fue interpretado en mayor número de veces (treinta y cinco) entre sesenta compositores, seguido no muy de cerca por Schumann (Quinteto para piano $e$ instrumentos de arco op.44; Arabesque op.18 y Papillons noirs op.12 para piano -por Enrique Granados-; Cuarteto op.47; 'J'ai pardonné', Flor de Lotus, L'oiseau prophéte, A ma fiancée, Nuit de printemps, lieder), Chopin (Impromptus, Baladas, Polonesas, Estudios, Nocturnos y Preludios, interpretados por E. Granados, el pianista navarro Joaquín Larregla, la zaragozana $\mathrm{M}^{\mathrm{a}}$ Ángeles Sirvent y Frank Marshall), y por Mendelssohn (Cuarteto para instrumentos de arco en mi $m$, op. $44 n^{\circ} 2 ;$ trío en re $m$ op.49 para piano, violín y violoncello; lied 'Sulla riva del Gange'; Sexteto para piano y cuerda op.110; otros tríos y cuartetos). La recepción tardía de los clásicos no fue un asunto local. Por estas fechas se admiraba, se elegía en veladas musicales, eran objeto de análisis o conferencias, y se interpretaba a Beethoven, Haydn y Mozart - este último en menor medida-. Un repaso a la programación deja ver claramente el interés predominante por la música de cámara en los inicios de esta sociedad zaragozana.

55. Sobre la creación de la Sociedad Filarmónica de Zaragoza, véase: -José Blasco Iijazo: ¡Aquí... Zaragoza!. Treinta y seis reportajes. Zaragoza, Ayuntamiento de Zaragoza, 1948-1960, tomo IV, [1953], pp.204-212. 


\section{d) Sociedad coral 'La Coronilla'}

De distinto signo que las anteriores, en 1863 se creó en Zaragoza una importante sociedad, $\mathbf{L a}$ Coronilla, de carácter cultural y popular, dedicada principalmente al canto coral y a la organización de bailes: de ella dependía la que nació algo más tarde como Sociedad Coral $^{56}$ con el mismo nombre. Zaragoza, como otras ciudades españolas, había recibido el influjo del movimiento coral iniciado en Cataluña a mediados de siglo por Anselmo Clavé y Juan Tolosa -cada uno de ellos con pretensiones diferentes, social y moralizante el primero, y en torno a una pedagogía popular el segundo-.

A pesar de su juventud como sociedad coral, La Coronilla participó ya en el Festival de Coros de Clavé en $1864^{57}$, significando un gran acontecimiento para Zaragoza el gran éxito que obtuvo. Se estrecharon lazos con sus colegas catalanes; en el diario El Correo de Aragón, se puede leer en la "Crónica local" de 19 de noviembre de ese mismo año de 1864 la siguiente nota, con motivo de la visita de aquéllos a Zaragoza:

Según habíamos anunciado, anoche á las diez y media tuvo lugar bajo los balcones de la casa fonda de las cuatro naciones [calle don Jaime] la serenata con que la Sociedad coral La Coronilla había acordado obsequiar al Sr. D. José Anselmo Clavé. Los coristas agrupados bajo su pendon cantaron muy bonitas piezas [dos composiciones de Clavé] [...], y la orquesta compuesta de gran número de profesores de ambos teatros [Principal y Variedades] ejecutó perfectamente bajo la dirección de D. Narciso López director de la de Variedades algunas piezas del escogido repertorio. La concurrencia era muy numerosa. (Ver fig.8)

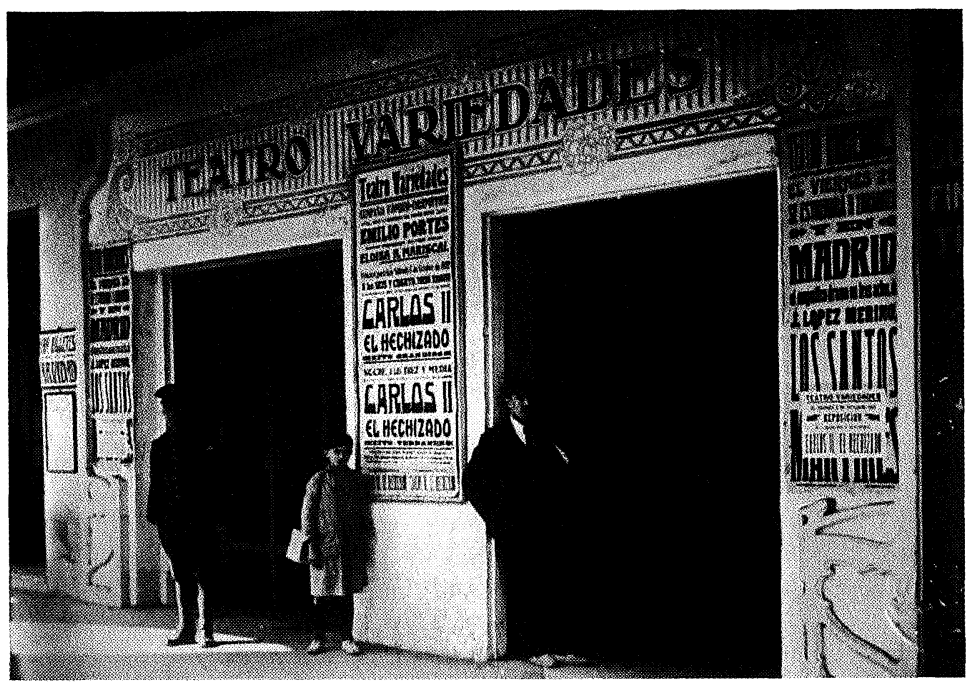

Fig. 8.

Teatro Variedades (1853-1873), construido en el solar donde estuvo el Convento de las Vírgenes (1531), "para solteras hidalgas y viudas de buena fama" (según José Blasco Ijazo), el cual, suprimido y vendido en 1846 , fue uno de los ejemplos de desamortización eclesiástica.

56. En el diario El Anunciador aparece la nota siguiente: "La Sociedad de la Coronilla se vé en los bailes que estos días celebra muy concurrida por el público, que premia de esta manera la laboriosidad de los socios, que siendo casi todos artesanos dedican á ejercitarse en el canto y música los ocios que el trabajo les deja en vez de pasarlos en ejercicios menos útiles". (El Anunciador, Diario Oficial de avisos de Zaragoza, 2 de febrero de 1864, Año II, n³3, sección "Gacetillas", propietario y editor Gregorio Casañal, Imprenta de Manuel Ventura).

57. Vid. -María Nagore Ferrer: "Coros", en Diccionario de la Música Española..., op. cit., vol. 4, p.25. Cfr. -Francisca Soria Andreu.: El Ateneo..., cit., pp.13-14. El gobernador de Zaragoza prohibió la recepción de la coral en procesión pública a su vuelta a Zaragoza. 
Retrocediendo en el tiempo unos meses, vemos cómo varias fuentes confirman la total falta de apoyo por parte de la corporación municipal a La Coronilla. Con fecha de 21 de marzo de ese año de 1864 aparece firmada la instancia donde ésta pide la confección de un estandarte y la protección del ayuntamiento zaragozano para que la Sociedad Coral La Coronilla representase a la clase trabajadora aragonesa en el próximo gran festival en Barcelona, al que sus componentes fueron invitados "por sus hermanos de aquel país", y de la que se deduce su creación en este año y no antes. En ella se lee lo siguiente:

Educar á las clases populares, ennoblecer su corazón por el cultivo de las bellas artes, es el más noble y grandioso de los fines que una sociedad puede proponerse. Y á este fin, nadie puede desconocerlo, contribuyen eficazmente las asociaciones corales que, fundadas en Cataluña por un dignísimo hijo del pueblo, se van propagando [...] por el resto de España, y son la admiración de nacionales y estrangeros. [...] Millares de jóvenes obreros recorren las calles [de la ciudad condal] divididos en grupos, cada uno de los cuales ostenta un estandarte más ó menos rico [...] que sirve de enseña, no á un ejército destructor y fratricida, sino á una legion pacífica de trabajadores [...]. Y aquí, en la Ciudad inmortal y siempre heróica [Zaragoza], se ha fundado una sociedad de este género, sociedad que inaugurada con una función á beneficio de las víctimas del terremoto de Manila, quiso después funcionar para con los productos que obtuviese, favorecer á los pobres de la localidad, mas su abnegación y buen deseo se estrelló contra fuertes é inesperados obstáculos. ${ }^{58}$

Que el movimiento coral en Zaragoza se estableció bajo el impulso del catalán queda reconocido en la diligencia firmada el 15 de abril de 1864 -así como en otros puntos de referencia-, que el funcionario de la sección $1^{\mathrm{a}}$ comunica al gobernador en relación con la petición anteriormente citada, y donde éste repite la declaración de intenciones de la agrupación:

La Sociedad Coral titulada 'La Coronilla', fundada en esta ciudad, á imitación de las que de su clase existen ya en Cataluña, ha recurrido á Vd. manifestando el objeto de su creación que según dice no es otro, que el de educar á las clases populares y ennoblecer su corazón por el cultivo de las bellas artes [...] y deseando tener un pendon parecido al que llevan en aquel país [Cataluña] otras sociedades corales, suplica á Vd. le preste su apoyo [...]. ${ }^{59}$

En esta ocasión se les niega la confección del estandarte y cualquier tipo de apoyo, así como el asesoramiento solicitado, alegando el gobernador no conocer los estatutos de esa sociedad ni sus "tendencias", y llegando a decir que "el proceder de otra manera sería una ligereza que un día podría comprometer el buen nombre del Ayuntamiento".

Tampoco les fue concedido el salón de la lonja en el Teatro Principal, para una función a beneficio de los damnificados por las inundaciones de Valencia, tal y como solicitaban. En otra ocasión,

58. La firman, entre un total de once, los socios Agustín Puigsech en primer lugar y, después, Tomás Ruiz, Florián Campos, Juan Piris, Tito Fages, Juan Francisco de Paula, José Pallaruelo, Mauricio Val, Andrés Sanz, Gil Lavorda y Manuel Martínez. (Archivo Municipal de Zaragoza, Gobernación, sección "General e indiferente", caja 143, expte. 200/1864).

59. Archivo Municipal de Zaragoza, misma caja y mismo expediente. 
para el concurso de canto y música instrumental, que se celebraría en Bayona el 28-29 de agosto de 1864 con motivo de la Exposición Franco-Española, el presidente francés de Bellas Artes solicita al alcalde de Zaragoza que le comunique las sociedades corales establecidas en esa ciudad que quieran formar parte en el concurso, invitándoles a que vayan a concurrir con las francesas (25 de abril); el 11 de mayo, el alcalde contesta:

Cúmpleme manifestar que aun cuando en esta ciudad existen profesores de una y otra clase [canto y música instrumental], muchos aficionados á la música, y dos capillas de canto é instrumental en ambas catedrales, no hay ninguna sociedad musical á la que pueda transmitirse su invitación, ni conozco tampoco en las poblaciones limítrofes sociedad alguna de esta índole. ${ }^{60}$

Por temores de naturaleza política por parte de las instituciones municipales -el gobernador y el alcalde recelaban de cualquier asociación de obreros y del tinte reivindicativo que una sociedad de este tipo pudiera tener-, La Coronilla no sólo no recibió nunca reconocimiento ni ayuda institucional alguna, sino que, finalmente, se acordó la orden para su disolución, que firmó el alcalde Pablo de Castro el 20 de diciembre de ese mismo año, argumentando que la sociedad había dejado de cumplir el reglamento y que no se había llevado a cabo el verdadero objeto "cual es la educación de las clases populares por medio del cultivo de las bellas artes". Aunque siguieron actuando sin ser sociedad, ésta resurgió un año después con otro nombre.

En otro orden de cosas, la década de 1860 resulta una fecha temprana en el contexto de las agrupaciones corales para el ámbito de provincias: sólo unas pocas ciudades vieron surgir sociedades corales $\mathrm{u}$ orfeones en estos primeros años ${ }^{61}$, entre las que estuvo Zaragoza. Tras los inicios vino una etapa de recesión para el orfeonismo con la Revolución de 1868 y la segunda guerra carlista, a la que siguió su recuperación y expansión en la década de 1880. Nuevamente en auge el movimiento orfeonista, Pedro Retana ${ }^{62}$ organizó y dirigió en sus comienzos (1886) el primer Orfeón Zaragozano ${ }^{63}$ como tal, dirigido después por Martín Mallén Olleta $^{64}$, y por José Espeita. A consecuencia del festival que los coros de Anselmo Clavé habían celebrado en la ciudad el 13 de mayo de ese mismo año (1886), se organizaron hasta tres orfeones más: el Orfeón Zaragoza (1894) que dirigió Martín Mallén Olleta, quien había cesado en su cargo de director del anterior Orfeón Zaragozano sucediendo a Pedro Reta-

60. Archivo Municipal de Zaragoza, Gobernación, General e indiferente, caja 143, expediente 427/1864. lla o Lugo.

61. En Valencia fue en 1862. En Madrid la primera sociedad coral se creó en 1863, y la misma fecha para Málaga, Sevi-

62. Pedro Retana: profesor de piano, de lengua francesa y compositor; memorable por sus trabajos en la organización de la primera Sociedad coral que tuvo Zaragoza (1886). Estudió composición y el género religioso con A. Lozano; compuso también para el género orfeónico. Vid.: -Antonio Ezquerro, ed.: Antonio Lozano: La Música..., op. cit., pp. [58] y 88.

63. Ibidem, pp.131[251], 145[265], 146[266]. La anterior sociedad coral La Coronilla respondía más al medio obrero y pequeña burguesía industrial propios del orfeonismo en sus comienzos, mientras que en esta época en los orfeones participan ya gentes de las clases acomodadas de la capital.

64. Martín Mallén Olleta: compositor, director y organista. Educado en Zaragoza, discípulo (y sobrino) de Domingo Olleta y del organista Francisco Anel en La Seo. Organista segundo de La Seo, y maestro de capilla de la catedral de Huesca. Su producción consta de obras en el género religioso, tres zarzuelas, obras sinfónicas, polonesas a gran orquesta, fantasías y cantatas. Director de orquesta, del Orfeón Zaragozano y del Orfeón Zaragoza. -Antonio Ezquerro: "Mallén Olleta, Martín”, en Diccionario de la Música..., op. cit., vol. 7, pp.74-75. 
na, para ocuparse del nuevo; el orfeón del Casino Artístico y Comercial, y el del Casino Republicano Federal, dirigidos por Enrique Bergua -alumno aventajado de la Escuela de Música en órgano y composición- y Blas Laborda -profesor de solfeo en la Escuela de Santa Cecilia-, respectivamente.

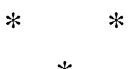

\section{La Escuela de Música de Zaragoza}

En el salón de actos de la Escuela de Música ofreció su primer concierto la Sociedad de Cuartetos de Zaragoza. La Escuela había sido creada el mismo año que la Sociedad-1890-, y estuvo ubicada en la Casa de la Infanta, calle de San Jorge, con subvenciones del Ayuntamiento y la Diputación de Zaragoza, siendo su director Ruperto Ruiz de Velasco, colaborador de El Correo Musical, y su vicedirector Antonio Lozano ${ }^{65}$, quien a la muerte de aquél se haría cargo de la dirección. Profesores honorarios eran Domingo Olleta, Valentín Faura, Francisco Anel, Ruperto Chapí, Tomás Bretón, Juan Goula y Justo Blasco.

Lozano nos cuenta que

se instaló la Escuela, y ha tenido sus locales siempre, en el piso principal de la histórica Casa llamada de la Infanta, hasta que el 10 de septiembre de este año [1895] los destruyó un horroroso incendio, que originó grandes perjuicios en mobiliario y documentación. Hoy se ha instalado en el magnífico principal de la Casa de los Sres. de Bobadilla. ${ }^{66}$

65. Antonio Lozano González (*Arenas de San Pedro -Ávila-, 1853; †Zaragoza, 1908): Maestro de capilla en Salamanca y, más tarde, en la capilla de El Pilar de Zaragoza. Compositor, musicógrafo y profesor de armonía y composición en esta Escuela de Música. Compuso música sacra, música de cámara, sinfónica y para orfeón. Con su Prontuario de Armonía obtuvo una medalla de oro en la Exposición Aragonesa de 1885 y la Internacional de Bolonia de 1890; también publicó un método completo de Teoría y práctica del Solfeo, que, junto con el anterior, se utilizaron hasta mediado el siglo XX. Entre sus obras de grandes proporciones sobresalen su Gran Salve solemne para dos coros y gran orquesta, y la Gran Misa a voces, coro y gran orquesta. Su obra La música popular, religiosa y dramática en Zaragoza desde el siglo XVI hasta nuestros días, prologada en su segunda edición por Felipe Pedrell, fue premiada con dos estatuas de metal plateado, con fanal sobre piedra de madera, símbolos de la música y poesía, en los Juegos Florales de Zaragoza en 1894 y en la Exposición Internacional de Bolonia de 1890, además de acordarse la recomendación de su impresión al Excmo. Ayuntamiento, por tratarse de "una monografía de inestimable valor para la historia del arte en Zaragoza [...] para encontrar en la mencionada memoria [Memoria histórico-crítica del desarrollo que en Zaragoza ha tenido el arte musical en sus tres géneros, popular, religioso y dramático, desde el siglo XVI en adelante], datos curiosísimos hasta hoy desconocidos por la generalidad de los aficionados, juicios críticos muy exactos de nuestros más ilustres músicos y maestros de Capilla de La Seo y de El Pilar, y muy buenas y valiosísimas referencias sobre los principios del género dramático, asombrando cómo han podido reunirse tal suma de datos y noticias en un plazo tan brevísimo", según consta en -Poesías y memorias premiadas en los Juegos Florales celebrados en Zaragoza, por primera vez el día 16 de octubre de 1894, bajo los auspicios del Excmo. Ayuntamiento. Zaragoza, Tip. de Julián Sanz, calle Alfonso I, n²0, 1895, pp.17-18. También realizó una intensa labor como polígrafo, impartiendo numerosas conferencias y escribiendo artículos literario-musicales en diversas revistas y periódicos. Fue maestro de Babil Belsué, Miguel Arnaudas, Pedro Retana, Francisco Agüeras, Ramón Borobia y Eduardo Viscasillas, entre otros grandes músicos zaragozanos. Vid.: -Antonio Ezquerro Esteban: "Lozano González, Antonio", en Diccionario de la música española..., op. cit., vol. 6, pp.1067-1070.

66. Vid. -Antonio Ezquerro, ed.: Antonio Lozano: La Música..., op. cit., pp. [47]-[51], 141. Se denominaba "principal" el piso bajo de una casa, símbolo de poder económico. Los diferentes domicilios que tuvo la Escuela, según datos recogidos de Antonio Lozano y José Blasco Ijazo, fueron: la Casa de la Infanta, en calle san Jorge (1890); el piso principal de la casa del marqués de 
Entre los profesores de aquella Escuela figuran Teodoro Ballo (de violín) ${ }^{67}$, director artístico de El Correo Musical hasta el $\mathrm{n}^{\circ} 16$ (1888), Faustino Bernareggi (secretario y profesor de piano y lenguas), Cosme Hernández (de piano), Elías Villarreal (de órgano y piano) ${ }^{68}$, Ruperto Ruiz de Velasco (de piano, canto y estética), Antonio Lozano (vicedirector y profesor de armonía y composición), Carmen Torres (de piano), Luis Calahorrano (de solfeo, profesor de viola en el Teatro Principal) y Santiago Carvajal (fagotista, pianista en la Sociedad de Cuartetos zaragozana y profesor de solfeo en la Escuela).

Gran parte de ellos provienen de las capillas eclesiásticas de la ciudad -son sus maestros de capilla u organistas titulares- o bien son discípulos, a su vez, de éstos; por un lado, las orquestas se nutrirán de los músicos que quedaron sin trabajo tras el Concordato y, por otro, la dedicación a la enseñanza -bien con apoyo de instituciones locales o privadas- será otra salida laboral. Si los recortes en las capillas eclesiásticas habían dañado la transmisión del oficio de músico, si las subvenciones para las bellas artes no llegaban a la música, y si se tiene en cuenta que el único centro estatal autorizado de enseñanza civil en España era el conservatorio madrileño fundado por la regente $\mathbf{M}^{\mathrm{a}}$ Cristina en 1830 -"Escuela Nacional de Música" en las fechas que nos ocupan-, podremos valorar, en este contexto, el gran acontecimiento que supuso la creación de esta Escuela de Música en Zaragoza, con no pocas materias a impartir, y que en 1933 devendría en el "Conservatorio Profesional de Música" al fusionarse con el "Conservatorio Aragonés de Música y Declamación”, creado en 1926; y no por evidente se puede obviar la anterior situación de las mujeres que quisieran acceder a la cultura musical en la ciudad, cuyo único recurso hasta entonces habían sido las clases de carácter privado. ${ }^{69}$

Bobadilla (Mauricio de Bobadilla y Escribá de Romaní) en la calle Espoz y Mina (1895-1906); a continuación estuvo en la casa del Marqués de Ayerbe, en la calle del Pilar; en 1908, el Gran Casino, en el edificio de la Exposición Hispano-Francesa, dio albergue a la Escuela; en 1911 estuvo en la calle Méndez Núñez, $\mathrm{n}^{\circ} 34$ y después en la calle Blancas, $\mathrm{n}^{\circ} 7$, dirección ésta última anterior a las que ha tenido ya en las últimas décadas. Vemos, pues, una vez más, el apoyo de la aristocracia a la cultura musical en aquellos años, al que acompañaba el crecimiento y desarrollo de las diferentes burguesías, emergentes, después de todo, de una influyente clase media.

67. Agradezco a Dña. $\mathbf{M}^{\mathrm{a}}$ Pilar Tardío Ballo, nieta de Teodoro Ballo, su amabilidad y gentileza al proporcionarme las dos fotografías que aparecen en las ilustraciones I y II.

68. Elías Villarreal (*iZaragoza?, 1843c.; †Zaragoza,1909): se educó como infante de El Pilar con los maestros Valentín Metón e Hilario Prádanos, y fue organista en la parroquia de San Pablo de Zaragoza. Su producción musical fue extensa. Profesor de órgano y piano en la Escuela de Música desde su fundación. Nombrado en 1892 académico de número en la de Bellas Artes de San Luis, de Zaragoza, fue premiado con una batuta por el Ayuntamiento de Zaragoza, junto con A. Lozano, E. Viscasillas y R. Ruiz de Velasco -valorada cada una en unos cinco duros, aunque siendo la de Viscasillas mejor que las del resto ( $i$ ?)-, también dirigió las orquestas de algunos teatros zaragozanos. Codirector de la colección Repertorio Sacro Musical, con A. Lozano, M. Arnaudas y R. Borobia, publicada en Zaragoza (1901-03). Formó parte en el tribunal de oposiciones, junto a Miguel Arnaudas y Alejo Cuartero, para cubrir la plaza de organista primero de El Pilar (1903), que ganó el discípulo de A. Lozano, Francisco Agüeras. De sus obras profanas sólo se conoce la mazurka Sol de oro, que regalaba El Correo Musical a sus suscriptores con el $n^{\circ} 7$, aunque Antonio Lozano habla de una extensa producción en este campo, además de sus composiciones sacras. Vid.: -Antonio Ezquerro, ed.: Antonio Lozano: La Música..., op. cit., pp.[25], [50], [90], 79. Cfr.: -Luis Antonio González Marín: "Villarreal, Elías Miguel", en Diccionario de la música..., op. cit., vol. 10, pp.940-941. -José Vicente González Valle, Luis Antonio González Marín y Antonio Ezquerro Esteban: "El compositor Juan Francisco Agüeras y González (*1876; †1936) y la música de su entorno", en Suessetania, Revista del Centro de Estudios de las Cinco Villas, n¹8 (1999), p.104.

69. Cuando sólo existía como único centro de educación musical estatal el Conservatorio de Madrid, Hilarión Eslava propuso un plan según el cual habría una escuela en cada ciudad donde hubiera catedral, dependiendo estas escuelas del Conservatorio Nacional, quien propondría su plan de estudios; en este plan adjudicaba 18 plazas, por lo menos, para alumnos. El dato significativo es el del reparto: doce varones y seis "hembras", en el que deja claro que era suficiente con la mitad de las plazas para las así denominadas (!). Véase Gaceta Musical de Madrid, órgano de la sociedad El Orfeo Español, 18 de febrero de 1855. 


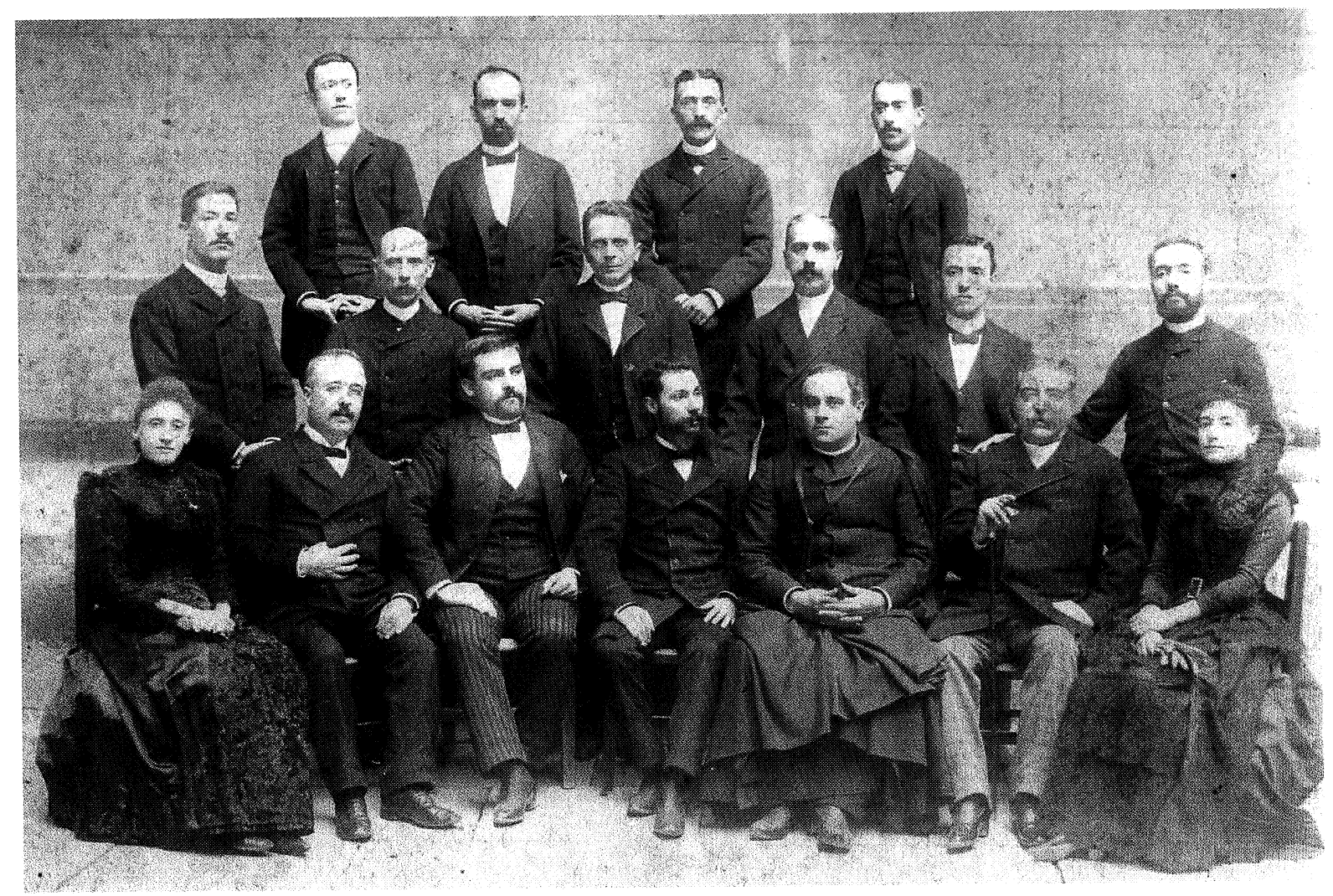

Ilustración I: Retrato de grupo de los profesores de la Escuela de Música de Zaragoza, al inicio de su creación (sentados, en el centro, Teodoro Ballo, Ruperto Ruiz de Velasco, y el sacerdote Antonio Lozano. De pie, extremo superior derecho, Luis Aula Guillén)

Ilustración II:

Retrato del joven Teodoro Ballo

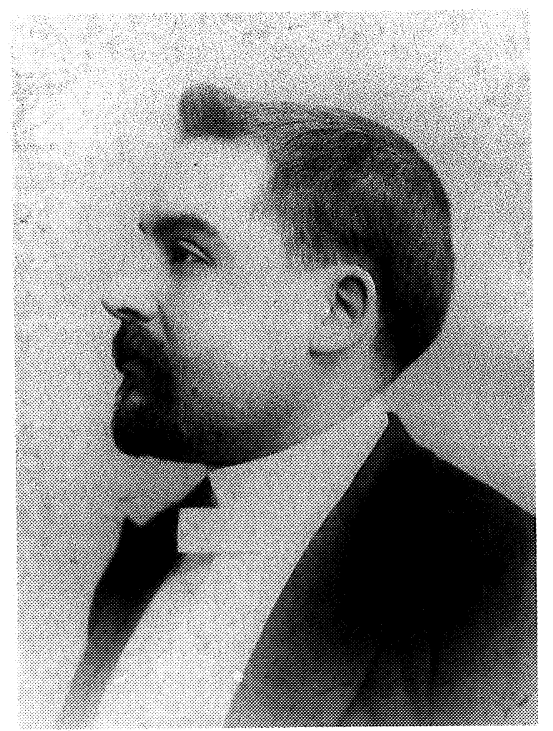


Otros centros en donde se podían recibir clases de música, según cuenta A. Lozano, eran la Escuela de Santa Cecilia, el Hospicio Provincial -dentro de la tradición de los "ospedali" italianos, donde se cuidaba especialmente la enseñanza de los instrumentos de cuerda-, cuyas clases de solfeo, piano, violín, violonchelo, contrabajo e instrumentos de banda costeaba para los asilados la Diputación desde principios de la década de 1890, o algunos colegios de segunda enseñanza para solfeo y piano y academias privadas.

Fue también la Regente quien autorizó, en el año 1887, a las Academias Provinciales de Bellas Artes para crear una sección de música donde se impartiría

enseñanza de piano y canto coral y si reúnen los elementos necesarios al efecto, clases de armonía, canto individuales, violín y demás instrumentos de cuerda que forman el cuarteto

según se recoge en un comunicado del Ministerio de Fomento al alcalde de Zaragoza, petición hecha a instancias de las academias de Bellas Artes de Oviedo, Sevilla y Valladolid, vistos los informes de la de San Fernando y del Colegio de Instrucción Pública zaragozano. ${ }^{70}$ De momento, la única enseñanza musical de subvención pública fue la que ofreció la citada Escuela a partir de 1890.

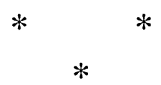

4. Música y sociedad en los teatros y cafés zaragozanos. Las temporadas de ópera y zarzuela.

Finalizo esta introducción con un recorrido por los varios locales con actuaciones musicales tales como los cafés La Iberia, Ambos Mundos (ver fig.1 y 3) ${ }^{71}$, café París ${ }^{72}$-situado en el patio del

70. Archivo Municipal de Zaragoza, Gobernación, secc. "Instrucción pública”, caja 1470, expte. 371/1887, arm. 66, legº 5.

71. Sobre los cafés zaragozanos en los primeros años del siglo XX, cfr.: -María Pilar Poblador Muga: "En los albores del siglo XX: la arquitectura modernista en Zaragoza y el ambiente de progreso y renovación que acompañó a la Exposición HispanoFrancesa de 1908", en La Modernidad y la Exposición Hispano-Francesa de Zaragoza en 1908. Zaragoza. Universidad de Zaragoza, 2004, pp.99-119. Este trabajo menciona, entre otros, los siguientes cafés de la ciudad en la época, muchos de ellos amenizados -junto a su actividad principal- con diversas actuaciones musicales: Café Oriental (situado en la Plaza de España, entonces llamada "de la Constitución", e inaugurado en 1900); el café Ambos Mundos, de dimensiones espectaculares (considerado entonces el más grande de Europa); el café Gambrinus (en la plaza de España); el Café Moderno ("también restaurante, en el que a menudo acudían músicos destacados, en la esquina de la calle de Alfonso I núm.1 con el Coso" - op. cit., p.101-), el Café de Levante; el Café de Europa (en la plaza de España, en los bajos del hotel más prestigioso de la época en la ciudad); el Café Suizo (en los bajos de la antigua sede del Banco Hispano Americano, junto a la Diputación Provincial); el Café de la Iberia ("que en verano utilizaba su terraza como Jardín de la Iberia con actuaciones musicales, siendo sustituido en 1910 por el modernista teatro Parisiana" también utilizado este último como variedades -op. cit., p.103-); el Café de Colón; el Universo; el Café de la Perla; el Café de Londres; el Peninsular; el Matossi; el Royalty (en la calle de los Mártires); el Café de París ("y sus conciertos, que amenizaban sus tertulias, estaba situado en los bajos del Palacio de Sástago, es decir, en el núm. 56 del Coso - op. cit., p.103-; luego reformado como modernista Nuevo Café de París entre 1909 y 1910); el café de las Cuatro Naciones (en el hotel de igual nombre, a mitad de la calle Don Jaime I); el café del teatro Circo (en la calle de San Miguel); el Café Cervantes (en la calle de San Pablo); el Café de España (en el núm. 11 de la calle de las Escuelas Pías, "en el que también se podían escuchar conciertos"-ibid.-), y ya en épocas algo posteriores, otros cafés, como el Salduba (en la Plaza de España), el Café Niké (en la calle Cinco de Marzo), o La Maravilla (en la plaza de España, esquina con el Paseo de la Independencia).

72. En el Café La Iberia dirigía los conciertos Florencio Lafita, en el Ambos Mundos dirigía José Ma Moneva, y en el París el violinista Teodoro Ballo. 
palacio de los Condes de Sástago-; o la importante y representativa actividad de los teatros, entre los que destacan, conviviendo en Zaragoza desde 1887, el Teatro Principal (ver Fig. 7) ${ }^{73}$, el Teatro Pignatelli, Teatro Goya ${ }^{74}$, en los que se representaban zarzuelas, operetas, fragmentos de ópera o adaptaciones, comedias diarias -todo ello precedido siempre, al estilo de la época, de la consabida

73. El origen del Teatro Principal, que se denominó así desde mediados del siglo XIX para distinguirlo de otros coliseos que empezaban a construirse en la ciudad, se remonta a la inauguración, en 1799, de la Casa de Farsas, construida en un solar del Coso (ubicación actual del teatro) donde habían estado los graneros del municipio. Si vamos más atrás en el tiempo hay que citar la Casa de Comedias del Hospital de Nuestra Señora de Gracia, que se incendió trágicamente en 1778, y más atrás, todavía, llegamos a las primeras casas de comedias que se pusieron en funcionamiento en el último tercio del siglo XVI, entre las que hubo una (1584-1599) de propiedad municipal en el Coso, ubicado en el mismo solar que ocupa actualmente el Teatro. Era, a finales del siglo XIX, uno de los más prestigiosos entre los españoles. Los espectáculos principales en esta época fueron el teatro, la zarzuela y la ópera. El Teatro resistió la competencia de los que se habían abierto por entonces en Zaragoza, como el Pignatelli, Goya, Novedades o Circo, a pesar de todos los cambios y reformas que sufrió en los últimos veinte años del siglo: entre ellos figura la instalación de agua corriente en 1860 o la de luz eléctrica el 8 de octubre de 1894 -como referencia, valga la fecha de julio de 1888 , en que se comenzaron los trabajos para el alumbrado eléctrico en el Teatro Real de Madrid-, acontecimiento que vio el estreno de la ópera La Gioconda, de Amilcare Ponchielli; las actuales estatuas alegóricas se colocaron en el pórtico en 1848, y el telón de boca conservado es el de Marcelino Unceta. Mientras se proyectaba una posible instalación eléctrica, la documentación referente a este Teatro Principal evoca un coliseo iluminado con gas hulla (entre otros sitios en el foso, salones de espectáculo, antepalcos o atrio), luces de aceite (encendidas obligatoriamente para la empresa durante las representaciones) y bujías esteáricas (de glicerina y un ácido usado en la fabricación de velas) para los camerinos (Archivo Municipal de Zaragoza, Gobernación, sección "Propios y recursos", exp. 418/1885-86, caja 1493). Sobre los espectadores, A. Martínez Herranz dice: "Gracias a una lista de abonados, la de la temporada de 1890-1891, sabemos qué tipo de público frecuentaba por entonces el coliseo municipal [...], políticos locales y Gobernador Civil [...], personalidades insignes de la cultura local [...], burgueses y comerciantes de cierta entidad [...], artistas de prestigio [...] y entidades representativas de la vida ciudadana, entre las que se contaban el Diario Mercantil ["periódico independiente, de noticias y anuncios", 1889-1899], El Diario de Zaragoza [perteneciente, a finales de siglo, al político conservador Tomás Castellano y Villarroya], La Derecha [1881- 1901, diario republicano de mayor continuidad en Aragón durante la Restauración] o La Alianza Aragonesa [1882, diario liberal vespertino], que estaban abonados a varios palcos". -Amparo Martínez Herranz: El Teatro Principal. Zaragoza, Ayuntamiento, Servicio de cultura, 1999, pp.13, 33, 45 y 47. Sobre prensa, véase: -Eloy Fernández Clemente y Carlos Forcadell: Historia de la prensa aragonesa. Zaragoza, Guara, 1975, pp.71, 95, 96. Vid., también, sobre el viejo Teatro Principal: -Roger Alier: "El incendio del Teatro de Zaragoza en 1778", en Anuario Musical, 51 (1996), pp. 157-164. Por otra parte, J. Blasco Ijazo escribió una larga lista, en uno de sus reportajes, de las óperas e innumerables zarzuelas, operetas, dramas y comedias que se representaron en el Teatro Principal, además de una detallada historia del coliseo y las reformas anteriormente señaladas. Vid.: -José Blasco Ijazo: Zaragoza y sus locales de espectáculos..., op. cit., pp.5-9.

74. Dice Amparo Martínez que se le llamó, también, El Prado aragonés, y Blasco Ijazo lo sitúa "en lo que fue Prado Aragonés, levantado sobre un terreno de huerta". Con un aforo de 1972 localidades, de ellas 380 sin visual, a finales de siglo, pasó a tener 1592 en el año 1951. Se inauguró como El Prado Aragonés en octubre de 1880, y como Teatro Goya en 1882, cuya función inaugural consistió en dos piezas líricas, La gallina ciega (M. R. Carrión / M. Fernández Caballero) y Casado y soltero (L. de Olona / J. Gaztambide), a cargo de la Compañía de Zarzuela Cómica que encabezaba, como maestro director, R. Ruiz de Velasco. Se instaló luz eléctrica en el otoño de 1885, mucho antes que en el Teatro Principal y tres años antes que en el Real de Madrid (!). Ubicado en la calle San Miguel, $n^{\circ} 8$, fue, primeramente, un salón de baile, para convertirse después, tras las reformas, en teatro, donde se representaron zarzuelas desde muy pronto. En él se utilizó por vez primera en Zaragoza la fórmula del teatro por horas -introducida por el entonces empresario Enrique Zopetti-, sistema que obligó a la empresa a reforzar la coordinación de entradas y salidas combinando dos puertas, la de la calle San Miguel y la trasera del teatro. Para el estreno de la zarzuela Luces y sombras, el 26 de mayo de 1883, que dirigieron sus autores, Salvador Lastra (libretista, actor y empresario, †Madrid, 1889) y Federico Chueca, se trajeron de Madrid todos los decorados y el atrezzo. El tenor Gayarre interpretó obras de Bellini y Donizetti -I Puritani, y La Favorita y Lucia de Lamermoor, respectivamente- en la temporada de ópera del mismo año, suponiendo un acontecimiento de gran éxito, tanto como para eclipsar al Teatro Principal. En noviembre de 1889 se contrató a la Orquesta de señoras húngaras, que tocaron los días 21 y 22, dirigidas por el maestro Pappsdorf -según la "Crónica del día" del Diario de Zaragoza, "el público aplaudió el mérito de las concertistas haciendo repetir muchos números de su ameno programa", del que no dice el cronista en qué consistió-. Ocuparon un lugar importante variedades, títeres, compañías "de Fantoches", temporadas ecuestres y de zarzuela -se estrenaron varias de género chico: La isla de San Balandrán (J. Picón / C. Oudrid), El club de los feos (M. Fernández Caballero), Caramelo (F. Chueca y J. Valverde), o A ti suspiramos (R. M. Liern y S. M. Granés / C. Mangiagalli y F. Caballero)- a precios muy módicos; aquí debutó la cantante Loreto Prado. Siguió siendo el centro de baile más reputado, junto al Principal, hasta que se abrió en 1887 el Teatro Circo, que junto con el Pignatelli provocaron que fuera a menos el Goya. También le restaron interés los conciertos de los cafés Ambos Mundos, París, Iberia o Matossi, este último ya en la década de 1890. El teatro Goya se clausuró en el verano de 1893. -J. Blasco Ijazo: Zaragoza y sus locales de espectáculos..., op. cit., pp.14-15 y vid. también, -Amparo Martínez Herranz: La arquitectura teatral..., op. cit., pp. 673-679; -Luis Iglesias de Souza: "Lastra, Salvador" en Diccionario de la música..., op. cit., vol.6, p.781; y -La Derecha, 5 de octubre de 1882, p.3. 
"sinfonía" u obertura-, y el Teatro Circo $^{75}$, más conocido al principio por su dedicación al baile y otro tipo de actuaciones. ${ }^{76}$

No hay que olvidar la presencia en aquellas fechas de la música militar, representada por los integrantes de las bandas de la guarnición, en locales públicos como los cafés, lo cual creaba competencia a los músicos que trataban de salir adelante como profesionales. Al respecto, podemos leer las quejas de "Morales" -Valentín Marqueta- en un artículo, el primero de tres, que se publica en la sección que titula "Protección al artista" de El Correo Musical":

Cuando vemos los conciertos que á diario, ó poco menos, se celebran en nuestros principales cafés, por las bandas militares y recordamos el inmenso número de padres de familia, cuyo medio de vivir es la música, no podemos menos que exclamar: ipobres artistas!

Y más adelante, dice:

Medios sobran en Zaragoza con los teatros, las fiestas religiosas y los conciertos de los centros de recreo para que puedan vivir estos infelices, muchos de ellos cargados de familia, y no obstante, si no fuera por las lecciones que Dios y su buena fortuna les depara, algunos perecerían de hambre. ${ }^{78}$

75. En la calle de San Miguel, $\mathrm{n}^{\circ} 10$ (hoy $\mathrm{n}^{\circ} 12$ ), proyecto del arquitecto Ricardo Magdalena, se inauguró este teatro el 1 de octubre de 1887, con un aforo de 1.972 localidades a finales de siglo: el debut lo hizo la Compañía ecuestre, gimnástica, acrobática y cómica del Circo Barcelonés. Como no era rentable ofrecer siempre el mismo tipo de espectáculo, se construyó un escenario para representaciones dramáticas y líricas y se inauguró la remodelación en mayo de 1888, con la compañía en la que figuraba el actor, cantante, libretista, director de escena y compositor zaragozano Julián Romea Parra -sobrino del actor y cantante Julián Romea Yanguas, escritor de poemas y autor del Manual de declamación e idea general sobre el arte del teatro-. Se representaron óperas, operetas, revistas, variedades y se celebraron conciertos de música culta, pero lo que más éxito tuvo fue la zarzuela, por lo que rivalizó con el Teatro Principal. Cabe destacar la primera actuación en Zaragoza del tenor Miguel Fleta o el estreno de La verbena de la palo$m a$, con la presencia de Tomás Bretón y Ricardo de la Vega, el 30 de abril de 1894, a dos pesetas el precio de la butaca y 0'50 el "paraíso". Ibídem., pp.17-19 e ibid., pp.691-699. En la prensa diaria que reseñaba las funciones de los teatros se le menciona, tras la remodelación, "reinaugurado como Jardín de Goya", y en la sección "Buzón" de El Correo Musical se lee "punto de cita de nuestras clases pudientes" (n`5, 20 de mayo de 1888, p.40). [No confundir con el Teatro Lope de Vega, también denominado Circo del Caballo Blanco, Circo de la Zarzuela, o Teatro del Circo, y que, habiéndose inugurado en 1869, se clausuró a finales de 1886].

76. Un breve resumen de las actuaciones en estos teatros durante el año 1888, como muestra en un espacio de tiempo coincidente con la publicación de El Correo Musical, es el que sigue: en el Teatro Principal: El sombrero de copa, del escritor Vital Aza, comedia y sainete Los tocayos, comedia de Manuel Tamayo Huyendo del perejil, un juguete cómico-lírico y una comedia en tres actos, zarzuela en tres actos La tempestad, Lobos marinos, Un tesoro escondido, "pasillo" cómico en un acto Coro de señoras (todo en el mes de enero), más una zarzuela diaria, a veces dos; ópera en cuatro actos de Donizetti La favorita (febrero), Il Trovatore de Verdi (marzo), La bruja de Chapí (abril), Roberto el diablo de Meyerbeer (octubre); en el Teatro Circo: actuaciones del clown Pichel, grandes bailes públicos de tarde y noche, repertorio de Cádiz y La Gran Vía -la entrada general de tarde costaba 2 reales, y la de noche de caballero una peseta, la misma de señora 0'10 céntimos-; compañía cómico-lírica bajo la dirección de los actores Vallés y Romea: comedia en dos actos Perecito, zarzuela en un acto Bola 30, de Manuel Nieto (abril); Novillos en Polvoranca, de Ricardo de la Vega y Barbieri (junio), reinaugurado como Jardín Goya se celebra en él la función de "fantoches" de Thomas Holden, I comici tronati (L. Palomino de Guzmán y J. de la Cuesta / C. Mangiagalli), La soirée de Capuchini [sic.] (agosto), compañía ecuestre, gimnástica y acrobática con precios de 10 pesetas para palcos y 2 para silla (septiembre), la zarzuela El milagro de la virgen (Chapí) en noviembre, y, en diciembre, La Bruja, con gran éxito; en el Teatro de Goya: comedia en tres actos Sullivan, y Las mujeres que matan (abril), inauguración de temporada con La gallina ciega (M. R. Carrión / F. Caballero) y El lucero del alba, con libreto de Pina Domínguez y música de F. Caballero, también (junio), piezas cómicas y prestidigitadores (octubre); en el Teatro Pignatelli: compañía italiana de opereta cómica de Rafaele Tomba, zarzuela Doña Juanita de Guillermo Cereceda (mayo); en el Café París: concierto todas las noches, de ocho y media a once. (Diario de Zaragoza, secciones "Espectáculos" y "Crónica del día", 1888, varios ejemplares). Veremos algunas crónicas de éstas y otras funciones comentadas en la continuación del presente artículo, procedentes de la sección Buzón, con la que cierra cada número El Correo Musical.

77. El Correo Musical, 30 de abril de $1888, \mathrm{n}^{\circ} 3, \mathrm{p} .17$

78. El subrayado es mío. 
La demanda afectaba a los artistas, ya que el soldado tenía al Estado que cuidaba de su manutención, y aquéllos -en palabras de Morales- "no tienen otro medio para comer que su trabajo y éste se le regatea". Tras estas palabras subyace una conciencia de clase artístico-musical y un cierto sentimiento de injusticia social para con ella.

No es difícil advertir cómo detrás de los deseos de protección que Valentín Marqueta -a quien conoceremos en la segunda parte de este artículo- refleja en sus escritos, se esconde un talante fuertemente discriminador, del que se infiere, junto con otros hechos y dichos, la intención de difundir a través de este tipo de publicaciones periódicas un ideal de clase -burguesa-y de regularizar lo socialmente correcto, digno o adecuado -por supuesto, para sí mismos-. Veremos también en la segunda parte de este estudio que algunos colaboradores de la revista no son del mismo signo.

Como se ha puesto de manifiesto anteriormente, las ocasiones para dar salida al trabajo profesional no eran pocas, pero parece ser que insuficientes si tenemos en cuenta las retribuciones.

Un ejemplo de programación cotidiana es la del día 11 de ese mismo mes de abril, en que el Diario de Avisos informa del concierto en el Café Ambos Mundos por la Banda del Regimiento de Infantería de Gerona, en el mismo café un concierto de Ballo, Anadón y Laclaustra a las 8'30 de la tarde y, en el Teatro Principal, "zarzuela por dos reales a las 8 de la tarde". ${ }^{79}$

Por el autor del artículo sabemos que los profesores directores de las bandas cobraban apenas 12 ó 14 reales por actuación a cambio de "ímprobo trabajo y muchas horas de academia, además de las reglamentarias del concierto", y los subordinados 15 céntimos de peseta. Sirvan para apreciar la consideración social y poder económico de los músicos de orquesta en esos años las referencias siguientes: los músicos de la orquesta que dirigió Viscasillas en la función regia que se dio en honor de la regente $\mathrm{M}^{\mathrm{a}}$ Cristina de Habsburgo en el Teatro Principal (1888), cobraron "50 reales las primeras partes, 40 las segundas y 60 los concertinos"; esto en una función en la que se había respetado el abono pero se aumentó el precio de las localidades: el espectador pagó 7 pesetas en butaca y 6 reales de vellón en el paraíso ${ }^{80}$-en esta ocasión, los sueldos y los precios fueron impuestos por el ayuntamiento-. Para el mismo acontecimiento, el consistorio pidió una rondalla de músicos cantores y bailadores exclusivamente para tocar, cantar y bailar la jota aragonesa "clásica del país", que debían actuar durante dos días en el hipódromo, y a los cuales se les pagó seis duros a cada uno, viajes incluidos -procedían de Tauste (Cinco Villas, Zaragoza)- ${ }^{81}$

La gran afición de los aragoneses a las funciones teatrales, a diferencia, tal vez, de otras zonas del país, queda plasmada en varios hechos: el fervor y entusiasmo que puso el Ayuntamiento zarago-

79. El otro coliseo que estaba funcionando en esos momentos en la ciudad era el Teatro Goya.

80. El paraíso era la zona donde estaban juntos hombres y mujeres, siendo la cazuela la destinada únicamente a mujeres, y que se llamó, también, gallinero -por las algarabías que, en principio, éstas formaban-, término que se utilizó más tarde, por extensión, para designar a toda la planta alta de los teatros.

81. Eusebio Castelló era el jefe de la rondalla, contratada para cuatro días ("uno de ida y otro de vuelta") con bailadores que tenían entre 29 y 40 años: se había pedido "que sean de 25 á 40 años y de buena presencia. Si en vez de 30 quieren venir 40 y en vez de dos parejas tres ó cuatro, se aceptan. Que vistan el traje del país. Como base la orquesta que vino al Pilar, pero aumentada hasta el número de treinta ó cuarenta"; se consiguió reunir a veinticinco personas en total, entre ellas cuatro parejas de baile. Vemos, pues, que Tauste tenía su propia orquesta de músicos por entonces y, en otro orden de cosas, los datos nos recuerdan la manera de viajar hace 120 años: la Subcomisión de Funciones y Festejos acuerda incluir dos días de viaje en el pago a la rondalla, que vendría desde una población -la más cercana de las Cinco Villas- que apenas dista 45 kilómetros de Zaragoza. (Archivo Municipal de Zaragoza, Gobernación, sección "Funciones Públicas", caja 1478, exp. 623/1888). 
zano en el fomento de este tipo de producciones desde sus principios (sus reiteradas ayudas al Hospital de Nuestra Señora de Gracia desde finales del siglo XV, para recoger ingresos de las farsas y comedias cediendo los derechos de parte de los impuestos; ayudas para construir un coliseo-Casa de Comedias en 1589, levantada por el Santo Hospital General, Nuevo teatro de la Real Sitiada en $1769^{82}$, Teatro de Comedias del Hospital en 1773, Teatro de Comedias del Ayuntamiento en 1799 tras el incendio de 1778, hoy Teatro Principal); o los esfuerzos del mismo Ayuntamiento por sacar adelante el coliseo, sin exención de impuestos, una vez concedida la cesión real, ni otras ventajas de las que disfrutó, por ejemplo, el Teatro Español del Ayuntamiento madrileño; y, por otro lado, la cantidad de domicilios que fueron punto de encuentro para representaciones teatrales, hecho que produjo una importante eclosión de teatros ${ }^{83}$ en las décadas de 1870 y 1880, dan muestras de ello. Algunos de estos locales, domicilios y asociaciones en estos años fueron: La Albarda en la calle Pabostría, La Violeta en Plaza Salamero, La Magnolia en Plaza de Boggiero; Pedro Aznar en la calle Palomar, Larripa -apellido del dueño de la casa- en Avda. de Madrid, otros de aficionados en la calle de las Armas; el Círculo Tradicionalista, con domicilio social en la calle D. Jaime I (vulgo "San Gil"), el Casino Artístico en la calle Torre Nueva y el Orfeón Zaragozano en el Teatro de la Exposición Aragonesa ${ }^{84}$ (ver Fig. 9c).

Tratamiento aparte requieren las programaciones de ópera y zarzuela en los teatros de Zaragoza -especialmente el Principal ${ }^{85}$ - en estas fechas, a través de las cuales, las conclusiones extraídas partiendo de los datos obtenidos reflejan aspectos de cierta relevancia para la vida cultural y musical zaragozana, y tal vez contribuyan, en su momento, a un más amplio conocimiento de ella. ${ }^{86}$ Aquí

82. Desde 1750, los asilados en ese hospital eran enfermos, dementes, presos, militares, distinguidos, parturientas y niños. R. Alier afirma que, ya en la Casa de las Comedias, a mediados del siglo XVIII la ópera italiana -todavía tardo-barroca- fue un género muy apreciado por el público zaragozano, y en la década de 1760 fue muy bien recibida la ópera bufa procedente de las escuelas napolitana y veneciana. Vid. -Roger Alier: "El incendio del Teatro de Zaragoza en 1778", en Anuario..., cit,, pp. 157-158.

83. De los construidos en la veintena que va desde 1870 a 1890, entre el Teatro Principal y el Pignatelli, además del Variedades (construido en el solar donde estuvo el Colegio de las Vírgenes, ejemplo de desamortización, situado en la calle de las Botigas Hondas, esquina con la calle de las Vírgenes, hoy Espoz y Mina, $\mathrm{n}^{\circ} 7$, desde 1853 y durante 20 años), el Novedades (Independencia -esquina con Casa Jiménez-, hoy n⿳2 28, de 1864 a 1892), y La Infantil (también Café de España y La Maravilla, en la calle Cinco de Marzo, 1873 a 1879), destacan por su actividad artístico-musical los siguientes: Lope de Vega, situado en la calle de los Sitios, $\mathrm{n}^{\circ} 8$ (hoy Amar y Borbón), inaugurado el 2 de octubre de 1870 y clausurado en 1886, en el que se cultivaron todos los géneros, ecuestre, ópera -La Favorita y Poliutto (Donizetti), Los mártires del cristianismo-, zarzuela y abundante comedia; aquí se escuchó por vez primera en Zaragoza al guitarrista Francisco Tárrega, en un concierto patrocinado por su amigo el impresor Calixto Ariño; el Goya, Circo y otro Variedades, éste en el Paseo de la Independencia, n ${ }^{\circ} 24$, inaugurado en octubre de 1899 y construido sobre el terreno donde estuvo la litografía de Portabella, con el escenario a espaldas de la calle de Cádiz: después de proyectar películas mudas durante bastante tiempo, se representaron zarzuelas del género chico, comedia, varietés y festivales de jota y, por último el Teatro de los Campos Elíseos, situado al principio del camino de Torrero (hoy paseo de Sagasta), en el lado derecho desde Independencia, que estuvo activo desde 1875 hasta, aproximadamente, 1880. Vid. -J. Blasco Ijazo: Zaragoza y sus locales de espectáculos..., op. cit., pp.10, 11, 20; -Amparo Martínez Herranz, op. cit., vol.2, pp.593, 601, 613, 625, 629, 635, 673, 691$693,733$.

84. Vid. -J. Blasco Ijazo: Zaragoza y sus locales de espectáculos..., op. cit., pp.78-79.

85. Otro teatro, el Pignatelli, tuvo temporada de zarzuela con la compañía dirigida por el Sr. Palau, que, supuestamente, representó Blanca de Saldaña (R. Ramírez / A. Brull), estrenada el año anterior, y La campana milagrosa (M. Zapata / P. M. Marqués y G. Catalá), estrenada el 3 de marzo de ese mismo año de 1888 por la misma compañía en el Teatro Price de Madrid. A propósito del compositor, Apolinar Brull, se dice en un suelto del Buzón: "el maestro Brull, autor de la música de El alcalde interino, acaba de obtener un triunfo ruidoso en La cruz blanca, que al decir de la prensa de Madrid le coloca á la altura de Arrieta, Caballero, Chapí y tantos otros. En nuestro humilde concepto, el que supo componer música como la de Blanca de Saldaña vale más que muchos que han logrado el epíteto de maestros. Reciba nuestra cordial enhorabuena" (El Correo Musical, 10 de agosto de 1888, $\left.\mathrm{n}^{\circ} 13, \mathrm{p} .104\right)$. En ese momento estaban en pleno funcionamiento, además de los nombrados, los teatros Goya y Circo.

86. Es mi intención presentar, próximamente, un estudio más completo sobre actuaciones de estos dos géneros en Zaragoza y su repercusión, abarcando un período más amplio del siglo XIX. 


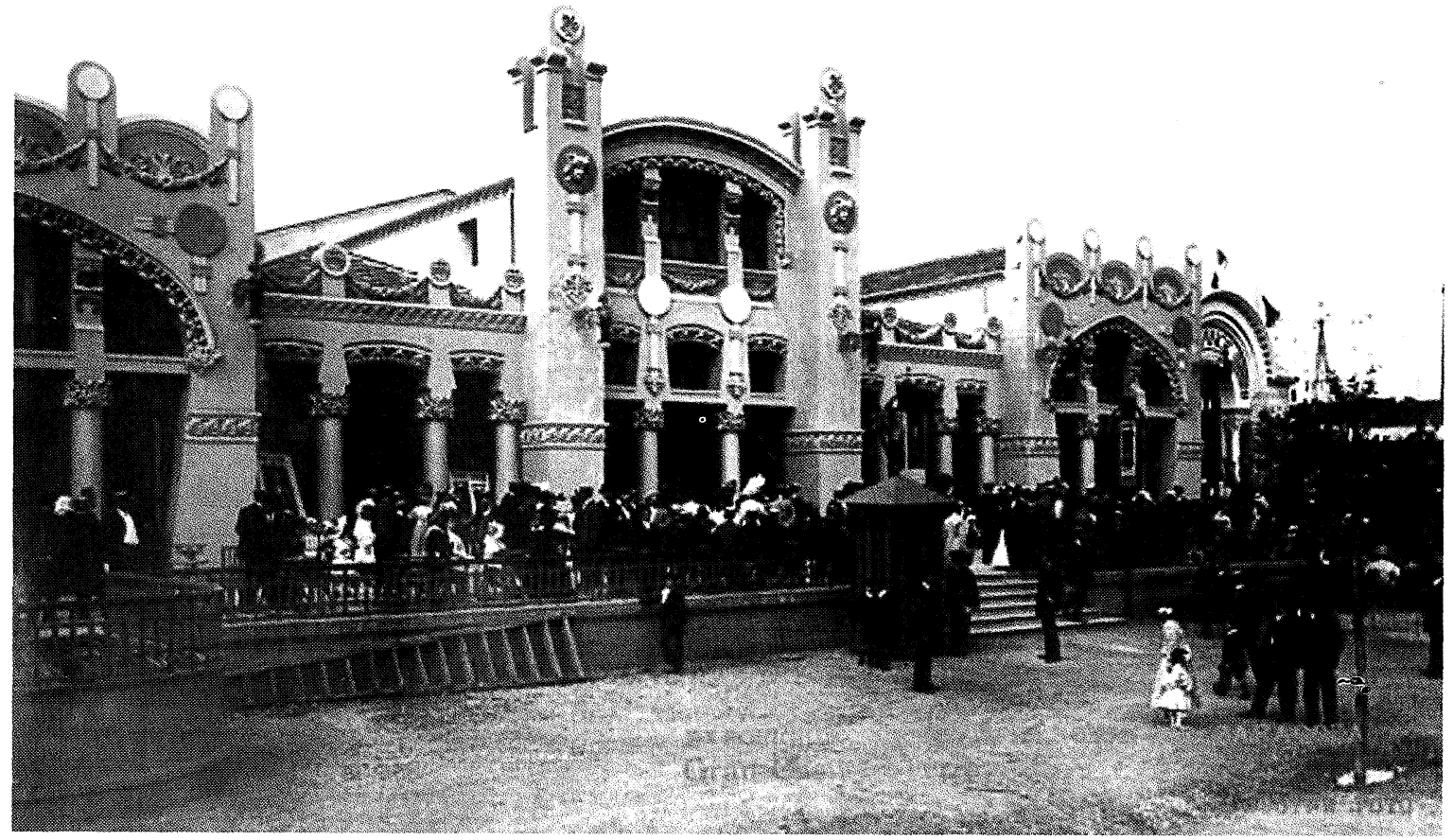

Fig. 9 a. El Gran Casino de la Exposición Hispano-Francesa ocupaba 2.500 metros cuadrados, con un vestíbulo (Fig. 9b) elegante y espacioso. Enfrente del pabellón, una orquesta tocaba a diario en la gran terraza; el edificio albergaba un teatro de dos pisos (Fig. 9c) que, coincidiendo con la Exposición, se mantuvo desde el 1 de mayo de 1908 hasta el 5 de diciembre del mismo año. Allí actuaron orquestas y orfeones, se celebraron festivales de Jota, funciones de variedades, etc.

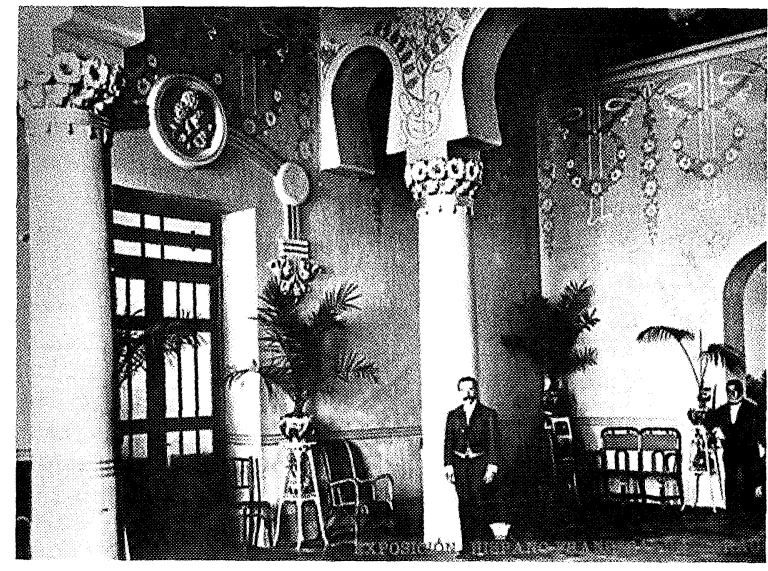

Fig. 9 b.

Vestíbulo del Gran Casino

de la Exposición Hispano-Francesa (1908)

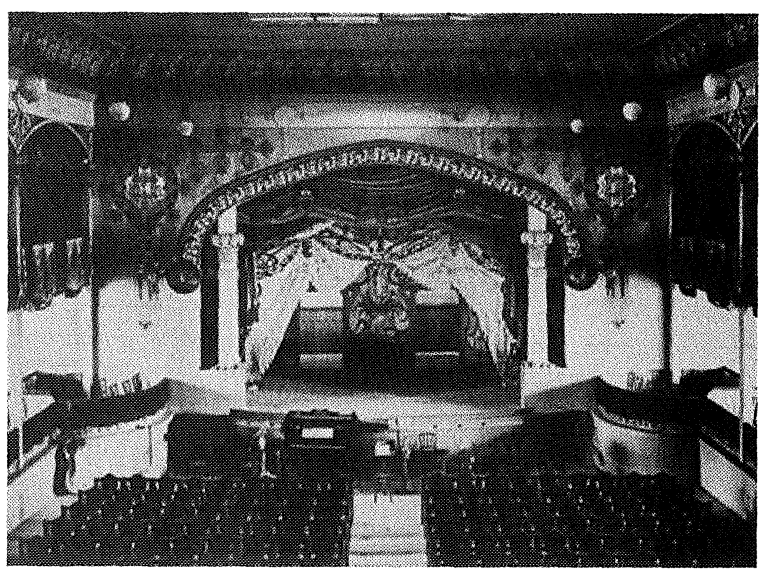

Fig. 9 c. Teatro del Gran Casino de la Exposición Hispano-Francesa (1908). [Repárese en los instrumentos bajo la escena] 
Figs. 10a, b y c.

Tres de los Pabellones instalados en el recinto de la Exposición, emplazado en la antigua Huerta de Santa Engracia, actual plaza de Los Sitios

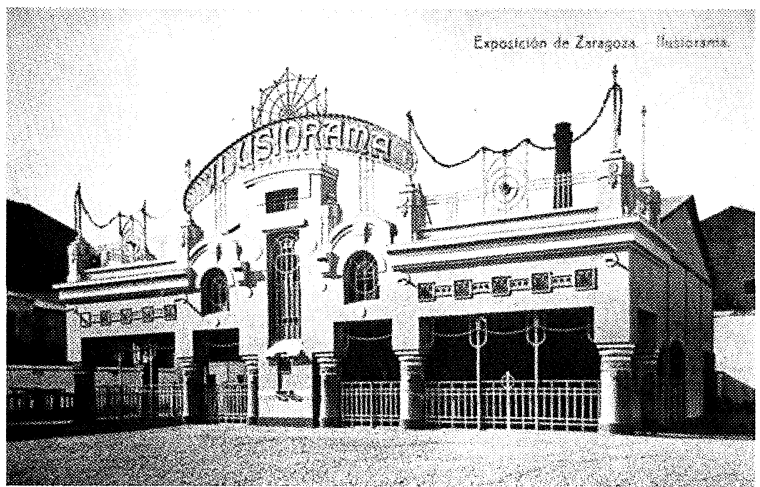

Fig. 10 a

Ilusiorama

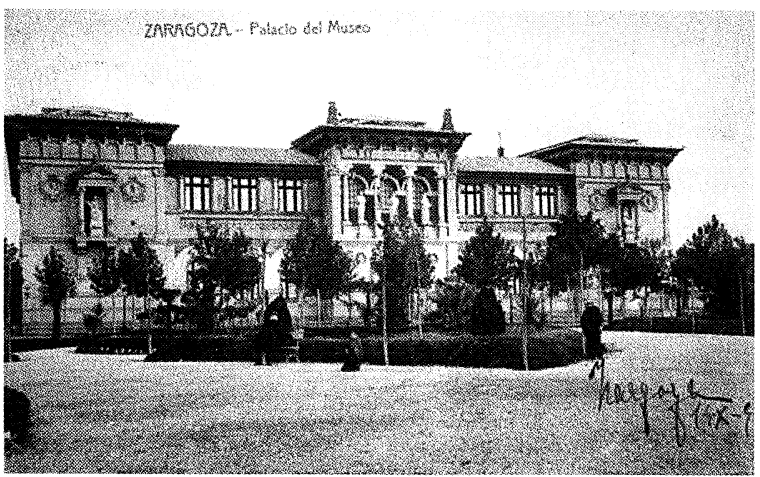

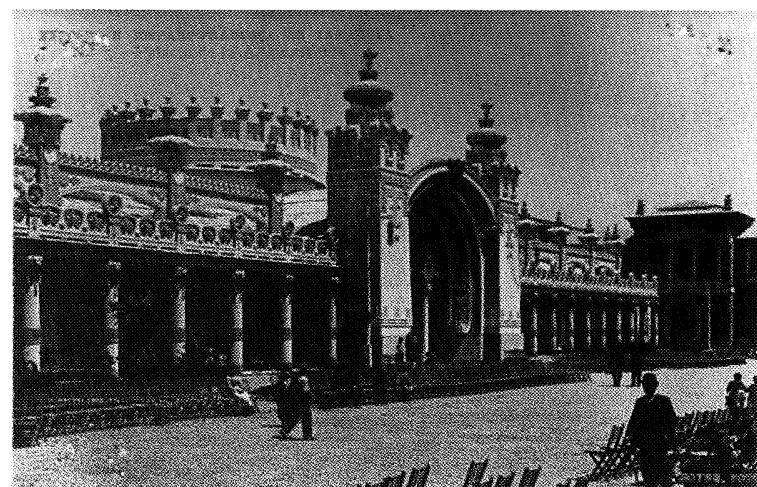

Fig. 10 b

Pabellón de Alimentación
Fig. 10 c

Museo de la Exposición

(hoy Museo Provincial de Zaragoza,

también sede social de la Real Academia de Nobles

y Bellas Artes de San Luis). El año 1908

se conmemoraba el centenario de la independencia, tras los asedios por parte de las tropas francesas en 1808 y 1809.

vemos, por ejemplo, la incidencia de obras y autores, dentro de cada uno de los dos géneros, en lo que venían siendo temporadas más estables y prolongadas que las que pudo haber a mediados de siglo, y en la primera mitad, en esta capital de provincias (sobre programación de ópera, ver Anexo $1{ }^{87}$. Ser-

87. A partir de los datos obtenidos según los listados de las relaciones de obras representadas en el Teatro Principal por compañías de ópera italianas en la década de 1880 (diciembre de 1882, enero, febrero, octubre y noviembre de 1883 , marzo y mayo de 1884 , abril, mayo y junio de 1886, y febrero, marzo, septiembre y octubre de 1888 ya que de 1887,1889 y 1900 figuran compañías lírico-dramáticas para zarzuela, no para ópera), se contabilizan ocho compositores diferentes: Verdi, que se representó 37 veces (con un total de 6 óperas diferentes), Donizetti 22 (con 4), Meyerbeer 13 (con tres), Gounod 12 (sólo Fausto), Bellini 6 (con 3 diferentes), Halévy 3 (La hebrea) y Pacini en una sola ocasión, con Saffo; la música de Wagner aún no había arraigado. Anteriores a esta década, de mediados de siglo, son las arias y dúos sueltos siguientes, interpretados en los intermedios o al final de las funciones: el aria de bajo de El Pirata (Bellini), aria bufa de La Cenicienta (Rossini), aria de bajo de Beatrice di Tenda (Bellini), la cavatina de Ernani (Verdi), el aria coreada de Attila (Verdi), aria coreada de Saffo (Pacini), aria de Sancia di Castiglia (Donizetti), cavatina de I lombardi [alla Prima Crociata] (Verdi); o los dúos de bajos de Clara de Rosenberg (G. A. Bécquer y R. Rodríguez Correa / F. Ricci) o de soprano y bajo en La vuelta de Columela (?), de L'elisir d'amore (Donizetti), dúo de bajos en Elisa y Claudio (Mercadante), dúo de Nabucco (Verdi), todo ello en una época en la que coexistían el auge de la ópera italiana y el progreso de la zarzuela; entre los cantantes españoles figuran los "Sres. Aznar, Sanz, la Srta. Soler" -aficionada-, los "Sres. Sáez, Segarra, Pozo, Sra. [Josefa] Chimeno", o el tenor Juan Giménez. O bien se interpretaban en estos intermedios piezas de canción española (La buño- 
virá saber, al respecto, que, en estos años, el empresario del Teatro Principal, Miguel Sisamón y Ostáriz - de cuarenta y cinco años de edad-, debía formar cada temporada cómica "dos compañías por lo menos, una de declamación nacional y otra de canto, entendiéndose por compañía de canto la ópera italiana o zarzuela española"88. Y en los años primero y tercero -es decir, temporadas de 1885/86 y 1887/88-, tenía obligación de traer compañía de ópera italiana ${ }^{89}$. También sabemos que, para garantizar la calidad o prestigio de compañías y cantantes que proporcionara el empresario, según este mismo contrato, el arrendatario -ayuntamiento- obligaba a aquél a cumplir lo siguiente:

lería, La esmeralda). Zarzuelas como El sacristán de San Lorenzo (zarzuela-parodia en tres actos de Agustín Azcona, inventor del género; ésta parodiaba y llevaba la música de Lucia di Lammermoor, "con los mejores trozos de Donizetti", según Cotarelo y Mori), Jeroma la castañera (M. Fernández / M. Soriano Fuertes) o Misterios de bastidores (Montemar / C. Oudrid), y bailes como El vals de la Rosita, Los valses de la locura o El zapateado son ejemplos que forman parte de las programaciones del Teatro Principal de Zaragoza en los últimos años de la década de 1850. De la misma manera que era frecuente y habitual por entonces (no así más tarde), que algún cantante local aficionado actuase con la compañía en cuestión, como apoyo o refuerzo, dado que podía ofrecer calidad de ejecución, con frecuencia, también, transitaban compañías mediocres algunas de las veces. Por otro lado, la del empresario José Valero -director de El Liceo de Valencia, actor y compositor que repitió varias veces en Zaragoza en la década de 1850-, como ejemplo de compañías que marchaban seguidamente a Barcelona o que venían de Madrid o de Valencia; o bien, representaciones como la de El duende (L. Olona / R. Hernando, en dos actos) tan sólo unos meses después de su estreno en Madrid -junio de 1849-, como muestra entre otros títulos y fechas de este siglo y anteriores; o la consolidada afición teatral, como queda de manifiesto a lo largo de este estudio y otros sobre Zaragoza; o la evidencia de las crónicas sobre ópera y zarzuela que se reseñan en la revista $E l$ Correo Musical, además de las diversas noticias locales, nacionales e internacionales sobre la actividad teatral, compañías, repertorios, etc., de los principales teatros, todo ello confirma la accesibilidad para el público zaragozano a la actualidad lírico-teatral como un hecho real, fruto de su situación geográfica, a mitad de camino entre Madrid y Barcelona, o formando parte del circuito Palma de Mallorca-Valencia-Zaragoza hacia el norte de la península -menos habitual-; Zaragoza era lugar de paso donde, también, un empresario aprovechaba a formar compañía rápidamente entre temporada y temporada. Es decir, que no estaría tan alejada -dentro de un orden jerarquizado de ciudades o circuitos de compañías- de los núcleos más activos, como se ha hecho ver en alguna ocasión. Otro ejemplo es la compañía lírico-dramática de Guillermo Cereceda, también compositor -que en esta ocasión representó su zarzuela en tres actos Rosa de mar-, y que actuaba en enero de 1886 en el Principal de Zaragoza (con 30 coristas, 40 profesores de orquesta, banda militar, guitarras y bandurrias, procedente de los teatros del Circo y La Zarzuela de Madrid. En el caso del año que nos ocupa, 1888, la expectación ante las compañías que actuaban en Madrid y sus repertorios estaba servida, tanto por saber lo que se estrenaba en la villa y corte como por la esperanza de verlo representado en la propia ciudad, a juzgar por el interés del público zaragozano y las promesas del mismo El Correo Musical en cuanto a tener informados a sus lectores. No hay que olvidar localidades de la misma provincia, como es el caso de Calatayud -de paso entre Madrid y Zaragoza-, con amplia y demostrada tradición teatral no sólo zarzuelística, sino operística, desde siglos atrás. Véase el estudio de M. Heilbron donde trata la recepción en España de la música teatral italiana en el ámbito de la iglesia, y que refleja el tránsito de compañías que actuaban en esa localidad: -Marc Heilbron Ferrer: "Un tal Baccano in chiesa, bel rispetto: ópera italiana en los archivos de iglesias de España. El caso de la Real Colegiata del Santo Sepulcro de Calatayud", en AEDOM, Boletín de la Asociación Española de Documentación Musical, VIII/1, (2001), pp. 65-124. Vid. también -Emilio Cotarelo y Mori: op. cit., pp. 199-203.

88. Miguel Sisamón pagó 20.451 pesetas por cada una de las cuatro temporadas que abrazaba el arriendo, y que abarcaba desde el 1 de noviembre de 1885 al 30 de mayo de 1889 . El documento nos informa, asimismo, de que el año cómico empezaba el 1 de octubre y terminaba el 15 de mayo, según las condiciones del contrato de arriendo. (Archivo Municipal de Zaragoza, Gobernación, sección "Propios y recursos", exp. 418/1885-86, caja 1493).

89. En el Buzón del $n^{\circ} 18$ de El Correo Musical (30 de septiembre, p.143) se da cuenta de la lista completa de la compañía que iba a actuar en el Teatro Principal para la temporada de 1888/89 y que comenzaba ya: se contaba con treinta coristas "de ambos sexos" y una orquesta de cuarenta profesores -el mínimo exigido al empresario del coliseo en el contrato de arrendamiento-, más una banda militar y un cuerpo de baile "para todas las óperas cuyo argumento lo exija", dirigido por Manuel Guerrero. Si se añade el maestro director y concertador, Jaime Subeas Bach, y el maestro de coros, Ricardo Mateo, se completa una información de la que, según la costumbre de la época, nada solían decir los cronistas: lo habitual en éstos era hablar del público -del que se dice, a menudo, que es "inteligentísimo", "selecto", "lo mejor de nuestra sociedad", etc.-, y de los y las cantantes. Más adelante (n²1, 30 de octubre de 1888, p.168), un periodista dice sobre la compañía que ya se despedía de Zaragoza: "Lucrecia Borgia, Sonámbula y Roberto el diablo, han sido las obras nuevamente conocidas, cantadas como nos tienen acostumbrados los artistas que en su ejecución intervinieron. Merece especial mención la última, donde los señores Metellio [sic.] y Bugatto, la Sra. Caligaris y la Srta. Fons, rayaron á gran altura. La Srta. Mas nos ha dejado inolvidable recuerdo. Su hermosa y bien timbrada voz, merece elogios". Si de la de zarzuela no había quedado el público contento en la temporada anterior, esta compañía de ópera sí satisfizo a los espectadores. (Archivo Municipal de Zaragoza, Gobernación, sección "Propios y recursos", exp. 418/1885-86, caja 1493). 
El primer actor, actor de carácter, actor cómico, galán joven, primera dama, [actriz] característica, actriz cómica y dama joven de la compañía de declamación nacional [...]; el maestro director y concertador, primer tenor, primer barítono, primer bajo, caricato, prima donna y primer contralto de la compañía de ópera italiana [...]; el maestro director, tenor, bajo, barítono, tenor cómico, primera tiple, tiple contralto, tiple cómica y tiple característica de la compañía de zarzuela nacional, justificarán con listas de compañía o certificación expedida por el alcalde respectivo, que han actuado en cualquiera de los tres años últimos y en teatro de igual ó superior categoría que el principal de esta ciudad, el papel con que vengan á figurar en la lista que se somete á la aprobación del Ayuntamiento, de la misma manera que queda prevenido en la condición 41 [anterior]. ${ }^{90}$

hecho que, en la actualidad, se convierte en un aporte de datos sobre actuaciones en años anteriores y en otros teatros de los artistas.

Mezclada en los escenarios zaragozanos con el auge reciente de la música instrumental, se encuentra entre las preferencias de empresarios, músicos y público, la omnipresente ópera italiana, con predominio de Verdi -dado el tránsito fluido de compañías italianas- y Donizetti, a quienes sigue, en orden, la Grand opéra francesa: Meyerbeer, Gounod -también éste en el género instrumental-, e incluso Halévy.

$\mathrm{Ni}$ que decir tiene que el género español por excelencia (en las múltiples variantes del teatro lírico -comedia, sainete, juguete, revista, cuadro costumbrista, episodio, leyenda, etc.- que contribuyeron al desarrollo de la zarzuela), llenó diariamente los teatros zaragozanos (ver Anexo 2$)^{91}$. Las programaciones son una muestra del eclecticismo propio de la década, en la que convivían la zarzuela grande, las breves del género chico y alguna muestra de influencia francesa con su ópera cómica y opereta, que también hemos visto en repertorios instrumentales con oberturas y arreglos de este género francés.

Respecto a la entrada de los clásicos, con la colaboración ya mencionada de Antonio Lozano o J. Joaquín Oña en el ciclo de conferencias del Círculo Mercantil, Agrícola e Industrial ${ }^{92}$, considero de interés, por tratarse de un testimonio directo de la época, lo que dice R. Ruiz de Velasco en la conferencia arriba citada:

Entiendo que las conferencias musicales teórico prácticas son hoy de verdadera necesidad; porque el movimiento de reacción hacia el género clásico iniciado en nuestros días, sería incompleto si el público no estuviera acostumbrado á saborear las bellezas encerradas en las obras de corte perfecto y sufi-

\section{Ibid.}

91. Chapí, Barbieri, Marqués, Arrieta, Chueca, Suppé, Gaztambide, Fernández Caballero y otros forman parte de la lista de autores que se interpretaron, sólo en el Teatro Principal de Zaragoza, a lo largo del "año cómico de 1888". Las cuarenta obras que figuran en el total de listados mensuales -que firma el representante, Vicente Salazar-, hacen que se disperse la valoración de obras o autores: no queda sino decir que el repertorio fue amplio y variado aunque con pocos estrenos, una gran parte era conocida ya por el público. Vemos en las numerosas reseñas y crónicas de la sección "Buzón", que se esperaban más títulos de los recién estrenados en Madrid, y que no llegaron sino más tarde, y algunos no llegaron. De otro lado, además de la compañía del señor Palau en el Teatro Pignatelli, también tuvieron éxito -según notas de prensa- las diferentes programaciones del Teatro Circo y alguna zarzuela en el Teatro Goya, con artistas zaragozanos.

92. Las influencias de las diversas tendencias italiana, francesa, alemana y nacionalismos en la música eclesiástica, modelos compositivos, o la actividad músico-dramática en Zaragoza a finales del XIX, se trata en el estudio realizado por: -José V. González Valle, Luis A. González Marín y Antonio Ezquerro Esteban: “El compositor Juan Francisco Agüeras y González...”, op. cit., pp.113-120. 
cientemente ilustrado acerca de la factura elevada de las frases, de los períodos melódicos y del pensamiento armónico de estas obras.

Vemos, pues, que fue grande el esfuerzo de los músicos por elevar a un mayor nivel la música instrumental -sinfónica o camerística- en un intento de añadir, que no desplazar, al panorama musical de la época otra música además del abundante repertorio de zarzuela -género nacional- y ópera -bien mediante compañías italianas o con la difusión por parte de músicos locales a través de oberturas, arias acompañadas, fantasías sobre temas de óperas, variaciones, etc.--.

Con la labor continuada que, pocos años después, iba a realizar la Sociedad Filarmónica, en Zaragoza se podría ampliar la visión de la producción musical europea en cuanto al conocimiento de compositores y obras que, en ocasiones, requerían un gran aparato orquestal -recuérdese el ejemplo de las sinfonías de Beethoven-.

Todo este movimiento en evolución deja claro que la música se hace sitio entre los valores culturales de la sociedad española en general y de provincias en particular, con una importante y sustanciosa aportación musical en sus variadas vertientes. En este final de siglo proliferan nuevas publicaciones y actividades musicales dirigidas a un público ávido de oportunidades para relacionarse socialmente a la vez que se nutre culturalmente, y que demanda actividad concertística, coincidiendo con la búsqueda de ocupaciones remuneradas por parte de los profesionales. ${ }^{93}$

Partiendo de la necesidad actual de nuevas valoraciones de la música del siglo XIX en España, quizás este estudio que se completa en una segunda parte con un análisis de El Correo Musical y lo que de él se deriva, sirva para contribuir con una pequeña aportación a enriquecer el conocimiento, en el ámbito zaragozano en particular, de la actividad cultural y especialmente musical de las últimas décadas de ese siglo, en las que estuvo interesada una sociedad burguesa con ciertas pretensiones aristocráticas. Por otro lado, se trata de una época de nuestra historia infravalorada durante mucho tiempo, a lo que ha contribuido, tal vez, una genealogía de hechos y personajes que pasa por alto la objetividad de criterios de calidad deseable en el ámbito historiográfico.

Ya se inició hace pocos años la tarea investigadora correspondiente a esta etapa de nuestra música, y tal vez podamos más adelante contemplar ésta con mejor criterio sin, para ello, tener que abstraernos de lo que aconteció musicalmente en el resto de Europa; es muy extenso el legado y nuestra mirada habría de llegar hasta la América hispana, donde también encontramos un patrimonio musical autóctono y mixto no menos rico que el que pueda corresponder a las grandes ciudades europeas de aquellos momentos.

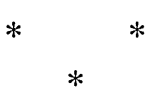

93. Merecería la pena una reflexión sobre la manera en que incidieron, en estas dificultades laborales de los músicos, las consecuencias de la desamortización en Zaragoza, anteriormente mencionada en un contexto nacional, ya que sabemos que la mayoría de ellos procedían, en el origen de su formación, de las capillas catedralicias zaragozanas. Sobre clero y desamortización, véase: -Carmen Lozano y Francisco Zaragoza: Estudios sobre la desamortización en Zaragoza. Zaragoza, Diputación General de Aragón, Departamento de Cultura y Educación, 1986, pp.138-142. 


\section{ANEXO 1 ${ }^{94}$ \\ Compañía de Ópera. Teatro Principal de Zaragoza. ${ }^{95}$ Año de 1888}

\begin{tabular}{|c|c|c|c|}
\hline Título & AUTTOR & FECHA & $\begin{array}{l}\text { REPRESEN- } \\
\text { TACIONES }\end{array}$ \\
\hline Lucrezia Borgia & G. Donizetti & 22, 26/II; 14/III; 19/X & 4 \\
\hline La traviata & G. Verdi & $23 / 11,3,8 \mathrm{~m} ; 16,23 / \mathrm{X}$ & 5 \\
\hline Ernani & G. Verdi & $25 / \mathrm{II} ; 15 / \mathrm{III}$ & 2 \\
\hline Rigoletto & G. Verdi & $27 / 11 ; 8,15 / X$ & 3 \\
\hline La favorite & G. Donizetti & $\begin{array}{c}29 / \mathrm{II} ; 1,11,19 / \mathrm{III} ; 29 / \mathrm{IX} \\
4,10,18 / \mathrm{X}\end{array}$ & 8 \\
\hline Il trovatore & G. Verdi & $4-5 M I, 30 / 1 X$ & 3 \\
\hline Fausto & Ch. Gounod & $6-7 / \mathrm{III} ; 16,21 / \mathrm{III} ; 6,12 / \mathrm{X}$ & 6 \\
\hline Lucia di Lammermoor & G. Donizetti & $10,17 M 13 / X$ & 3 \\
\hline Un ballo in maschera & G. Verdi & $12,18 / \mathrm{III}$ & 2 \\
\hline I puritani & V. Bellini & $22 / 111,1,9 / \mathrm{X}$ & 3 \\
\hline Les huguenots & G. Meyerbeer & $2,7,17 / \mathrm{X}$ & 3 \\
\hline La hebrea (La juive) & J. F. Halevy & $5,14 \times \mathbb{X}$ & 2 \\
\hline L'africaine & G. Meyerbeer & $11,22 / \mathrm{X}$ & 2 \\
\hline Macbeth & G. Verdi & $13.20 / X$ & 2 \\
\hline La sonnambula & V. Bellini & $21 / \mathrm{X}$ & 1 \\
\hline Robert le Diable & J. Meyerbeer & $24-25 / x$ & 2 \\
\hline
\end{tabular}

\section{Total de representaciones por autor -en número de ocasiones- y obra más representada del mismo:}

\begin{tabular}{|c|c|c|c|}
\hline AUTOR & $\begin{array}{l}\text { Número total de } \\
\text { representaciones }\end{array}$ & $\begin{array}{c}\text { Número de obras } \\
\text { diferentes }\end{array}$ & $\begin{array}{l}\text { Obra representada } \\
\text { mayor núm. de veces }\end{array}$ \\
\hline G. Verdi & 17 & 6 & La traviata $(5)$ \\
\hline G. Donizetti & 15 & 3 & La favorite (8) \\
\hline G. Meyerbeer & 7 & 3 & Les huguenots (3) \\
\hline Ch. Gounod & 6 & 1 & Fausto (6) \\
\hline V. Bellini & 4 & 2 & I puritani (3) \\
\hline J. F. Halevy & 2 & 1 & ta hebrea (2) \\
\hline
\end{tabular}

94. Se ha tenido en cuenta el año natural de 1888 -de enero a diciembre- en la confección de los listados, por una más precisa contextualización de la revista estudiada, aun cuando se rompe, así, la temporada natural de ópera y zarzuela en este teatro zaragozano, siendo el año coincidente con el período de publicación de El Correo Musical; hubo, pues, representaciones de ópera del 22 de febrero al 24 de marzo y del 29 de septiembre al 26 de octubre. Por otro lado, aun cuando el empresario del teatro no estaba obligado a ofrecer ópera italiana en esta cuarta temporada de su contrato, es claro que se debía, finalmente, a las exigencias del público.

95. No están contabilizados los actos sueltos que de algunas óperas se interpretaron el último día de la actuación de la compañía y que podrían ser, sin embargo, significativos del éxito obtenido entre el público; para el 24 de marzo constan el $3^{\circ}$ de $L u c i a$ di Lammermoor (Donizetti), el $2^{\circ}$ de I puritani y el $3^{\circ}$ de La sonnambula (Bellini); el 26 de octubre fueron el ler. acto de La favorite (Donizetti), el $1^{\circ}$ de Il trovatore (Verdi) y el $2^{\circ}$ de I puritani (Bellini), el mismo acto que en marzo. 

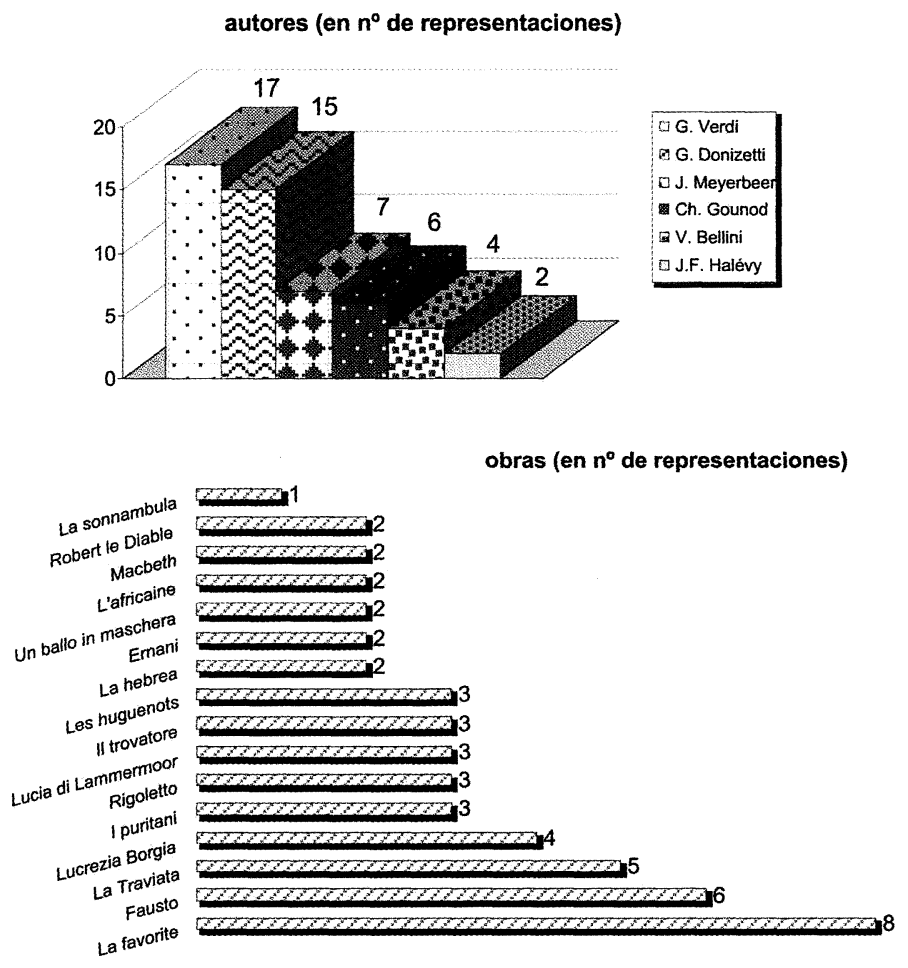

Puede verse en las tablas y gráficos que casi todas son obras que han permanecido en repertorio hasta nuestros días, contabilizándose un total de 16 títulos de ópera montados en un año correspondientes a sólo seis autores diferentes. Entre ellos, Verdi (17 funciones) fue el más representado, con seis de sus obras (con gran éxito de La traviata y escaso para Ernani), al que sigue de cerca Donizetti con 15 representaciones de tan sólo tres de sus óperas que, claramente, tuvieron "gran impacto" y, ya con una diferencia notable les sigue el resto de compositores. Curiosamente se representó menos Bellini que los franceses Meyerbeer -de origen prusiano- y Gounod, y en cambio aquél ha permanecido más en el tiempo.

Tal vez el menor interés por Bellini -entre los tres italianos- por

parte de las compañías que actuaban en Zaragoza se deba a que éste quedaba más atrás en el tiempo: en España se estrenó La sonnambula el año 1834, e I puritani en 1836, mientras que los estrenos de Donizetti y Verdi se llevaron a cabo, principalmente, las décadas de 1840, 1850 e incluso 1861 es el año en que se estrenó Un ballo in maschera (Gran Teatro del Liceo, Barcelona). Lo que sí queda demostrado mediante las críticas en El Correo Musical es que hubo elogios para cantantes, director de orquesta, coros y la propia orquesta -como podría verse en la segunda parte de este estudio-, en lo que a Bellini se refiere.

Recuérdese que el público gustaba de asistir una y otra vez a las representaciones de una misma obra a lo largo de varias temporadas, o incluso dentro de la misma: esto les permitía comparar cantantes, dotes interpretativas como actores o puestas en escena -no importaban tanto los directores ni las orquestas-, estando interesados en seguir de cerca el éxito obtenido en otras ciudades por la misma o diferente compañía.

A través del gráfico de obras, se puede observar que la que mayor número de veces fue representada no corresponde al autor más representado: así, es La favorite de Donizetti ( 8 veces) la que ocupa el primer puesto, y le sigue el Fausto de Gounod, compositor que, como hemos visto, ocupa el cuarto lugar entre los seis por número de representaciones pero, seguramente, no es que el francés no gustase sino que tan sólo se llevó a escena una única obra.

En la cota de mínimos Halévy da la máxima en los dos parámetros: dos representaciones de una única obra. 


\section{ANEXO $2^{96}$ \\ Compañía de Zarzuela. Teatro Principal de Zaragoza. Año de 1888}

\begin{tabular}{|c|c|c|c|}
\hline Título & $\begin{array}{l}\text { AUTOR } \\
\text { letra / música }\end{array}$ & ГЕСНА & $\begin{array}{l}\text { REPRESEN- } \\
\text { TACIONES }\end{array}$ \\
\hline La tempestad 97 & M. Ramos Carrión / R. Chapí & $11,22 / \mathrm{I} ; 26 / \mathrm{IV}$ & 3 \\
\hline Picio, Adán y compañia & R. M $\mathrm{M}^{\mathrm{a}}$. Liern / C. Mangiagalli & $7-81$ & 3 \\
\hline Jugar con fuego & L. de Olona / E. Arrieta & $12 / I$ & 1 \\
\hline Boccaccio 98 & L. M. de Larra / F. von Suppé & $13 / 1$ & 1 \\
\hline El reloj de Lucerna & M. Zapata / P.M. Marqués & $14,23 / \mathrm{I}$ & 2 \\
\hline Château Margaux* & $\begin{array}{l}\text { J. Jackson Veyán / F. } \\
\text { Caballero }\end{array}$ & $7 *-8 / 1$ & 2 \\
\hline Niña Pancha & $\begin{array}{l}\text { C. Gil / J. Romea y J. } \\
\text { Valverde }\end{array}$ & $5 / \mathrm{I}$ & 1 \\
\hline Marina 99 & F. Camprodón / E. Arrieta & $15 / I$ & 1. \\
\hline Los lobos marinos & $\begin{array}{l}\text { Vital Aza y R. Carrión / R. } \\
\text { Chapí }\end{array}$ & 16-17,28/I; 25/IV & 4 \\
\hline Un tesoro escondido & V. de la Vega / A. Barbieri & $18,24 / I$ & 2 \\
\hline El juramento & L. de Olona / J. Gaztambide & $19,29 / \mathrm{I}$ & 2 \\
\hline Cádiz & $\begin{array}{l}\text { J. Burgos I Chueca y } \\
\text { Valverde }\end{array}$ & $20-21 / 1$ & 2 \\
\hline El cercado ajeno & J. Estremera / T. Reig & $20 / \mathrm{I}, 14 / \mathrm{IV}$ & 2 \\
\hline Coro de señoras & $\begin{array}{l}\text { V. Aza y R. Carrión / R. } \\
\text { Chapi }\end{array}$ & 21,281 & 2 \\
\hline El anillo de hierro & M. Zapata / P. M. Marqués & $25 / 1$ & 1 \\
\hline La bruja*100 & $\begin{array}{l}\text { M. Ramos Carrión / R. } \\
\text { Chapí }\end{array}$ & 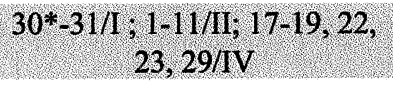 & 19 \\
\hline
\end{tabular}

96. (El asterisco en algunos títulos indica su estreno en Zaragoza).

Hubo compañías de zarzuela del 5 de enero al 11 de febrero y del 31 de marzo al 30 de abril. Ya a partir del mes de enero siguiente (1889), las representaciones de zarzuela ocuparon, sin interrupción, desde el 7 de ese mes hasta el 11 de abril -fecha en la que comenzó la Semana Santa-, excepto diez días de marzo, siendo el empresario el mismo que en 1885. Pudo ser que, a raíz de las presiones, exigencias y frecuentes amenazas de sanciones por parte del ayuntamiento zaragozano al empresario, Sr. Sisamón, se cuidase éste de proporcionar una mejor temporada de zarzuela para ese último año de su contrato, ya que de la compañía anterior constan algunas quejas, en el ámbito periodístico al menos.

97. Esta zarzuela en tres actos se representó, también, en el Teatro Circo de Zaragoza, el 28 de diciembre del mismo año, a beneficio de la Casa-Amparo, junto con El gorro frigio (F. Limendoux y C. Lucio / M. Nieto): el gran tenor zaragozano Eduardo García Bergés, que ya había estrenado La tempestad (1881), era, además, empresario del Teatro Circo y director de la Compañía Nacional de Zarzuela en estas fechas (según consta en el expediente n 1495 , caja 1475, Archivo Municipal de Zaragoza, Gobernación, sección "Beneficencia"). Cfr. -Emilio Casares: "García Bergés, Eduardo" en Diccionario de la zarzuela..., op. cit., vol. 1, pp. $825-826$.

98. Con letra de Luis Mariano de Larra y música de Franz von Suppé, esta obra es una imitación de la ópera cómica alemana de Camilo Walzel y Ricardo Genée.

99. Se entiende que se trata de la versión zarzuelística.

100. Esta zarzuela en tres actos se había estrenado el 10 de diciembre anterior en el madrileño Teatro de la Zarzuela; si allí tuvo gran éxito desde el principio, en Zaragoza fue la que más se representó en este año de 1888 entre 39 títulos. 


\begin{tabular}{|c|c|c|c|}
\hline El diablo en el poder & F. Camprodón / A. Barbieri & $31 / \mathrm{III}$ & 1 \\
\hline La Marsellesa & M. R. Carrión / F. Caballero & $1,20 / \mathrm{IV}$ & 2 \\
\hline La Mascota ${ }^{101}$ & $\begin{array}{l}\text { A. Duru y H. Chivot / E. } \\
\text { Audran }\end{array}$ & $2-3 / I V$ & 2 \\
\hline Entre el alcalde y el rey & G. Núñez de Arce / E. Arrieta & $4,11 / \mathrm{IV}$ & 2 \\
\hline La guerra santa & L. M. de Larra / E. Arrieta & $5,6,8 / \mathrm{IV}$ & 3 \\
\hline Catalina & $\begin{array}{l}\text { L. de Olona / A. Barbieri y J. } \\
\text { Gaztambide }\end{array}$ & $7 / \mathrm{IV}$ & 1 \\
\hline Amar sin conocer & $\begin{array}{l}\text { L. de Olona / A. Barbieri y J. } \\
\text { Gaztambide }\end{array}$ & 9-10/IV & 2 \\
\hline Frasquito & R. de la Vega / F. Caballero & $12-13 / \mathrm{IV}$ & 2 \\
\hline Cuba libre* & F. Jaques / F. Caballero & $12 *-16,25 / \mathrm{IV}$ & 6 \\
\hline Lagran Via & F. Pérez / Chueca y Valverde & $15-16 / \mathrm{IV}$ & 2 \\
\hline Mis dos mujeres & L. de Olona / A. Barbieri & $21 / \mathrm{IV}$ & 1 \\
\hline Las dos princesas & $\begin{array}{l}\text { M. Ramos Carrión y M. Pina } \\
\text { Domínguez / F. Caballero }\end{array}$ & $24 / \mathrm{IV}$ & 1 \\
\hline Artagnan $* 102$ & J. Nombela / P. A. Vidal & $27 / \mathrm{IV}$ & 1 \\
\hline Llamada y tropa & $\begin{array}{l}\text { A. García Gutiérrez / E. } \\
\text { Arrieta }\end{array}$ & $28 / \mathrm{IV}$ & 1 \\
\hline Losfeos & R. Ma. Liern / F. Caballero & $28 / \mathrm{IV}$ & 1 \\
\hline El salto del pasiego & L. Eguilaz / F. Caballero & $30 / I V$ & 1 \\
\hline Un día en el gran mundo & E. Zamora / F. Caballero & $29 / \mathrm{X}$ & 1 \\
\hline El teniente cura* & C. Gil y J. Romea / J. Romea & $30 / X$ & 1 \\
\hline
\end{tabular}

101. Se trata de una traducción del francés de la ópera cómica en tres actos La Mascotte (1881), con música de Edmond Audran $(* 1842-\dagger 1901)$, compositor francés, principalmente, de operetas; de varias de ellas, los libretistas fueron Henri Chivot y Alfred Duru. Ejemplo exitoso de los títulos que se representaban todavía, reminiscencias de la influencia que la opereta francesa ejerció años antes en la zarzuela; éste se reeditó en 1886.

102. Se trata de una opereta de Paul-Antonin Vidal (*Toulouse, 1863; †París, 1931), profesor del Conservatorio de París y director de la Ópera Cómica y la Ópera de esta ciudad; así pues, el autor de la música contaba 25 años de edad cuando se estrenó en Zaragoza. De esta opereta se dice en el "Buzón" (El Correo Musical, n³, 30 de abril): "es la partitura un modelo acabado de la excelente música francesa, genérica y original cual ninguna; matizada de frases y situaciones hermosas; satisfizo á los inteligentes. Si los artistas supieran lo que traen entre manos, Artagnan sería una opereta digna de escucharse, pero cuando los cantantes lo hacen tan mal, hay que resignarse á no oírlos." A continuación dice: "Como despedida diremos á los zarzuelistas del Principal que no vengan otra vez á Zaragoza, donde con su presencia ha desaparecido hasta el buen gusto musical que teníamos" (!). El cronista sólo salva a la tiple María González y al bajo Sr. Brandón.. 


\section{Autores más representados (de un total de 17):}

\begin{tabular}{l|c|c}
\hline & $N^{\circ}$ DE REPRESENTACIONES & $\begin{array}{c}N^{*} \mathbf{D E} \\
\text { TítuLos }\end{array}$ \\
\hline Chapí & 28 & 4 \\
\hline Fernández Caballero & 16 & 8 \\
\hline Arrieta & 8 & 5 \\
\hline Barbieri & 7 & 5 \\
\hline Gaztambide & 5 & 3 \\
\hline Valverde & 5 & 3 \\
\hline Chueca & 4 & 2 \\
\hline Mangiagalli & 3 & 1 \\
\hline Marqués & 3 & 2 \\
\hline
\end{tabular}

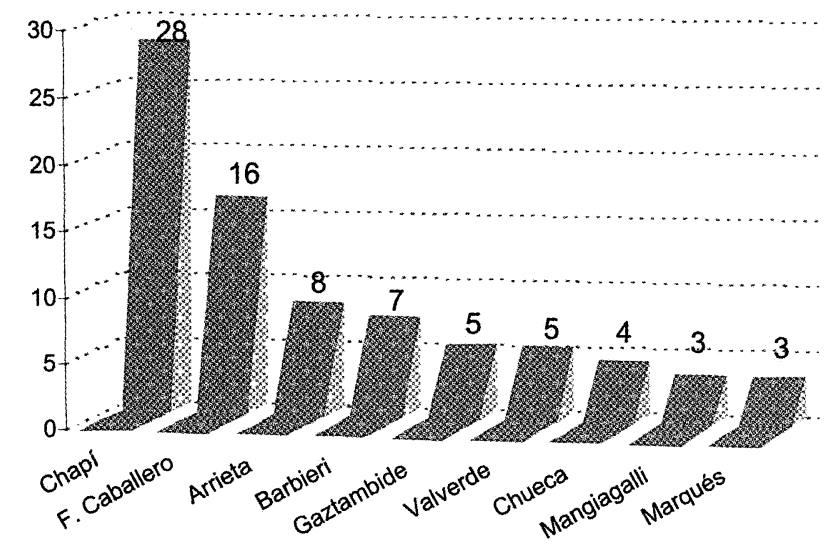

Chapí, Fernández Caballero y Arrieta son los autores más representados con diferencias significativas entre ellos; sin embargo, es Fernández Caballero el autor con más títulos diferentes representados, doblando en variedad al repertorio ofrecido de Chapí. Y de este mismo compositor son dos de las tres zarzuelas más representadas, como puede verse en los gráficos: se trata de La bruja y Los lobos marinos. La primera se volvió a representar en el zaragozano Teatro Circo, reinaugurado como Jardín Goya, en el mes de agosto, obteniendo gran éxito según las crónicas de El Diario de Zaragoza y El Correo Musical.

De Carlos F. Mangiagalli, también profesor de canto, se conocieron en Zaragoza, además de Picio, Adán y compañía -ya en diciembre de 1887-, las zarzuelas A ti suspiramos, en colaboración con Fernández Caballero (letra de Rafael M. Liern y Salvador M. Granés) en el Teatro Principal, e I comici tronati (letra de L. Palomino de Guzmán y J. de la Cuesta) en el Teatro Circo, dentro de la programación de verano.

En las relaciones mensuales de obras representadas, manuscritas y firmadas por el representante, Vicente Salazar, figura a pie de página la indicación "no se há construido nada nuevo" salvo en dos ocasiones - entre los ocho listados donde se da parte-, en las que se lee: "lo hecho nuevo para el Roberto [el Diablo] y D. Juan Tenorio la empresa lo cede á favor del Excmo. Aymto.” (2 de noviem- 
bre de 1888), y "se há construido un forillo que representa un invernadero, y lo regala la empresa al Excmo. Ayuntamiento" (1 de enero de 1889, donde consta lo representado en diciembre de 1888). Todo esto responde a lo firmado en el contrato de arrendamiento: era obligación del contratista, en las temporadas $1^{\mathrm{a}}$ y $3^{\mathrm{a}}$, de las cuatro del contrato, construir una decoración nueva, estando ésta "graduada" en 1.625 pesetas, y si no cumplía el empresario con esto, el ayuntamiento lo tomaría de la fianza (12.500 pesetas, "en obligaciones de la deuda municipal") para satisfacer la cantidad. El empresario estaba obligado a presentar mensualmente a la Sección $1^{\mathrm{a}}$ del ayuntamiento una relación detallada de decoraciones, enseres y "trastos" que hubiera construido, y de no haber construido ninguno lo haría constar también. Se sabe de la gran habilidad de los empresarios para escatimar recursos y demás, lo que nos lleva a explicar la precariedad de medios y el aprovechamiento de éstos -con escenografías intercambiables y la habitual recuperación de decorados- para distintas funciones, aun cuando en nada se parecieran unas representaciones a otras.

Por otro lado, las críticas negativas en El Correo Musical se dirigen hacia la compañía de zarzuela del Teatro Principal (enero-abril), dirigida por Rafael Navarro -el mismo que fuera director de la Sociedad de Conciertos de Zaragoza-; sin embargo en las mismas fechas (abril - mayo) se habla de los éxitos obtenidos por la compañía de Miguel Cepillo (discípulo de Emilio Mario) en el Teatro Goya y de la compañía de los Sres. Romea y Vallés en el Teatro Circo, de la que se resaltan las dotes como actriz de alguna de sus componentes, siguiendo la costumbre generalizada en este tipo de crónicas de dar prioridad al mérito en el aspecto escénico -a veces incluso como el único- antes que al mérito como cantante. Tal vez esto sea producto del predominio de crónicas de índole literaria en el ámbito periodístico en detrimento de las emitidas por profesionales de la música, a lo que se puede añadir una concepción social y jurídica ${ }^{103}$ de los artistas en la que el término "actor" se utilizaba con un sentido de gran amplitud.

De la compañía que se contrató para la temporada siguiente -en octubre- se dice que son "distinguidos artistas todos muy apreciados del público zaragozano"; esta compañía contaba con una orquesta de sólo 25 profesores, mientras que la anterior tenía cuarenta. Hay que decir, respecto a las últimas informaciones, que El Correo Musical en su segunda etapa -tras el cambio de dirección y propietario- no se ocupa de los espectáculos locales de ópera y zarzuela de la misma manera que los cronistas de la anterior etapa de la revista, más bien se limitan a enumerar obras y componentes de las correspondientes compañías. No parece, después de todo, que la zarzuela fuera objeto de interés en la revista estudiada; sí, en cambio, es asunto que ocupa y preocupa, constantemente, la ópera, por otro lado tema omnipresente en la prensa musical de la segunda mitad de siglo. Aún así, no dejan de ser significativas las cifras que se recogen en las tablas y los gráficos de estadísticas para valorar, a través de ellos, el gusto del público o la acogida de algunas obras y autores.

103. Téngase en cuenta que la gran actividad teatral se desarrollaba en una extensa tipología de teatros -Español, del drama, de la comedia, lírico español, lírico italiano- y abarcaba varios géneros, entre los que zarzuela y ópera eran sólo dos, siendo el primero, además de cantado, hablado y representado. Ya en el Decreto orgánico de los Teatros del Reino (8 de febrero de 1849) se dedica un capítulo a "los actores y demás dependientes de los Teatros", y en el Reglamento del Teatro español para la ejecución de dicha ley se dedican dos a "los autores" y "los actores", respectivamente. Con rango de capítulo no aparece ninguno dedicado a compositores, cantantes o instrumentistas. A esto se añade lo expuesto arriba sobre el tradicional talante literario de las crónicas. 


\section{Obras más representadas (de un total de 39 títulos):}

\begin{tabular}{|l|l|}
\hline OBRA & $\begin{array}{l}\text { No DE } \\
\text { REPRE- } \\
\text { SENTA- } \\
\text { CIO-- } \\
\text { NES }\end{array}$ \\
\hline La bruja & 19 \\
\hline Cuba libre & 6 \\
\hline Los lobos marinos & 4 \\
\hline La guerra santa & 3 \\
\hline La tempestad & 3 \\
\hline Picio, Adán y compañía & 3 \\
\hline
\end{tabular}

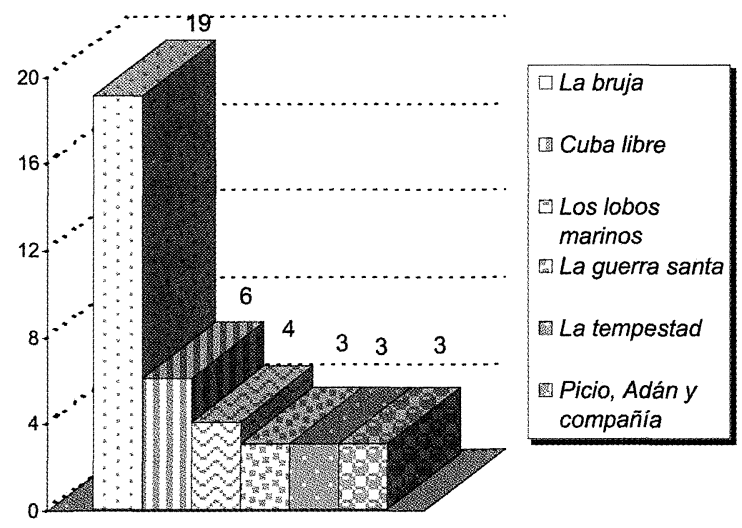

\section{CONCLUSIONES}

Se ha visto en la primera parte de este trabajo el nacimiento y desarrollo de las asociaciones musicales zaragozanas en la época estudiada; cómo surgió y creció la Escuela de Música y la presentación de sus profesores; la música y otras actividades culturales y sociales en teatros y lugares de reunión o puntos de encuentro de la sociedad burguesa zaragozana, con un estudio detallado de las temporadas de ópera y zarzuela: apuntadas las conclusiones en su momento, dentro del capítulo correspondiente, quiero señalar respecto al último apartado una conclusión relevante: la gran actividad teatral, operística y de zarzuela que tuvo Zaragoza en esas décadas y anteriores -como se ha visto al repasar someramente la década de 1860-, en contra de lo que se ha dado por supuesto; aquí se ha demostrado la accesibilidad del público zaragozano a la actualidad lírico-teatral, fruto de su situación geográfica, formando parte la ciudad de las principales rutas de las compañías, bien de Madrid a Barcelona y viceversa, o desde Valencia si comenzaba en Baleares hacia el norte de la península. Así, pues, Zaragoza no estaría alejada de los núcleos más activos, como se ha hecho ver en alguna ocasión, amén de la también demostrada afición teatral desde siglos atrás. 


\section{ÍNDICE ONOMÁSTICO}

Las cifras que aparecen en cursiva se refieren al número de nota a pie de página y la negrita indica que se trata de una nota biográfica.

Adam, Adolph Charles, 181, 37, 39

Agüeras, Francisco, 65, 68

Alard, Delphin, 51

Albéniz, Isaac, 16

Alfonso XII, 182, 34

Alfonso XIII, 16

Álvarez Quintero, Serafín y Joaquín, 17

Alvira, José $\mathrm{M}^{\mathrm{a}}, 4,16$

Anadón, José, 197

Anel, Francisco, 191, 64

Arana, Lucrecia, 4, 17

Arenas, M., 16

Ariño, Calixto, 83

Arista, A. S., 16

Armingaud, Jules, 51

Arnaudas, Miguel, 65, 68

Arrieta, Emilio, 206, 207, 208, 10, 50, 51, 85, 91

Asenjo Barbieri, Francisco de Asís Esteban, 175, 206, 207, 208, 16, 23, 76, 91

Auber, D. F. E., 180, 183, 37, 39

Audran, Edmon, 182, 207, 101

Aula Guillén, Luis, 193

Aza, Vital, 206, 44, 76

Azcona, Agustín, 14, 87

Aznar, Ángel, 185

Aznar, José, 87

Aznar, Pedro, 198

Ballo, Teodoro, 174, 184, 187, 192, 193, 197, 25, 45, 54, 67, 72

Barbieri (ver Asenjo Barbieri, Francisco)

Barcelona, Juan Pedro, 3

Barrera Saavedra, Tomás, 16

Baselga, Mariano, 187

Bazin, Emmanuel Joseph François, 51
Bazzini, Antonio, 181, 183, 37

Bécquer, Gustavo A., 87

Beethoven, L. Van, 184, 185, 203, 54

Bellini, Vincenzo, 184, 204, 205, 74, 87, 95

Belsué, Babil, 65

Bergua, Enrique, 191

Berlioz, Héctor, 51

Bernareggi, Faustino, 185, 192, 48

Bizet, Georges, 181, 37

Blasco Ijazo, José, 188, 29

Blasco, Cosme, 3

Blasco, Eusebio, 186, 3, 17, 44

Blasco, Justo, 191, 16

Bobadilla y Escrivá de Romaní, Mauricio (Marqués de Bobadilla y de Romaní), 191, 54, 66

Boggiero, Luis, 44

Borao, Gerónimo, 3

Borbón, $\mathrm{M}^{\mathrm{a}}$ Cristina de, 21

Bordoy, Melchor, 4

Borobia, Ramón, 65, 68

Brandón, 102

Bretón, Tomás, 191, 16, 75

Brull Ayerra, Apolinar, 185, 50, 85

Burgos, Javier de, 206

Calahorrano, Luis, 192

Calvo Revillo, Rafael, 180, 34

Calvo Revillo, Ricardo, 180, 34

Campos, Florián, 58

Camprodón, Francisco, 206, 207

Cariñena, Benigno, 178, 179, 31, 32, 40

Carvajal, Santiago, 184, 187, 192, 46

Casamitjana, Juan, 23

Casañal, Gregorio, 56

Castellano y Villarroya, Tomás, 73 
Castelló, Eusebio, 81

Castro, Pablo de, 190

Catalá, G., 85

Cavia, Mariano de, 170, 3, 6, 40

Cepillo, Miguel, 209

Cereceda, Guillermo, 76, 87,

Chabrier, E., 16

Chapí, Ruperto, 181, 183, 191, 206, 208, 37, 40, 4, 54, 76, 85, 91

Chavarri, B., 17

Chimeno, Josefa, 87

Chivot, Henri, 207, 101

Chopin, F., 16, 54

Chueca, Federico, 206, 207, 208, 74, 91

Clavé, Anselmo, 188, 190

Compta, Edmundo, 50

Costa, Joaquín, 10, 34

Cuartero, Manuel, 184

Cuartero, Alejo, 40, 68

Cuesta, José de la, 208, 76

Czibulka, Alfons, 181

$$
95
$$

Donizetti, G., 202, 204, 205, 41, 74, 76, 83, 87,

Duprato, Jules-Laurent, 181, 37

Duru, Alfred, 207, 101

Eguilaz, Luis, 207, 44

Enciso, S., 4

Eslava Elizondo, Miguel Hilarión [Hilarión Eslava], 170, 38, 40, 69

Espeita, José, 190

Esperanza y Sola, J. M., 40

Espín y Guillén, Joaquín, 170

Espinosa, Gaspar, 181, 183, 37, 38

Estremera, José, 206

Fages, Tito, 58

Falla, M. de, 16

Fañanás, Pascual, 40
Faura, Valentín, 191

Fauré, Gabriel, 54

Fernández de la Puente, Manuel, 17

Fernández Caballero, Manuel, 206, 207, 208, 16, 17, 31, 44, 74, 76, 85, 91

Fernández, Mariano, 87

Fleta, Miguel, 75

Foglietti Alberola, Luis, 17

Fontana, Julián, 16

Frank, César, 54

Fuster y Camprovín, Rafael, 5

Fuster y Sas, Rafael, 171, 5

García Bergés, Eduardo, 44, 97

García Gutiérrez, Antonio, 207

Gayarre, Julián, 74

Gaztambide, Joaquín, 175, 206, 207, 208, 74, 91

Genée, Ricardo, 97

Gevaert, François Auguste, 16

Gil y Luengo, Constantino, 206, 207

Gil, Miguel, 25

Gil, Pedro León, 40

Giménez, Juan, 87

Giner de los Ríos, Francisco, 10

Glinka, M., 16

Godefroid, Jules, 181, 183, 37

González, María, 102

Gonzalo, J., 16

Gottschalk, L.M., 16

Goula, Juan, 179, 181, 183, 191, 33, 37

Goula, Juan (hijo), 179, 33

Gounod, Charles, 181, 183, 185, 202, 204, 205, 37,87

Granados, Enrique, 16, 54

Granés, Salvador $M^{\mathrm{a}}$, 208, 74

Grieg, Edvard, 54

Guelbenzu, José, 175

Guerrero, María, 17, 34

Guerrero, Manuel, 89 
Habsburgo, $\mathrm{M}^{\mathrm{a}}$ Cristina de, 192, 197, 30, 45

Halévy, J., 202, 204, 205, 87

Haydn, J., 174, 180, 184, 37, 54

Hernández, Isidoro, 16

Hernández, Cosme, 192

Hernando, Rafael, 87

Holden, Thomas, 76

Ibarra, Luis, 187

Iglesias, Juan, 180, 183, 185, 37

Iradier, Sebastián, 14, 16

Iriarte, Teodoro, 8

Jackson Veyán, J., 206

Jaques, Federico, 207

Laborda, Blas, 191

Laclaustra, Juan, 184, 187, 197, 25

Lafiguera, Mariano, 187

Lafita, Florencio, 72

Lamote de Grignon, R., 54

Lanaspa, Tomás Urbano, 8

Lapuente, Santiago, 3, 16

Larra, Luis Mariano de, 206, 207, 97

Larregla, Joaquín, 54

Larripa, 198

Lastra, Salvador, 74

Latre, Mariano, 25

Lavorda, Gil, 58

Liern, Rafael Ma , 206, 207, 208, 74

Limendoux, F., 97

Liso y Torres, Joaquín, 4

Liszt, F., 16, 54

López de Zubiría, Joaquín, 25

López, Narciso, 188

López-Tudela, Ángel, 187

López-Tudela, Eugenio, 187

Lorda, Santiago, 4

Lozano, Antonio, 174, 175, 179, 191, 192, 193, $194,202,14,27,31,35,37,45,46,62,65,68$
Lucca, F., 42

Lucio, Celso, 97

Luna, Pablo, 34

Madoz, Pascual, 175

Magdalena, Ricardo, 75

Mahler, Gustav, 16

Mallén Olleta, Martín, 190, 64

Mangiagalli, Carlos F., 206, 208, 74, 76

Mario, Emilio, 209

Marliani, Marco Aurelio, 180, 183, 37

Marqués, Pedro Miguel, 185, 206, 208, 51, 85, 91

Marqués de Ayerbe (ver Urriés, Juan Jordán de)

Marqueta, Valentín, 196, 197

Marshall, Frank, 54

Martínez, Manuel, 58

Massart, Joseph Lambert, 51

Massenet, J., 16

Mateo, Ricardo, 89

Mediano, Baldomero, 170

Meglio, Vincenzo di, 184, 47

Mendelssohn, Félix, 181, 183, 184, 37, 54

Méndez Vigo, Caralampia, 30

Mendizábal (Juan Álvarez Méndez), 175

Mendoza Tenorio, Elisa, 180, 34

Mercadante, Saverio, 87

Metón, Valentín, 14, 40, 68

Meyerbeer, Giacomo (Jakob Liebmann Beer), 180, 183, 202, 204, 205, 37, 76, 87

Monasterio, Jesús de, 175, 184, 23, 45, 51

Monasterio, Ricardo, 50

Moneva, José $\mathrm{M}^{\mathrm{a}}, 72$

Montemar, 87

Montestruc, Luis, 171, 3, 7

Mozart, W.A., 174, 54

Navarro, Rafael, 176, 179, 209, 26

Navarro, Félix, 180, 34

Nieto, Miguel, 44, 97

Nieto, Manuel, 76 
Nombela y Campos, Julio, 207

Núñez de Arce, Gaspar, 207

Núñez Herranz, Eladio, 4

Olleta, Domingo, 181, 191, 14, 32, 37, 40, 64

Olona, Luis de, 206, 207, 39, 74, 87

Oña, José Joaquín, 174, 202

Orensanz, Balbino, 16

Orós, José, 187

Oudrid, Cristóbal, 16, 39, 74, 87

Pacini, Giovanni, 87

Palau, 85, 91

Pallaruelo, José, 58

Palomino de Guzmán, Leopoldo, 208, 76

Pappsdorf, 74

Pascual Frutos, Luis, 17

Paula, Juan Francisco de, 58

Pedrell, Felipe, 170, 40, 65

Peiró, Agustín, 3, 6

Pérez, F., 207

Pérez Soriano, Agustín, 173, 184, 185, 3, 4, 16, 17

Pescador, Alejo, 17

Picón y Espinar, José, 74

Pina Domínguez, Mariano, 207, 76

Piris, Juan, 58

Ponchielli, Amilcare, 73

Portabella Arrizabalaga, Eduardo, 83

Pozo, Félix, 87

Prádanos, Hilario, 68

Prado, Loreto, 74

Puigsech, Agustín, 58

Ram de Viu, Ramón, 6, 31

Ramírez, R., 85

Ramos Carrión, Miguel, 206, 207, 74, 76

Reber, Napoleón Henri, 181, 37

Reig, Tomás, 206

Retana, Pedro, 190, 16, 62, 65
Ribera y Tarragó, Julián, 16

Ricart Matas, J., 40

Ricci, F., 87

Ricordi, Tito, 47

Rodríguez Correa, R., 87

Romea Parra, Julián, 206, 207, 209, 75, 76

Romea Yanguas, Julián, 75

Rossini, Goacchino, 181, 183, 185, 37, 87

Royo Villanova, José M., 187

Ruiz, Tomás, 58

Ruiz de Velasco, Eduardo, 14

Ruiz de Velasco, Ruperto, 172, 191, 192, 193, $202,14,15,16,40,42,68,74$

Sáez, José, 87

Saint-Saëns, Camille, 16

Salazar, Vicente, 208, 91

Saldoni, Baltasar, 40

Salmerón, Nicolás, 10

Sancho y Gil, Faustino, 3, 6

Sanz, Andrés, 58

Sanz, José, 87

Sástago, Condes de, 195

Savirón, Paulino, 187

Schubert, Franz, 54

Schumann, Robert, 54

Segarra, 87

Severo Aragonés, Felipe, 50

Sigler, José, 4

Sirvent, $\mathrm{M}^{\mathrm{a}}$ Ángeles, 54

Sisamón y Ostáriz, Miguel, 201, 44, 88, 96

Sola, Ángel, 3, 16

Soriano Fuertes, Mariano, 170, 87

Soteras, Roberto, 187

Subeas Bach, Jaime, 89

Suppé, Franz von, 185, 206, 37, 41, 91, 97

Taberner, Mariano, 14

Tamayo y Baus, José, 180, 34

Tárrega, Francisco, 83 
Thomas, Ambroise, 181, 37

Tolosa, Juan, 188

Tomba, Rafaele, 76

Torres, Carmen, 192

Tremps, José, 184, 187

Unceta, Marcelino, 73

Urrecha, Federico, 17

Urriés, Juan Jordán de (Marqués de Ayerbe), 178, 30, 66

Val, Mauricio, 58

Valero, José, 87

Vallés, José, 209, 76

Valverde, Joaquín, 206, 207, 208, 74

Vega, Ventura de la, 206

Vega, Ricardo de la, 207, 75, 76

Ventura, Manuel, 56

Verdi, Giuseppe, 185, 202, 204, 205, 76, 87, 95
Viada, F., 40

Vidal y Llimona, Andrés, 48

Vidal, Paul-Antonin, 207, 102

Vieuxtemps, Henri, 181, 37

Villagrasa, Félix, 171, 3, 4, 14

Villarreal, Elías, 192, 4, 68

Viscasillas Blanque, Eduardo, 178, 181, 197, 16, $31,37,42,65,68$

Wagner, Richard, 181, 37, 87

Walzel, Camilo, 97

Weber, Carl $\mathrm{M}^{\mathrm{a}}$ von, 54

Yanguas, Agustín, 4

Zamora, E., 207

Zapata, Marcos, 206, 85

Zopetti, Enrique, 74

Zozaya, Benito, 17 